\title{
Transient Model of Heat, Mass, and Charge Transfer as well as Electrochemistry in the Cathode Catalyst Layer of a PEMFC
}

\author{
Daniel B. Genevey \\ Thesis submitted to the Faculty of the \\ Virginia Polytechnic Institute and State University \\ in Partial fulfillment of the requirements for the degree of \\ Master of Science \\ In \\ Mechanical Engineering \\ Michael R von Spakovsky, Chair \\ Michael W. Ellis \\ Douglas J. Nelson \\ Benoît Olsommer \\ Frédéric Topin
}

December 17, 2001

Blacksburg, Virginia

Keywords: PEMFC; Cathode Catalyst Layer; Transient Heat, Mass and Charge Transfer, Electrochemistry

Copyright 2001, Daniel B. Genevey 


\title{
Transient Model of Heat, Mass, and Charge Transfer as well as Electrochemistry in the Cathode Catalyst Layer of a PEMFC
}

\author{
Daniel B. Genevey
}

(Abstract)

A transient model of the cathode catalyst layer of a proton exchange membrane fuel cell is presented. The catalyst layer structure can be described as a superposition of the polymer membrane, the backing layer, and some additional platinum particles. The model, which incorporates some of the features of the pseudo-homogeneous models currently present in the literature, considers the kinetics of the electrochemical reaction taking place at the platinum surface, the proton transport through the polymer agglomerates, and the oxygen and water transport within the pores as well as the membrane material of the catalyst layer. Due to the lower porosity of this region and the higher liquid water content, the catalyst layer can be current limiting in the fuel cell. Furthermore, since the cost of the catalyst material is critical, it is important to have a model predicting the effective utilization of this catalyst layer as well as one, which gives insights into how it might be improved.

Equations are presented for the mass conservation of reactants and products, the electrical and ionic currents, and the conservation of energy. A discussion of a number of the closure relations such as the Butler-Volmer equation employed is included as is a discussion of the initial and boundary conditions applied. The mathematical model is solved using a finite elements approach developed at the I.U.S.T.I. 
Chapter 1. Introduction 1

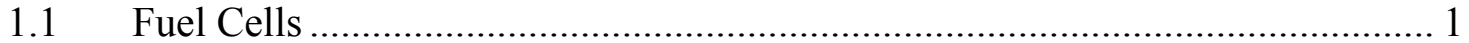

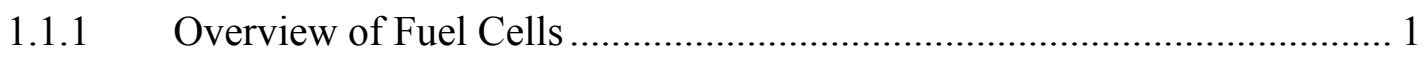

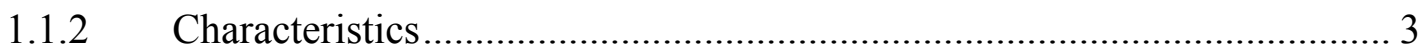

1.1.3 Different Types of Fuel Cells …………………..................................... 4

1.2 Proton Exchange Membrane Fuel Cells ……….............................................. 6

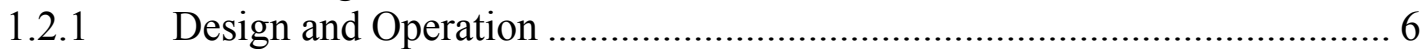

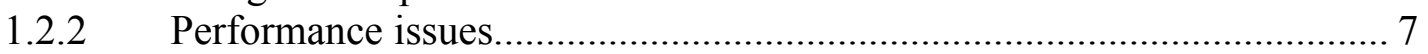

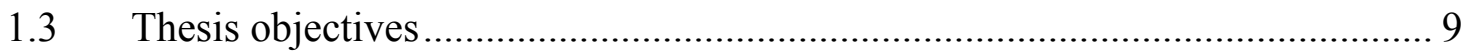

Chapter 2. Fuel Cell Model 11

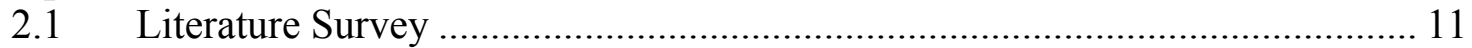

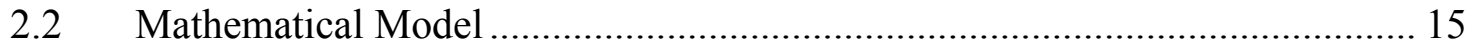

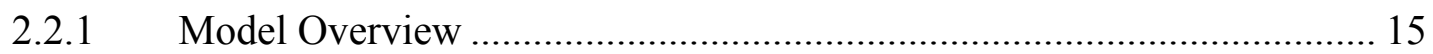

2.2.2 Component Model Summaries …………………................................... 15

Chapter 3. Catalyst Layer Model 21

3.1 Phenomena and Geometry in the Catalyst Layer............................................. 21

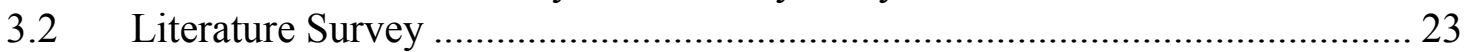

3.3 Cathode Catalyst Layer Model Assumptions ............................................. 26

$3.4 \quad$ Governing and Constitutive Equations …………............................................ 27

3.4.1 Model at the Catalyst Surface ……………........................................... 28

3.4.2 Model in the Porous Media of the Catalyst Layer .................................... 30

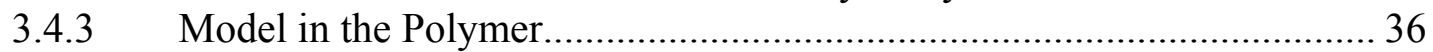

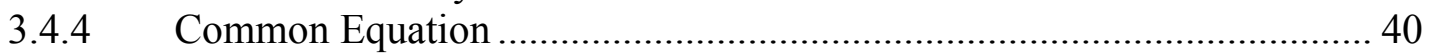

3.5 Boundary Conditions and Initial Conditions ................................................ 42

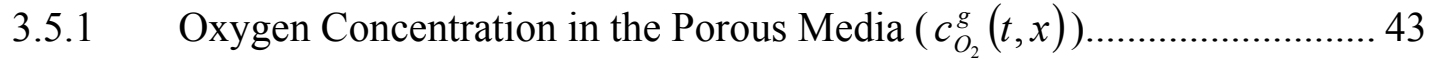

3.5.2 Concentration of the Gas Mixture in the Porous Media $\left(c^{g}(t, x)\right) \ldots \ldots \ldots . . .43$

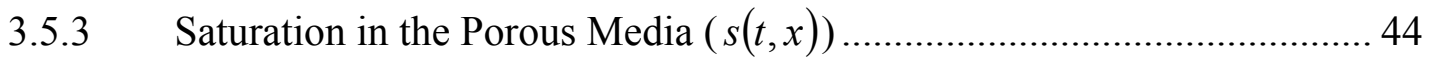

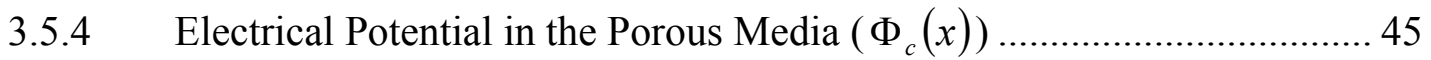

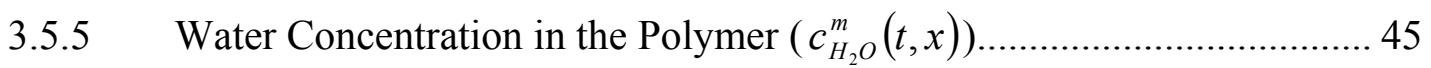

3.5.6 Proton Potential in the Porous Media $\left(\Phi_{m}(x)\right)$........................................ 47

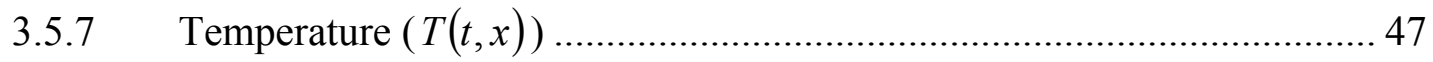

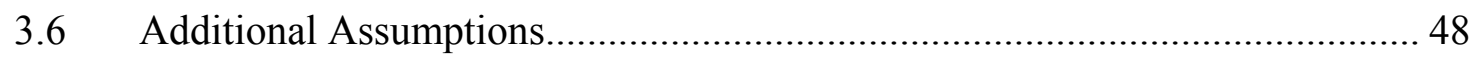

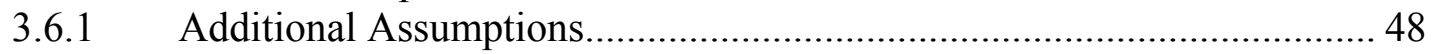

3.6.2 Diffusion Layer Model ....................................................................... 48

Chapter 4. Numerical Solution Approach $\quad 53$

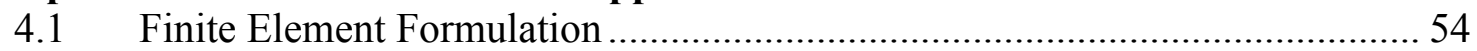

4.1.1 Formulation of the Problem .............................................................. 54

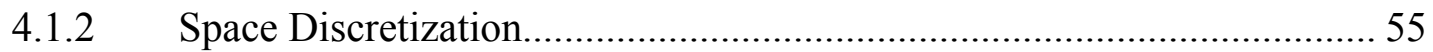

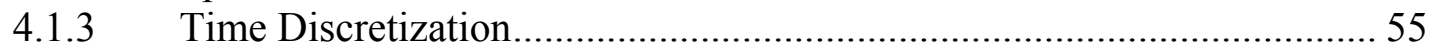

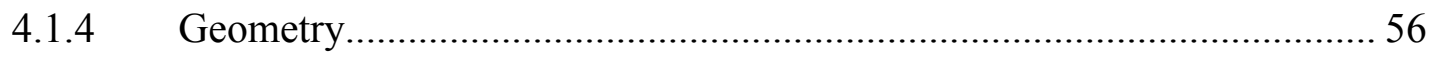

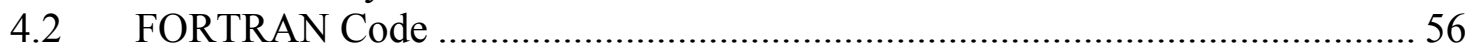




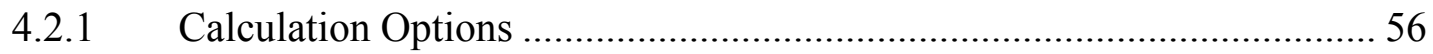

4.2.2 Main Functions and Program Structure ................................................ 57

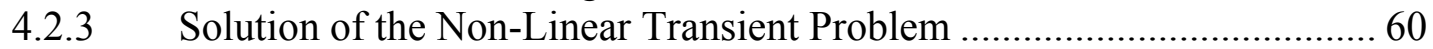

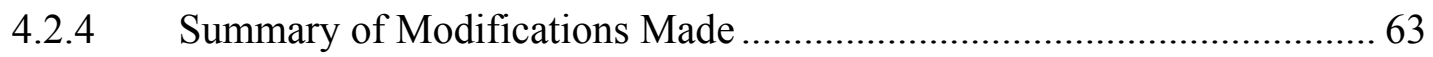

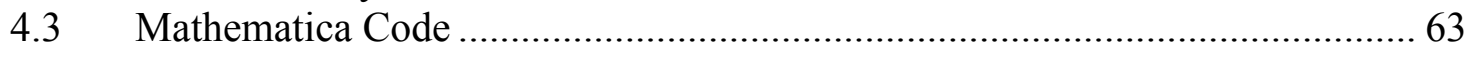

$\begin{array}{llr}\text { Chapter 5. } & \text { Results } & 64\end{array}$

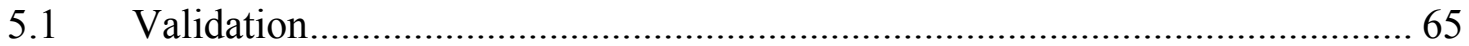

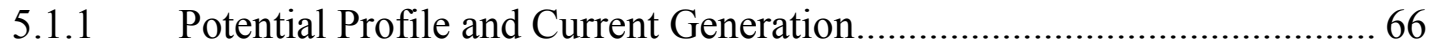

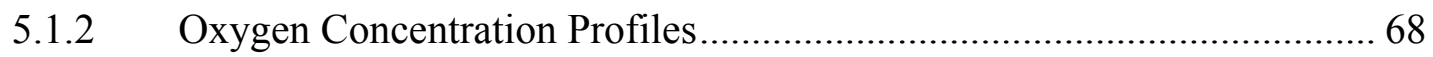

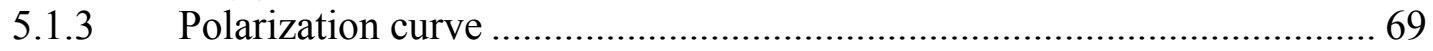

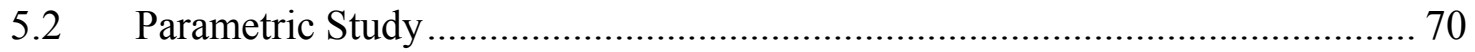

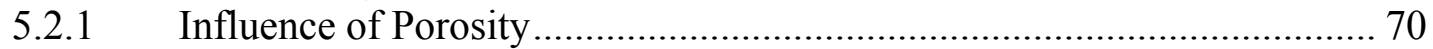

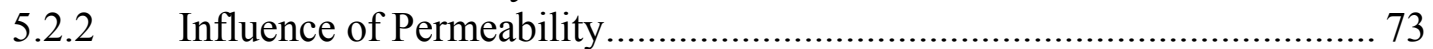

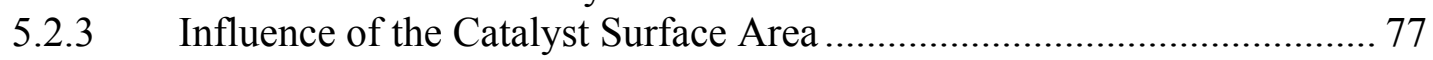

5.3 Influence of Membrane Water Content ......................................................... 79

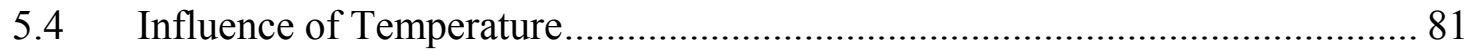

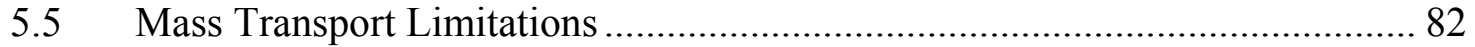

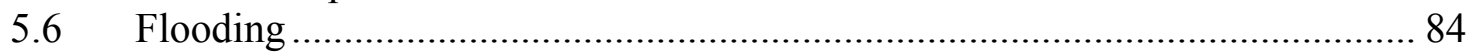

5.7 Transient Behavior of the Catalyst Layer ................................................. 90

Chapter 6. Conclusions and Recommendations 95

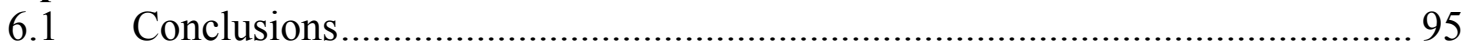

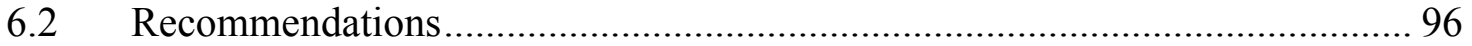




\section{List of Multimedia Objects}

Figure 1.1 Individual fuel cell schematic (Fuel Cell Handbook, $5^{\text {th }}$ edition)................... 2

Figure 1.2 A fuel cell system with external reforming (US Department of Defense)....... 3

Figure 1.3 A membrane-electrode assembly (Barbir, 1999)......................................... 6

Figure 1.4 Phenomena in a PEMFC (Barbir, 1999) ...................................................... 7

Figure 3.1 Structure of a membrane-electrode assembly (Broka and Ekdunge, 1997) .... 21

Figure 3.2 Schematic of a membrane-electrode assembly (Barbir, 1999)...................... 22

Figure 3.3 Species transported in the cathode catalyst layer (Olsommer, 2000)............ 23

Figure 3.4 Schematic of the diffusion layer model for the case of a pseudo-homogeneous

model of the catalyst layer. ...................................................................... 50

Figure 3.5 Schematic of the diffusion layer model for the case of an agglomerate model

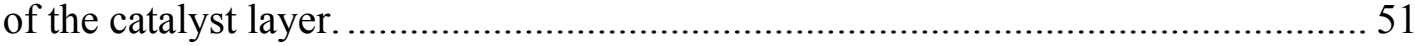

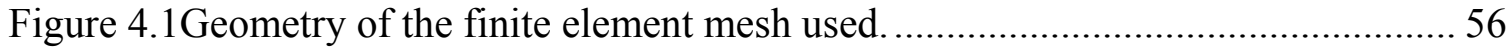

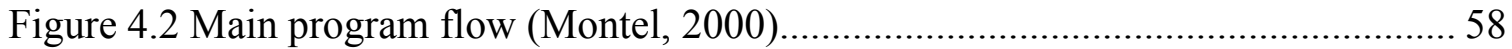

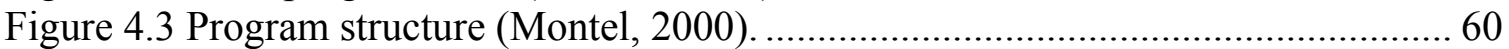

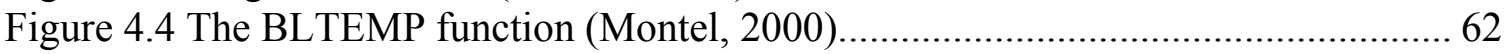

Figure 5.1 Profile across the catalyst layer of the potential $\Phi_{m}$ in the polymer membrane

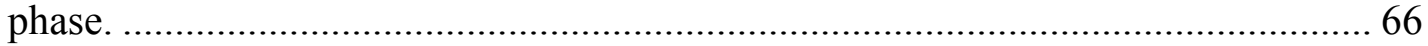

Figure 5.2 Current generation (current density per unit volume) across the catalyst layer.

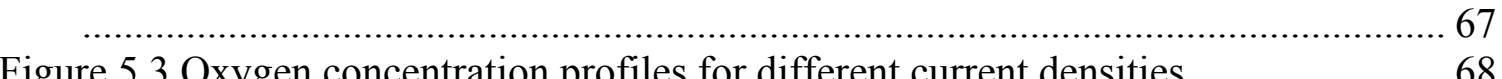

Figure 5.3 Oxygen concentration profiles for different current densities........................ 68

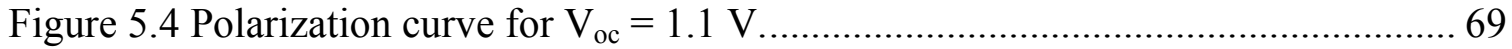

Figure 5.5 Polarization curves from Bernardi and Verbrugge (1992), and Sui and Chen

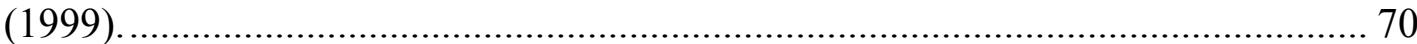

Figure 5.6 Effect of porosity on the oxygen concentration. ......................................... 71

Figure 5.7 Effect of porosity on the concentration of the gas phase.............................. 71

Figure 5.8 Effect of porosity on the current generation for an overpotential of $0.28 \mathrm{~V} \ldots 73$

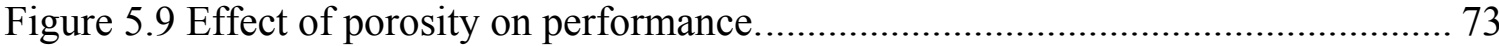

Figure 5.10 Effect of permeability on the oxygen concentration. ................................. 74

Figure 5.11 Effect of permeability on the concentration of the gas............................... 75

Figure 5.12 Effect of permeability on the current generation for an overpotential of 0.28

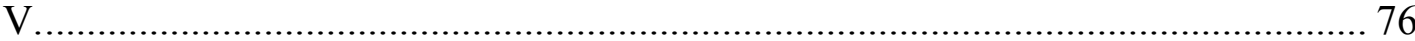

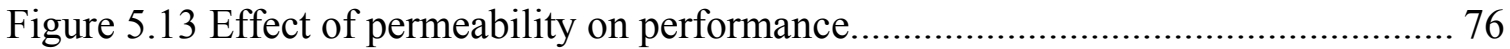

Figure 5.14 Effect of catalyst surface area on the oxygen concentration. ....................... 77

Figure 5.15 Effect of catalyst surface area on the concentration of the gas. ................... 78

Figure 5.16 Effect of catalyst surface area on current generation for an overpotential of

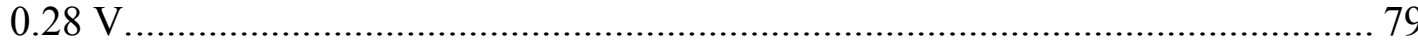

Figure 5.17 Influence of the membrane water content in the catalyst layer on

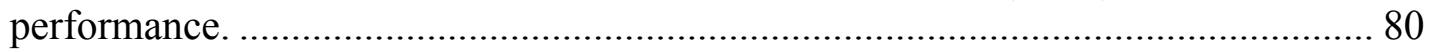

Figure 5.18 Influence of temperature on performance. ........................................ 82

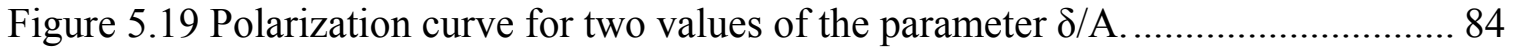

Figure 5.20 Saturation profiles for different values of the boundary conditions at the

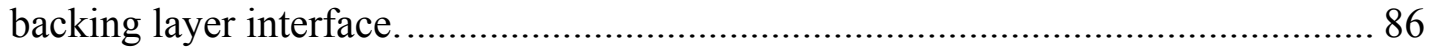




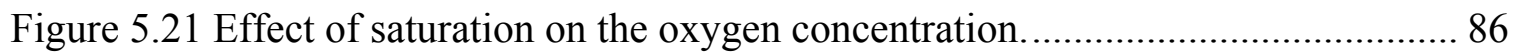

Figure 5.22 Effect of saturation on the concentration of the gas phase........................ 87

Figure 5.23 Effect of the saturation on the current generation for an overpotential of 0.28

$\mathrm{V}$.

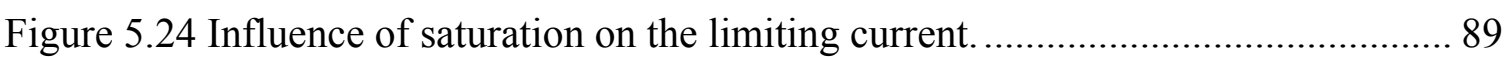

Figure 5.25 Concentration of oxygen profiles along the polarization curve. .................. 90

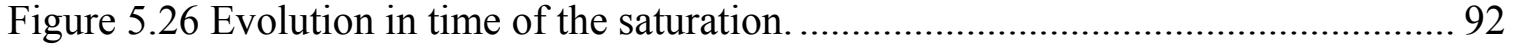

Figure 5.27 Evolution in time of the concentration of water in the polymer phase. ....... 92

Figure 5.28 Evolution in time of the temperature........................................................ 93

Figure 5.29 Evolution in time of the concentration of oxygen.................................. 93

Figure 5.30 Evolution in time of the concentration of gas. ........................................ 94

Table 1.1 Characteristics of different types of fuel cells. .............................................. 5

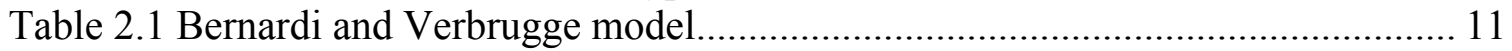

Table 2.2 Springer, Zawodzinski and Gottesfeld model............................................. 12

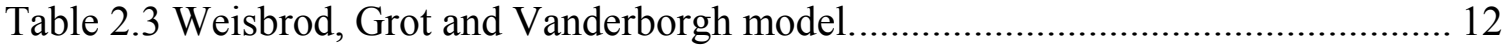

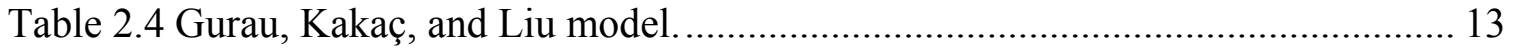

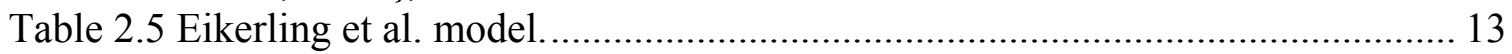

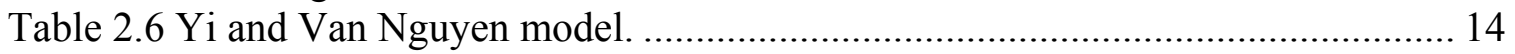

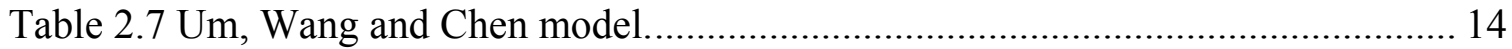

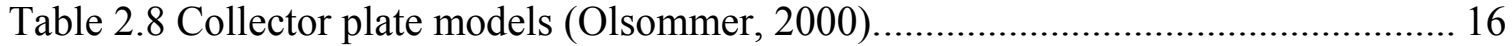

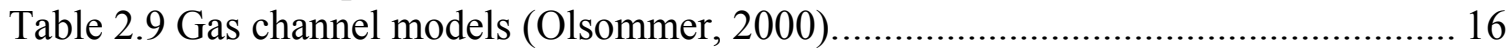

Table 2.10 Backing layer/electrode/gas diffuser models (Olsommer, 2000). ................. 17

Table 2.11 Catalyst layer models based on Olsommer (2000), the work present here in

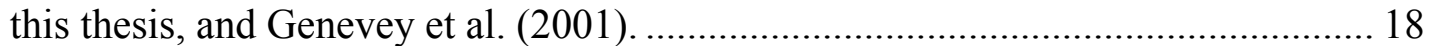

Table 2.12 Membrane model (Olsommer, 2000; Eaton, 2001; Eaton et al., 2001)......... 19

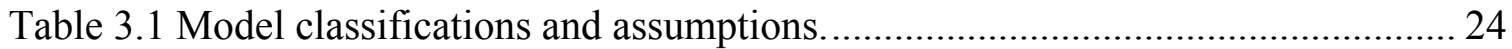

Table 3.2 Base-case catalyst layer parameters and properties (Bernardi and Verbrugge,

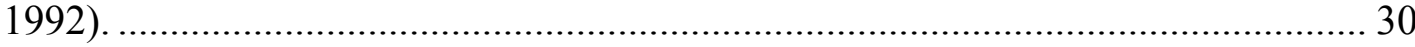

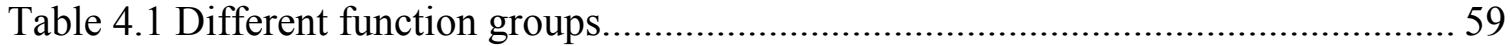

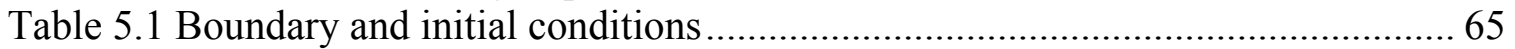

Table 5.2 Boundary and initial conditions for the results presented in section 5.3........ 80

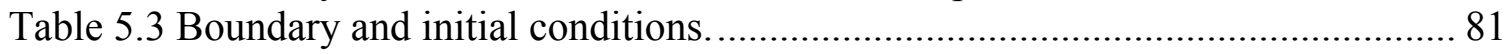

Table 5.4 Boundary and initial conditions for the results presented in section 5.5........ 83

Table 5.5 Boundary and initial conditions for the results of section 5.6..................... 85

Table 5.6 Boundary and initial conditions for the results of section 5.7 ...................... 91 


\section{Chapter 1. Introduction}

As environmental concerns receive increasing attention, the need for developing new technologies that address the conflicting issues of energy production and protection of the environment becomes evident. The extraordinary environmental quality and high efficiency of fuel cells make them a potential alternative energy source for both stationary and transportation applications. Fuel cells have the opportunity to end the carbon-dominated energy system of the 20th century and make the most of the broadly available hydrogen molecule. While fuel cell technology matures and further research advances are made, the challenge for the fuel cell industry will be to commercialize fuel cell systems by improving their performance and cost. This chapter gives a general introduction to fuel cells with an emphasis on polymer electrolyte membrane fuel cells (PEMFCs) and presents the objectives for this thesis work.

\subsection{Fuel Cells}

\subsubsection{Overview of Fuel Cells}

A fuel cell is an electrochemical device that converts the chemical energy of a reaction directly into electrical energy. Since it operates without combustion, it is virtually pollution free ${ }^{1}$. Typically, a fuel cell consists of two porous electrodes (anode and cathode) separated by an electrolyte layer allowing ions transfer between the electrodes to complete the electric circuit. Gaseous fuels (hydrogen) are fed to the anode and the oxidant (in general, the oxygen in the air) is fed at the cathode by the way of flow channels cut into two electronically conductive collector plates. At the anode, the fuel catalytically splits into ions and electrons. The electrons go through an external circuit to provide electric current while the ions move through the electrolyte towards the opposite electrode (see figure 1.1). Depending on the nature of the electrolyte, different reactions

\footnotetext{
${ }^{1}$ In fact, if a fuel cell, as opposed to fuel cell systems, operates on neat $\mathrm{H}_{2}$ then it is pollution free. If, however, it operates on reformate (a mixture of $\mathrm{H}_{2}$ and other gases such as $\mathrm{CO}$ and $\mathrm{CO}_{2}$ ) then some pollution will occur but at levels significantly below that of conventional combustion devices.
} 
will occur at the electrodes. As a result of this process, heat is generated and water is produced. Since an individual fuel cell produces approximately one Volt at full load, fuel cells are stacked in series to produce usable voltages.

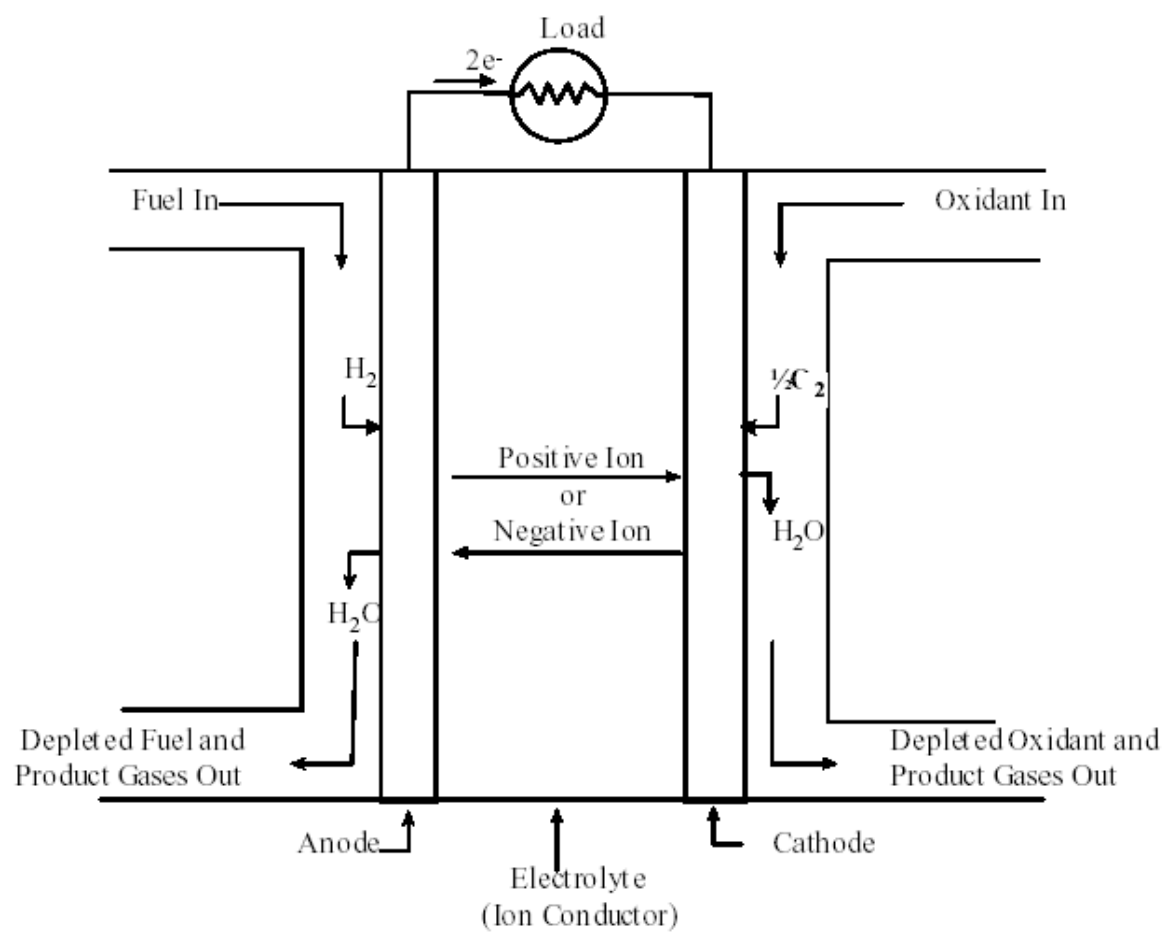

Figure 1.1 Individual fuel cell schematic (Fuel Cell Handbook, $5^{\text {th }}$ edition).

The hydrogen necessary for fuel cell operation is not naturally occurring as a gaseous fuel and must, therefore, be generated from another primary fuel via a fuel processor (external reforming) before being fed into the fuel cell or the fuel cell stack. Some fuel cell operating temperatures are high enough that the reforming reaction can actually occur within the cell (internal reforming). In addition, the electric power generated by the stack needs to be converted from DC to AC for many applications. Water generated and that used for humidification requires management, and heat generated must be removed in order to maintain a constant fuel cell operating temperature. As a result, a complete fuel cell system includes a fuel processor, the fuel cell stack, a power conditioner, and both heat and water management sub-systems (see Figure 1.2). 


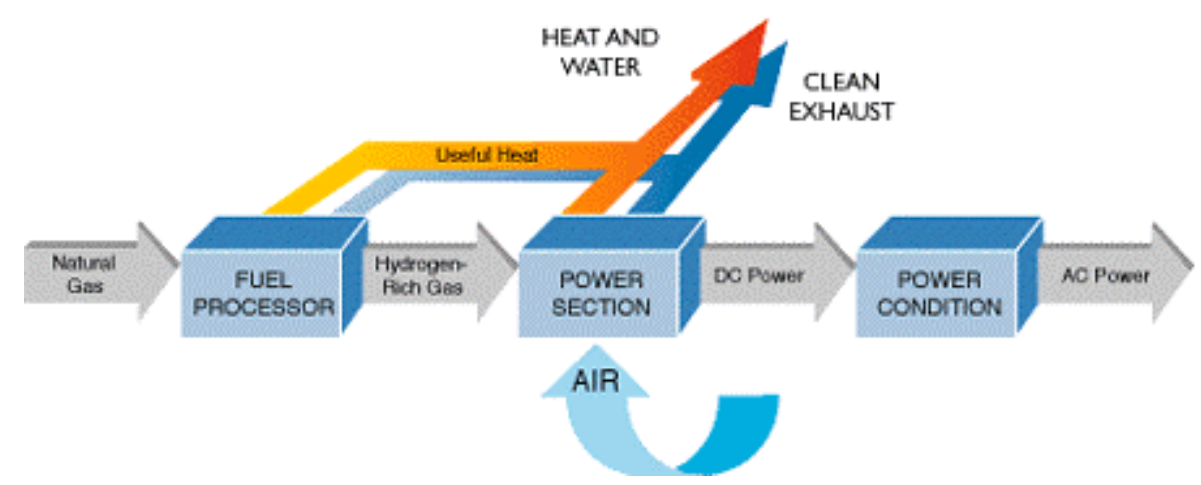

Figure 1.2 A fuel cell system with external reforming (US Department of Defense).

\subsubsection{Characteristics}

As mentioned earlier, fuel cells have many characteristics that make them a possible alternative to conventional energy conversion systems:

- Efficiency: because they convert chemical energy directly into electrical energy, fuel cell efficiencies are not limited to the Carnot limit. Therefore, even at low temperature, they are potentially more efficient than internal combustion engines. Efficiencies of present fuel cell plants are in the range of 40 to $55 \%^{2}$, and hybrid fuel cell/gas reheat turbine cycles have demonstrated efficiencies greater than $70 \%$ (Fuel Cell Handbook, $5^{\text {th }}$ edition). In addition, the efficiency is nearly independent of the electric load down to a small fraction of full load. This makes fuel cells very suitable for applications such as vehicles, where good efficiency is desired even far from peak power (full load).

- Low emissions: when pure hydrogen is used directly as a fuel, only water is created and no pollutant is rejected. However, the processing of hydrocarbon fuels into hydrogen can result in a small output of $\mathrm{NO}_{\mathrm{x}}, \mathrm{SO}_{\mathrm{x}}, \mathrm{CO}$, and an amount of $\mathrm{CO}_{2}$ significantly lower when compared, for example, to classical internal combustion engines.

\footnotetext{
${ }^{2}$ Based on the lower heating value (LHV) of the fuel.
} 
- Cogeneration capability: the exothermic chemical and electrochemical reactions produce usable heat.

- Scalability: fuel cells can be configured to suit a wide range of sizes for applications, ranging from a few watts to megawatts. Thus, fuel cells are expected to serve as a power source for portable computers as well as vehicles or large power plants.

- Fuel flexibility: fuel cells can be operated using commonly available fuels such as natural gas, methanol, and various complex hydrocarbons.

- Reliability and low maintenance: the absence of moving parts reduces the maintenance requirements and minimizes system down-time.

- Quiet operation.

In spite of these many positive characteristics, additional improvements in fuel cell technology are needed as is a focus on the reduction of the high cost of current fuel cell systems as well as the development of the infrastructure necessary for the widespread use of hydrogen fuel.

\subsubsection{Different Types of Fuel Cells}

Fuel cells are usually classified by the nature of the electrolyte they use. Table 1.1 summarizes the major technical differences between them. These distinctions allow one to choose the type of fuel cell that best matches a given application. 
Table 1.1 Characteristics of different types of fuel cells.

\begin{tabular}{|l|c|c|c|c|c|}
\hline Fuel Cell Type & $\begin{array}{c}\text { Proton } \\
\text { Exchange } \\
\text { Membrane } \\
\text { (PEMFC) }\end{array}$ & $\begin{array}{c}\text { Alkaline } \\
\text { (AFC) }\end{array}$ & $\begin{array}{c}\text { Phosphoric } \\
\text { Acid } \\
\text { (PAFC) }\end{array}$ & $\begin{array}{c}\text { Molten } \\
\text { Carbonate } \\
\text { (MCFC) }\end{array}$ & $\begin{array}{c}\text { Solid } \\
\text { Oxide } \\
\text { (SOFC) }\end{array}$ \\
\hline Mobile Ion & $\mathrm{H}^{+}$ & $\mathrm{OH}^{-}$ & $\mathrm{H}^{+}$ & $\mathrm{CO}_{3}{ }^{2-}$ & $\mathrm{O}^{2-}$ \\
\hline $\begin{array}{l}\text { Operating } \\
\text { Temperature } \\
\left({ }^{(\mathbf{C})}\right.\end{array}$ & $50-100$ & $50-200$ & $\sim 220$ & $\sim 650$ & $600-1000$ \\
\hline $\begin{array}{l}\text { Power Density } \\
\left(\mathbf{k W} / \mathbf{m}^{2}\right)\end{array}$ & $3.8-2.6$ & $0.7-8.1$ & $0.8-1.9$ & $0.1-1.5$ & $1.5-2.6$ \\
\hline Reforming & external & external & external & $\begin{array}{c}\text { external or } \\
\text { internal }\end{array}$ & $\begin{array}{c}\text { external or } \\
\text { internal }\end{array}$ \\
\hline $\begin{array}{l}\text { Electrical 1 } \\
\text { Law } \\
\text { Efficiency (\%) }\end{array}$ & $\begin{array}{c}40-55 \\
\text { (stack) }\end{array}$ & $\begin{array}{c}45-60 \\
\text { (stack) }\end{array}$ & $\begin{array}{c}40-50 \\
\text { (stack) }\end{array}$ & $\begin{array}{c}50-60 \\
\text { (system) }\end{array}$ & $\begin{array}{c}50-65 \\
\text { (stack) }\end{array}$ \\
\hline Start-up Time & sec - min & min & hours & hours & (system) \\
\hline
\end{tabular}

As shown in Table 1.1, PEMFCs deliver significantly higher power density than the other types of fuel cells, with the exception of the AFC and SOFC, which have comparable performance. Their electrical efficiency of 40 to $55 \%$ is also relatively high in comparison to the efficiency of a spark-ignition internal combustion (IC) engine of comparable size (e.g., 37.6 \% at full load (von Spakovsky, Nelson and Ellis, 2000)). For compression-ignition IC engines, this efficiency at full load compares favorably (e.g. 48 $\%$ at full load (von Spakovsky, Nelson and Ellis, 2000)). It is, however, at partial load that the fuel cell system has a significant advantage over both of these types of IC engines. In addition, the low operating temperature of the PEMFC allows for quick startup and fast response to changes in electrical load. These characteristics, along with their relatively long expected lifetime, make the PEMFC a very suitable power system for vehicular applications as well as small stationary power plants. The technical issues involved in a PEMFC will be developed in the next section. 


\subsection{Proton Exchange Membrane Fuel Cells}

\subsubsection{Design and Operation}

A PEMFC uses a polymer electrolyte membrane usually made of Nafion ${ }^{\circledR}$ (from DuPont), whose chemical structure consists of a fluorocarbon polymer with sulfonic acid groups attached. Through this structure, the protons and water molecules are free to migrate. However, the Nafion ${ }^{\circledR}$ material remains impermeable to reactants (hydrogen at the anode and oxygen at the cathode) and is a good electronic insulator. The membrane is sandwiched between the two electrodes on which a small amount of platinum catalyst has been deposited at the membrane interfaces to form the catalyst layers. The catalyst particles are supported by the electrode material, which can be considered as a thin sheet of porous carbon paper that has been wet-proofed with Teflon ${ }^{\circledR}$. The carbon fiber material is also referred to as the backing layer. These components produce a membraneelectrode assembly or MEA (see figure 1.3). This structure is about 725 microns thick, the electrodes being approximately 300 microns each and the catalyst layers 10 microns each.

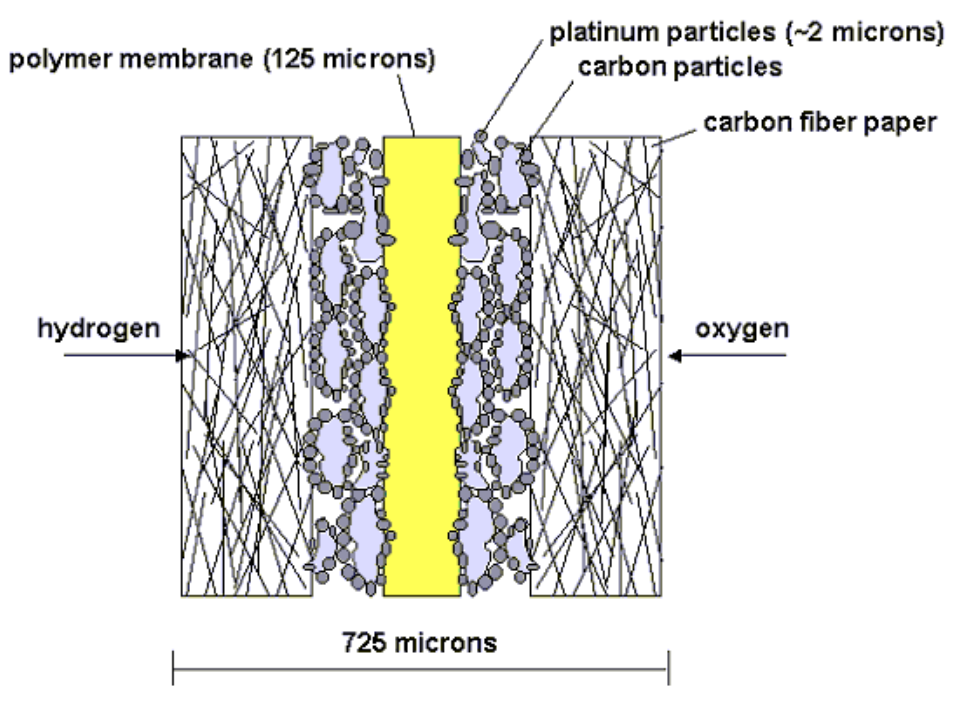

Figure 1.3 A membrane-electrode assembly (Barbir, 1999).

The MEA is connected on each side to electronically conductive collector plates, which supply the fuel and the oxidant to the electrodes via gas channels and conduct the 
current to the external circuit. The reactants are transported by diffusion through the porous electrodes to the reaction site. At the anode, the oxidation of hydrogen fuel releases hydrogen protons that are transported through the membrane and electrons that produce the electrical current. At the cathode, oxygen reacts with the protons and electrons to produce liquid water. Figure 1.4 summarizes the main phenomena in a PEMFC. The electrochemical reactions are

$$
\begin{aligned}
& \mathrm{H}_{2} \leftrightarrow 2 \mathrm{H}^{+}+2 e^{-} \quad \text { (anode) } \\
& 2 \mathrm{H}^{+}+\frac{1}{2} \mathrm{O}_{2}+2 e^{-} \leftrightarrow \mathrm{H}_{2} \mathrm{O} \text { (cathode) }
\end{aligned}
$$

The overall reaction is

$$
\mathrm{H}_{2}+\frac{1}{2} \mathrm{O}_{2} \leftrightarrow \mathrm{H}_{2} \mathrm{O}
$$

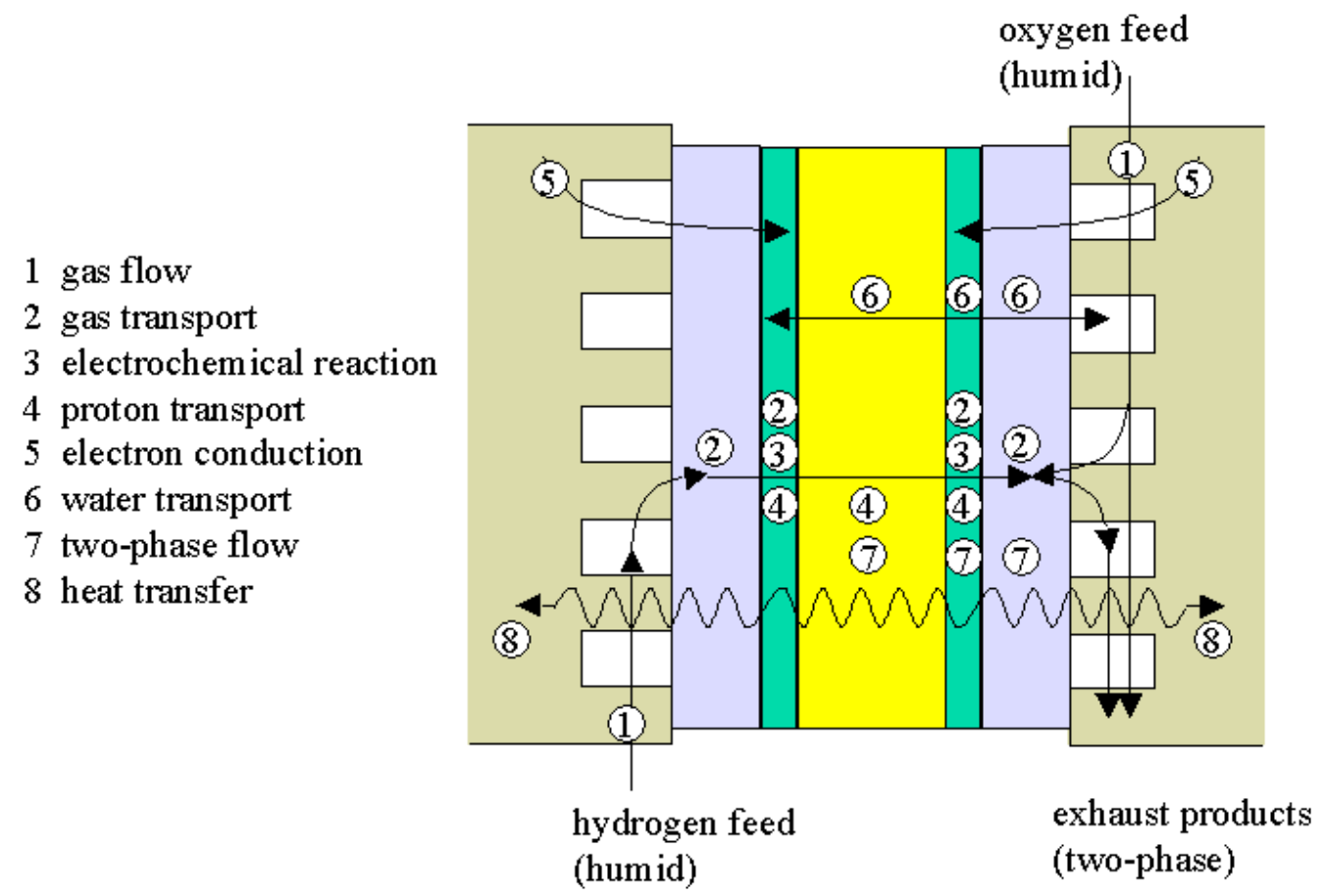

Figure 1.4 Phenomena in a PEMFC (Barbir, 1999).

\subsubsection{Performance issues}

Fuel cell performance is affected by many parameters. To ensure good cell operation, the following issues need to be addressed: 
- Reactant distribution: the concentration of each reactant at the interface between the gas channels and the electrodes must be uniformly distributed in order to avoid losses due to concentration polarization.

- Water management: in order to ensure good proton conductivity, the polymer membrane must remain hydrated. It is also necessary to avoid damage to the membrane structure. However, too much water could result in flooding in the electrodes, blocking the pores that allow reactant transport, and affecting the reaction rate. Therefore, it is necessary to balance these two phenomena.

Sources of water in a fuel cell include the water vapor which is transported by the reactants flow both at the anode and cathode sides, since the reactants are usually humidified to help ensure membrane hydration. In addition, at the cathode, water is produced in liquid phase during the electrochemical reaction, providing another source for membrane hydration. Excess water at the cathode can be removed toward the gas channels thanks to the capillary forces that result from the partial evaporation of liquid water in the pores of the backing layer (Olsommer, 2000). Water is, furthermore, transported in the membrane by convection due to a pressure gradient between the electrodes, by diffusion due to a concentration gradient, and by the drag force caused by proton migration. When combined together, the action of these phenomena can result in an uneven water distribution in the membrane. For example, at high current densities, the anode side may dry out even if the cathode side remains hydrated. Fortunately, all of these phenomena of water movement can be predicted and controlled.

- Transport properties in the catalyst layer and the catalyst effective utilization: the cost of the catalyst material is critical. In order to ensure the best utilization of the catalyst layer, the reactants need to be transported at a uniform rate to the reaction site at the surface of the agglomerates of Teflon $\AA$ and platinum particles (see Figure 1.3). Reactant transport occurs within the pores separating these agglomerates, while proton transport occurs in the polymer phase. The transport of reactants becomes a limiting factor if too 
much resistance is offered to diffusion of species in the pores. This can occur at high current densities, or in the case of flooding due to excess liquid water. In these cases, the catalyst layer is not utilized in its totality (Olsommer, 2000).

- Heat management: temperature can affect the material properties of the cell components and, therefore, cell performance. It is important to remove the heat that is produced within the cell by ohmic heating, partial phase change and electrochemical reaction and, thus, insure a homogeneous cell temperature. In general, the critical factor that determines maximum cell operating temperature is the membrane material. In a PEMFC, this temperature is about $80{ }^{\circ} \mathrm{C}$.

\subsection{Thesis objectives}

Current research work on PEMFCs tries to improve cell performance by increasing current density and cell efficiency while decreasing costs. These improvements are made possible by more efficient cell design and the incorporation of new materials. Within the past years, catalyst loadings have decreased from $5 \mathrm{mg} \mathrm{Pt} / \mathrm{cm}^{2}$ to $0.05 \mathrm{mg} \mathrm{Pt} / \mathrm{cm}^{2}$ (Yi, Van Nguyen, 1999). Also, improved MEA preparation techniques have resulted in a higher electrode-membrane contact area, allowing for higher current densities (Yi, Van Nguyen, 1999). However, further improvements of the PEMFC in terms of performance and cost are necessary before systems become competitive in the market place.

Simulation models of PEMFCs already exist but are only capable of individually addressing the performance issues described in the previous section. At Virginia Tech, a comprehensive mathematical model of a PEMFC has been developed to describe the overall behavior of the cell, for any geometry and any set of operating conditions. It is a 3D transient model in which all the components of the cell have been included (i.e. nine separate component models have been developed). This model is capable of dealing with all the different performance issues in a PEMFC and will eventually act as a valuable design tool for future developments once a comprehensive solution scheme for the model has been developed and implemented. 
In order to arrive at such a tool, each individual component model is first solved separately. At present, the mathematical 1D transient model of the membrane has been solved using both a finite difference and a finite element scheme. The solutions obtained with the former, for example, not only validated this particular model but also permitted a more detailed analysis of the phenomena in the polymer membrane (Eaton, 2001). With my thesis work, the development and implementation of a solution scheme for the 1D, transient cathode catalyst layer model has been realized.

The objectives for my thesis work are as follows:

- to understand the mathematical formulation of the heat, mass and charge transfer phenomena as well as electrochemical phenomena in the catalyst layer model developed by Olsommer (2000)

- to suggest modifications to this model if warranted and implement them

- to understand and modify as necessary the research finite element code developed by Topin (1995) at the Institut Universitaire des Systèmes Thermiques Industriels (IUSTI) of the Université de Provence

- to implement and solve the system of governing and constitutive equations and closure relations comprising the cathode catalyst model

- to validate the model using numerically predicted data found in the literature

- to generate an extensive set of results and perform a detailed analysis of the phenomena present and to identify any sensitivities to key parameters

- to develop recommendations for future work which could lead to improvements in the existing model and which couples this model to others in the fuel cell. 


\section{Chapter 2. Fuel Cell Model}

\subsection{Literature Survey}

Most current fuel cell models have been developed to only individually address the PEMFC performance issues. None of them consider the fuel cell stack as a whole so as to deal simultaneously with all the phenomena. In addition, the experimental data and mathematical models found in the literature are valid only under specific assumptions and idealized conditions that often times are unrealistic. Nevertheless, some of the most pertinent contributions to the mathematical modeling of a PEMFC are presented in the Tables 2.1 to 2.7 below.

Table 2.1 Bernardi and Verbrugge model.

\begin{tabular}{|c|c|}
\hline Model & Bernardi and Verbrugge (1992) \\
\hline Assumptions & $\begin{array}{l}\text { - Steady-state } \\
\text { - Isothermal } \\
\text { - One-dimensional } \\
\text { - } \text { Pseudo-homogeneous model of the catalyst layers }\end{array}$ \\
\hline Regions & $\begin{array}{l}\text { - Membrane } \\
\text { - Catalyst layers (anode and cathode) } \\
\text { - Gas diffuser (cathode) }\end{array}$ \\
\hline $\begin{array}{l}\text { Investigated } \\
\text { phenomena }\end{array}$ & $\begin{array}{l}\text { - Limiting factors to cell performance } \\
\text { - Species transport in the gas, liquid and solid phases } \\
\text { - Influence of the porosity of the electrodes } \\
\text { - Effects of membrane properties }\end{array}$ \\
\hline Main conclusions & $\begin{array}{l}\text { - Due to capillary forces, the liquid and the gas pressures are } \\
\text { not in mutual equilibrium in the backing layer } \\
\text { - The inefficiencies due to unreacted hydrogen or oxygen } \\
\text { transport through the membrane are negligible } \\
\text { - At practical operating current densities, catalyst utilization } \\
\text { is low }\end{array}$ \\
\hline Limits & $\begin{array}{l}\text { - Valid only for fully hydrated membranes } \\
\text { - Does not account for the drag force on water molecules. } \\
\text { - Unable to predict flooding in the cathode backing layer due } \\
\text { to water production } \\
\text { - The polarization curve diverges from experimental data at } \\
\text { high current densities }\end{array}$ \\
\hline
\end{tabular}


Table 2.2 Springer, Zawodzinski and Gottesfeld model.

\begin{tabular}{|l|l|}
\hline Model & Springer, Zawodzinski and Gottesfeld (1991) \\
\hline Assumptions & $\bullet \quad$ Steady-state \\
& $\bullet \quad$ Isothermal \\
\hline Regions & $\bullet \quad$ One-dimensional \\
& $\bullet \quad$ Anode \\
& $\bullet \quad$ Cathode \\
\hline $\begin{array}{l}\text { Investigated } \\
\text { phenomena }\end{array}$ & $\bullet \quad$ Water transport within the membrane \\
\hline Main conclusions & $\begin{array}{l}\text { The convective transport of water is limited to the drag force on } \\
\text { water molecules due to proton flux }\end{array}$ \\
\hline Limits & $\begin{array}{l}\text { Use of artificially fitted parameters (such as the cathode backing } \\
\text { layer effective porosity) to predict water flooding }\end{array}$ \\
\hline
\end{tabular}

Table 2.3 Weisbrod, Grot and Vanderborgh model.

\begin{tabular}{|c|c|}
\hline Model & Weisbrod, Grot, Vanderborgh (1996) \\
\hline Assumptions & $\begin{array}{l}\text { - Steady-state } \\
\text { - Isothermal } \\
\text { - One-dimensional } \\
\text { - Pseudo-homogeneous model of the cathode catalyst layer }\end{array}$ \\
\hline Regions & $\begin{array}{ll}\text { - } & \text { Electrodes (anode and cathode) } \\
\text { - } & \text { Cathode catalyst layer } \\
\text { - } & \text { Membrane } \\
\end{array}$ \\
\hline $\begin{array}{l}\text { Investigated } \\
\text { phenomena }\end{array}$ & $\begin{array}{l}\text { - Water balance in the backing layers } \\
\text { - Influence of the catalyst layer thickness and platinum } \\
\text { loading } \\
\text { - Impact of temperature and cathode pressure on performance }\end{array}$ \\
\hline Main conclusions & $\begin{array}{l}\text { The cell performance passes through a maximum with respect } \\
\text { to the platinum loading of the catalysts }\end{array}$ \\
\hline Limits & Kinetic resistance at the anode catalyst layer is neglected \\
\hline
\end{tabular}


Table 2.4 Gurau, Kakaç, and Liu model.

\begin{tabular}{|c|c|}
\hline Model & Gurau, Kakaç, and Liu (1998) \\
\hline Assumptions & $\begin{array}{l}\text { - Steady-state } \\
\text { - Two-dimensional } \\
\text { - } \quad \text { Non-isothermal }\end{array}$ \\
\hline Regions & $\begin{array}{l}\text { - } \text { Gas channels } \\
\text { - Gas diffusers } \\
\text { - Catalyst layers } \\
\text { - } \text { Membrane }\end{array}$ \\
\hline $\begin{array}{l}\text { Investigated } \\
\text { phenomena }\end{array}$ & $\begin{array}{l}\text { - The effect of the gas diffuser porosity on cell performance } \\
\text { - The effect of the inlet air velocity on cell performance. } \\
\text { - The oxygen concentration distribution at the gas channel/gas } \\
\text { diffusion interface } \\
\text { - The effect of the oxygen concentration distribution on the } \\
\text { operating current density } \\
\text { - The current density distribution at the membrane/cathode } \\
\text { catalyst layer interface }\end{array}$ \\
\hline Main conclusions & $\begin{array}{l}\text { A non-uniform reactant distribution has an important impact on } \\
\text { the current density }\end{array}$ \\
\hline Limits & $\begin{array}{l}\text { - Assumes an indefinitely thin catalyst layer. } \\
\text { - Unable to predict the overpotential due to transport } \\
\text { limitation in the catalyst layer }\end{array}$ \\
\hline
\end{tabular}

Table 2.5 Eikerling et al. model.

\begin{tabular}{|l|l|}
\hline Model & Eikerling, Kharlats, Kornyshev and Volfkovich (1998) \\
\hline Assumptions & $\begin{array}{l}\text { - Steady-state } \\
\text { - One-dimensional } \\
\text { - Isothermal }\end{array}$ \\
\hline Regions & $\begin{array}{l}\text { Membrane } \\
\text { - Electrodes (anode and cathode) through an infinitely thin } \\
\text { model }\end{array}$ \\
\hline $\begin{array}{l}\text { Investigated } \\
\text { phenomena }\end{array}$ & $\begin{array}{l}\text { The effects of membrane parameters on cell performance } \\
\text { Comparison between a diffusion model and a convection } \\
\text { model of the membrane }\end{array}$ \\
\hline Main conclusions & $\begin{array}{l}\text { Experimental data confirms that water transport through the } \\
\text { membrane is carried out by convection, for the most part }\end{array}$ \\
\hline Limits & $\begin{array}{l}\text { Does not account for gas transport limitations in the } \\
\text { electrodes } \\
\text { Only capillary forces are assumed to affect the equilibrium } \\
\text { water content in the membrane }\end{array}$ \\
\hline
\end{tabular}


Table 2.6 Yi and Van Nguyen model.

\begin{tabular}{|c|c|}
\hline Model & Yi and Van Nguyen (1999) \\
\hline Assumptions & $\begin{array}{ll}\text { - } & \text { Steady-state } \\
\text { - } & \text { Isothermal } \\
\text { - } & \text { Two-dimensional } \\
\end{array}$ \\
\hline Regions & $\begin{array}{ll} & \text { Cathode electrode } \\
\text { - } & \text { Cathode gas channels (an interdigitated gas distributor) }\end{array}$ \\
\hline $\begin{array}{l}\text { Investigated } \\
\text { phenomena }\end{array}$ & $\begin{array}{l}\text { - Effects of the gas distributor design } \\
\text { - } \quad \text { Effects of the electrode dimensions }\end{array}$ \\
\hline Main conclusions & $\begin{array}{l}\text { - The design of the gas distributor can reduce the gas } \\
\text { diffusion layer thickness } \\
\text { - Diffusion plays an important role in the transport of oxygen } \\
\text { to the reaction surface }\end{array}$ \\
\hline Limits & Does not take into account the effects of liquid water \\
\hline
\end{tabular}

Table 2.7 Um, Wang and Chen model.

\begin{tabular}{|c|c|}
\hline Model & Um, Wang and Chen (2000) \\
\hline Assumptions & $\begin{array}{ll}\text { - } & \text { Transient } \\
\text { - } & \text { Isothermal } \\
\text { - } & \text { Multi-dimensional } \\
\text { - } & \text { Homogeneous electrodes, catalyst layers and membrane }\end{array}$ \\
\hline Regions & $\begin{array}{l}\text { - Gas channels (anode and cathode) } \\
\text { - Gas diffusers (anode and cathode) } \\
\text { - } \text { Catalyst layers (anode and cathode) } \\
\text { - } \text { Membrane }\end{array}$ \\
\hline $\begin{array}{l}\text { Investigated } \\
\text { phenomena }\end{array}$ & $\begin{array}{l}\text { - Hydrogen dilution effects on PEMFCs running on reformate } \\
\text { gas } \\
\text { - Transient response of the cell current density to a step } \\
\text { change in voltage }\end{array}$ \\
\hline Main conclusions & $\begin{array}{l}\text { - Hydrogen dilution can result in a low current density that is } \\
\text { limited to the diffusive transport of hydrogen to the reaction } \\
\text { site } \\
\text { - Single-phase analysis can provide a good approximation for } \\
\text { current densities as high as } 0.6 \mathrm{~A} / \mathrm{cm}^{2}\end{array}$ \\
\hline Limits & $\begin{array}{l}\text { - Assumes that water exists only in the liquid phase } \\
\text { - Unable to predict concentration overpotential at the cathode }\end{array}$ \\
\hline
\end{tabular}




\subsection{Mathematical Model}

The mathematical model developed at Virginia Tech (Olsommer, 2000) is a comprehensive, transient, 3-dimensional model capable of dealing with all the issues affecting cell performance. It incorporates the combined effects of mass and species transfer, momentum and energy conservation, electrical current distribution through the gas channels, the electrodes and the membrane, and the electrochemical kinetics of the reactions in the anode and cathode catalyst layers. This section gives a brief description of this model. A more detailed description is presented in Oslommer $(2000)^{3}$.

\subsubsection{Model Overview}

The fuel cell stack can be decomposed into nine separate components:

- two (anode, cathode) collector plates as electron conductors,

- two (anode, cathode) gas channels that supply the fuel cell with reactants,

- two (anode, cathode) porous electrodes (backing layers) that transport the reactants/products to/from the catalyst layers and conduct electrons to/from the catalyst layers from/to the collector plates,

- two (anode, cathode) catalyst layers at the electrode/membrane interface where the electrochemical reactions take place,

- $\quad$ one polymer membrane in which protons and water are transported.

\subsubsection{Component Model Summaries}

The mathematical model for each of the fuel cell stack components can be found in Olsommer (2000). What follows is a summary of the essential characteristics of each

\footnotetext{
${ }^{3}$ Note that since its initial development by Olsommer, the Virginia Tech model has undergone a number of modifications such as, for example, the ability to capture the concentration overpotential at high current densities. Some of these modifications are documented in this thesis, others have been documented in Eaton (2001) and Eaton et al. (2001) and still others will be documented in futures publications.
} 
model (see Tables 2.8 to 2.12). The catalyst layer model will be described in greater detail in Chapter 3.

Table 2.8 Collector plate models (Olsommer, 2000).

\begin{tabular}{|c|c|}
\hline Domain & Collector Plates (anode and cathode) \\
\hline Structure & $\begin{array}{l}\text { Non-porous media, solid electron conducting plate containing a } \\
\text { complex channel network in contact with the electrodes. }\end{array}$ \\
\hline Dimension & $3 \mathrm{D}$ \\
\hline Transported Species & $\begin{array}{ll}\text { - } & \text { Anode: electrons } \\
\text { - } & \text { Cathode: electrons }\end{array}$ \\
\hline Phenomena & $\begin{array}{l}\text { - Electrons are transferred from/to the backing layer to/from } \\
\text { the collectors } \\
\text { - Energy generated within the MEA and the collector is } \\
\text { transferred to the cooling system. Homogeneous heat } \\
\text { transfer is important for optimum operation of the stack. } \\
\text { - Reactants and products are transported to/from the MEA }\end{array}$ \\
\hline Unknowns & $\begin{array}{l}\text { - Temperature } \\
\text { - } \text { Current } \\
\text { - } \quad \text { Electrical potential }\end{array}$ \\
\hline $\begin{array}{l}\text { Governing } \\
\text { Equations }\end{array}$ & $\begin{array}{ll}\text { - } & \text { Conservation of current } \\
\text { - } & \text { Electrical potential equation (Ohm's law) } \\
\text { - } & \text { Conservation of energy } \\
\end{array}$ \\
\hline Assumptions & $\begin{array}{l}\text { - The cooling system is formed by a liquid film with infinite } \\
\text { capacity (constant temperature), flowing on the external } \\
\text { collector surface } \\
\text { - The impedance of the plate is restricted to electrical } \\
\text { resistance so that there are no transient effects }\end{array}$ \\
\hline
\end{tabular}

Table 2.9 Gas channel models (Olsommer, 2000).

\begin{tabular}{|l|l|}
\hline Domain & Gas Channels (anode and cathode) \\
\hline Structure & $\begin{array}{l}\text { Plain media, series of gas channels running through the } \\
\text { collector plates and feeding into the electrodes }\end{array}$ \\
\hline Dimension & 3-D \\
\hline Transported Species & $\begin{array}{l}\bullet \quad \text { Anode: gases (hydrogen, water) } \\
\bullet \quad \text { Cathode: gases (air, water), liquid (water) }\end{array}$ \\
\hline
\end{tabular}




\begin{tabular}{|c|c|}
\hline Phenomena & $\begin{array}{l}\text { - Reactants are transported to the electrodes and products are } \\
\text { transported out of the MEA. In particular, liquid water must } \\
\text { be removed at the cathode to prevent flooding } \\
\text { - Homogeneous distribution of the reactants is important to } \\
\text { avoid losses due to parasitic currents } \\
\text { - No charged species exist in the flow. No chemical or } \\
\text { electrochemical reaction occurs }\end{array}$ \\
\hline Unknowns & $\begin{array}{l}\text { - } \text { Densities } \\
\text { - } \text { Flow velocity vector } \\
\text { - } \text { Pressure } \\
\text { - } \text { Tempecies concentration } \\
\end{array}$ \\
\hline $\begin{array}{l}\text { Governing } \\
\text { Equations }\end{array}$ & $\begin{array}{ll}\text { - } & \text { Continuity equation } \\
\text { - } & \text { Momentum equations } \\
\text { - } & \text { Conservation of energy } \\
\text { - } & \text { Species equations } \\
\text { - } & \text { Equation of state } \\
\text { - } & \text { Mixture model (Dalton) }\end{array}$ \\
\hline Assumptions & $\begin{array}{l}\text { - Single-phase flow } \\
\text { - The liquid water velocity is set constant to a realistic value } \\
\text { - Water is not subject to phase change in the gas channels } \\
\text { - The irreversible work due to viscous forces and the work of } \\
\text { compression are neglected in the energy equation }\end{array}$ \\
\hline
\end{tabular}

Table 2.10 Backing layer/electrode/gas diffuser models (Olsommer, 2000).

\begin{tabular}{|l|l|}
\hline Domain & $\begin{array}{l}\text { Backing Layers/Electrodes/Gas Diffusers (anode and } \\
\text { cathode) }\end{array}$ \\
\hline Structure & Porous media usually made of carbon \\
\hline Dimension & 3-D \\
\hline Transported Species & $\begin{array}{l}\text { - Anode: gases (hydrogen, water), electrons } \\
\text { - Cathode: gases (air, water), liquid (water), electrons }\end{array}$ \\
\hline Phenomena & $\begin{array}{l}\text { Through the pores of the backing layer, reactants are } \\
\text { transported towards the catalyst layers and products are } \\
\text { evacuated into the gas channels. In particular, liquid water } \\
\text { must be removed at the cathode to prevent flooding } \\
\text { - The matrix (solid) phase carries electrons from the catalyst } \\
\text { layers to the collector plates or vise versa } \\
\text { - } \begin{array}{l}\text { Homogeneous distribution of the reactants is important to } \\
\text { avoid losses due to parasitic currents }\end{array}\end{array}$ \\
\hline
\end{tabular}




\begin{tabular}{|c|c|}
\hline Unknowns & $\begin{array}{ll}\text { - } & \text { Densities } \\
\text { - } & \text { Mass velocity vectors } \\
\text { - } & \text { Pressure } \\
\text { - } & \text { Temperature } \\
\text { - } & \text { Electrical current } \\
\text { - } & \text { Electrical potential } \\
\end{array}$ \\
\hline $\begin{array}{l}\text { Governing and } \\
\text { Constitutive } \\
\text { Equations }\end{array}$ & $\begin{array}{l}\text { - Mass conservation equations } \\
\text { - Momentum (Darcy) equations } \\
\text { - Conservation of energy equation } \\
\text { - Equation of state } \\
\text { - Conservation of current } \\
\text { - Electrical potential equation in the matrix (Ohm's Law) } \\
\text { - Capillary pressure (Leverett) equation } \\
\text { - Water vapor pressure (Kelvin) equation } \\
\text { - } \quad \text { Mixture model (Dalton) }\end{array}$ \\
\hline Assumptions & $\begin{array}{l}\text { - The anode backing layer includes only two phases: solid and } \\
\text { gas } \\
\text { - The liquid phase at the cathode contains only water } \\
\text { - The liquid phase is assumed incompressible. } \\
\text { - The temperature is considered uniform in all phases } \\
\text { (thermal local equilibrium) } \\
\text { - The momentum conservation equation can be approximated } \\
\text { by Darcy's relation } \\
\text { - Interfacial liquid-gas shear forces, the irreversible work of } \\
\text { viscous forces as well as the work of compression are } \\
\text { neglected in the energy equation } \\
\text { - The water vapor pressure and the liquid phase pressure as } \\
\text { well as the capillary pressure are in equilibrium }\end{array}$ \\
\hline
\end{tabular}

Table 2.11 Catalyst layer models based on Olsommer (2000), the work presented here in this thesis, and Genevey et al. (2001).

\begin{tabular}{|l|l|}
\hline Domain & Catalyst Layers (anode and cathode) \\
\hline Structure & $\begin{array}{l}\text { Porous media, mixture made from the superposition of the } \\
\text { polymer membrane, the backing layer and the catalyst particles }\end{array}$ \\
\hline Dimension & 1-D \\
\hline Transported Species & $\begin{array}{l}\text { Anode: gases (hydrogen, water), electrons, ions (hydrogen } \\
\text { protons) } \\
\text { Cathode: gases (air, water), liquid (water), electrons, ions } \\
\text { (hydrogen protons) }\end{array}$ \\
\hline
\end{tabular}




\begin{tabular}{|c|c|}
\hline Phenomena & $\begin{array}{l}\text { - Protons are transported by migration and convection } \\
\text { through the polymer agglomerates } \\
\text { - The other reactants and the water produced at the cathode } \\
\text { are transported within the pores of the catalyst layer, as in } \\
\text { the backing layer or in the polymer agglomerates }\end{array}$ \\
\hline Unknowns & $\begin{array}{l}\text { - Densities } \\
\text { - Species concentrations within the polymer phase } \\
\text { - Mass velocity vectors } \\
\text { - } \text { Pressure } \\
\text { - Temperature } \\
\text { - Electrical and ionic current } \\
\text { - } \text { Electrical and ionic potential } \\
\end{array}$ \\
\hline $\begin{array}{l}\text { Governing } \\
\text { Equations }\end{array}$ & See chapter 3 for details \\
\hline Assumptions & See chapter 3 for details \\
\hline
\end{tabular}

Table 2.12 Membrane model (Olsommer, 2000; Eaton, 2001; Eaton et al., 2001).

\begin{tabular}{|c|c|}
\hline Domain & Membrane \\
\hline Structure & Polymeric, dynamic structure commonly made of Nafion $\AA$. \\
\hline Dimension & $1-\mathrm{D}$ \\
\hline Transported Species & $\begin{array}{ll}\text { - } & \text { Protons } \\
\text { - } & \text { Water } \\
\text { - } & \text { Impermeable to hydrogen, oxygen and other species } \\
\end{array}$ \\
\hline Phenomena & $\begin{array}{l}\text { - Protons are transported from the anode to the cathode } \\
\text { - Water is transported by convection, diffusion, and potential } \\
\text { driven flow (due to the drag force of protons on the water } \\
\text { molecules) } \\
\text { - The membrane must remain hydrated to ensure good proton } \\
\text { conductivity }\end{array}$ \\
\hline Unknowns & $\begin{array}{l}\text { - Species concentrations } \\
\text { - Velocity vectors } \\
\text { - Pressures } \\
\text { - Temperatures } \\
\text { - Ionic current } \\
\text { - Ionic potential }\end{array}$ \\
\hline $\begin{array}{l}\text { Governing and } \\
\text { Constitutive } \\
\text { Equations }\end{array}$ & $\begin{array}{l}\text { - } \text { Mass conservation equations } \\
\text { - Momentum (Darcy) equations } \\
\text { - Conservation of energy equation } \\
\text { - } \text { Conservation of current } \\
\text { - Electrical potential equation in the polymer } \\
\text { - Mixture pressure relation } \\
\text { - Relation for the water activity at the electrode interfaces } \\
\text { - Relation for the water activity }\end{array}$ \\
\hline
\end{tabular}




\begin{tabular}{|l|l|}
\hline Assumptions & $\begin{array}{l}\text { - Water does not exist in a particular form. Thus, the mixture } \\
\text { is made of protons and water molecules. } \\
\text { - } \text { Mono-phase flow } \\
\text { - }\end{array}$ \\
- Capillary forces are neglected \\
- Constant pressure gradient \\
Electroneutrality, which implies a constant concentration of \\
- $\begin{array}{l}\text { No chemical or electrochemical reactions occur in the } \\
\text { membrane }\end{array}$ \\
\hline
\end{tabular}




\section{Chapter 3. Catalyst Layer Model}

A good understanding of the microscopic structure of the catalyst layer is important in developing a model that best describes the phenomena taking place in this region. This first step is presented in section 3.1. Then, a brief overview of existing models is presented in section 3.2, and the catalyst layer model presented and implemented in this thesis work is given in section 3.3. The work outlined here although limited to the cathode catalyst layer where the electrochemical reaction exhibits slower kinetics than at the anode, is, nonetheless, in its majority applicable with appropriate modifications to the anode catalyst layer as well. Much of the information contained in this chapter can be found in more detail in Olsommer (2000).

\subsection{Phenomena and Geometry in the Catalyst Layer}

The catalyst layer can be described as a mixture made up of the superposition of the polymer membrane (Nafion), the backing layer (porous media), and some additional catalyst particles (in general, platinum). A cross section of the membrane-electrode assembly (Figures 3.1 and 3.2) shows that the active catalyst layer region contains small agglomerates consisting of carbon, platinum and Nafion, separated by gas pores.

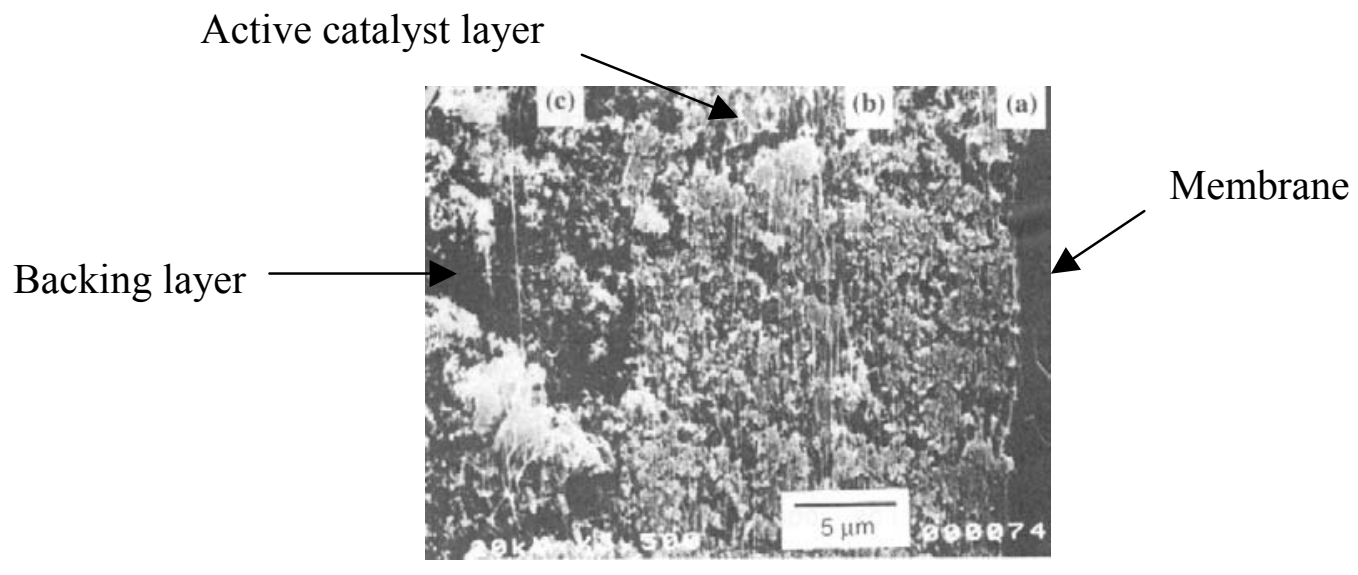

Figure 3.1 Structure of a membrane-electrode assembly (Broka and Ekdunge, 1997) 


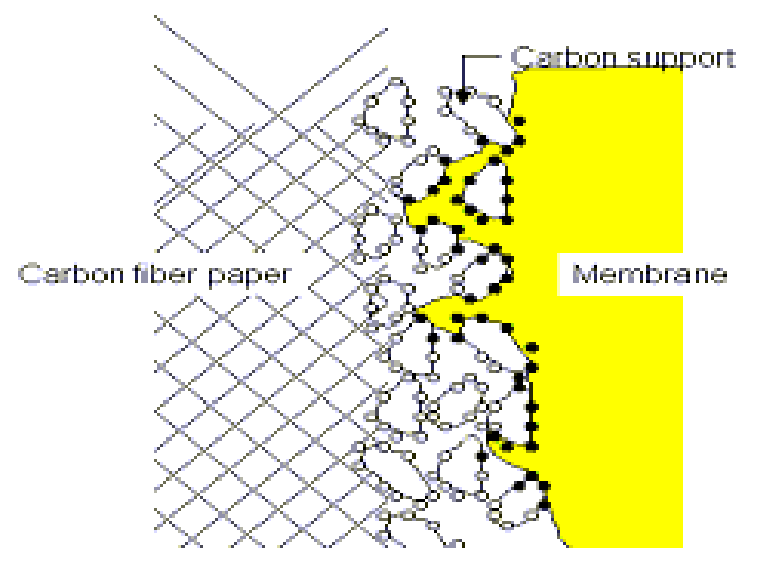

- Platinum with ionic \& electronic contact

- Platinum with electronic contact only

Figure 3.2 Schematic of a membrane-electrode assembly (Barbir, 1999).

Figure 3.3 represents the species transported in the catalyst layer. The protons are transported by diffusion and convection through the polymer phase of the agglomerates. The electron transport occurs in the carbon phase of the catalyst layer. The oxygen coming from the backing layer diffuses through the gas pores and possibly polymer material surrounding a catalyst site and reacts with the protons at the reaction site, i.e. at the platinum surface of the agglomerates. The water produced during the electrochemical reaction is transported within the porous media.

Thus, models created to model the phenomena of species transport and reaction occurring within the catalyst layer must wholly or partially (depending on the goals of the modeling) capture a number of diverse interactions. A look at what models exist in the literature is, therefore, warranted before proceeding with the catalyst model presented in this thesis. 


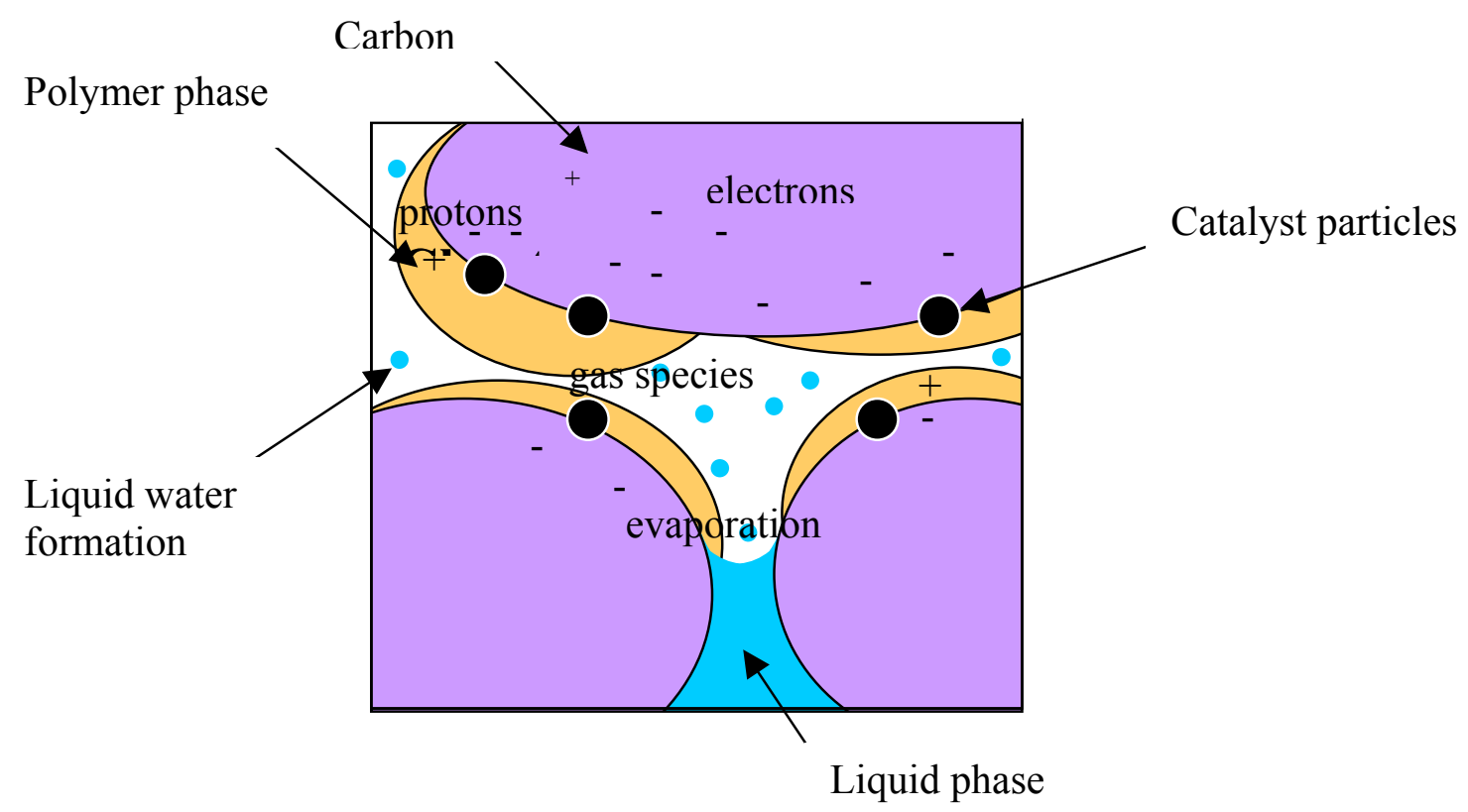

Figure 3.3 Species transported in the cathode catalyst layer (Olsommer, 2000).

\subsection{Literature Survey}

The current catalyst layer models can be classified into different groups by the level with which they deal with the catalyst structure (see Table 3.1). Macroscopic models consider the catalyst as a continuous medium, and consequently are not able to identify the effects of the discrete distribution of the agglomerates, whereas microscopic models deal with the local geometry of the catalyst layer. 
Table 3.1 Model classifications and assumptions.

\begin{tabular}{|c|c|c|}
\hline \multicolumn{2}{|c|}{ Macroscopic models } & \multirow{2}{*}{ Microscopic models } \\
\hline Pseudo-homogeneous & Agglomerate & \\
\hline $\begin{array}{l}\text { The catalyst is } \\
\text { treated as a } \\
\text { homogeneous } \\
\text { phase. } \\
\text { - The oxygen } \\
\text { diffuses through the } \\
\text { porous media. }\end{array}$ & $\begin{array}{l}\text { The catalyst is } \\
\text { assumed to form } \\
\text { agglomerates of } \\
\text { certain ordered } \\
\text { geometry. } \\
\text { - The oxygen diffuses } \\
\text { from the pores to the } \\
\text { agglomerates. } \\
\text { The oxygen } \\
\text { concentration in the } \\
\text { pores is constant. }\end{array}$ & $\begin{array}{l}\text { - The geometric } \\
\text { arrangement of the } \\
\text { agglomerates, as } \\
\text { well as their shape, } \\
\text { is taken into } \\
\text { account. } \\
\text { - The mutual } \\
\text { influence of the } \\
\text { catalyst particles is } \\
\text { studied. }\end{array}$ \\
\hline
\end{tabular}

What follows is an overview of the most important catalyst layer models in the literature to date:

- At the University of Miami:

You and Liu (2000) present a steady state, isothermal, one-dimensional pseudohomogeneous model of the cathode catalyst layer of a PEMFC derived from a basic mass-current balance. Their model considers the kinetics of the electrochemical reaction along with oxygen diffusion through the pores and proton transport within the membrane phase. A relaxation method is used to solve the two-point boundary value problem resulting from the equations. They assumed a value for the overpotential at the catalyst/membrane interface in order to predict the current, overpotential and oxygen distribution across the layer. The influence of various parameters such as overpotential, proton conductivity, porosity and active catalyst surface are presented.

- At the Royal Institute of Technology in Stockholm and at the Electrochemical and Physicochemical Laboratory for Materials and Interfaces at INPG in Grenoble:

- Broka and Ekdunge (1997) present a steady state, isothermal, one-dimensional model of the PEMFC cathode catalyst layer and show the influence of geometry through a comparison of a pseudo-homogeneous model and an agglomerate model of the 
catalyst layer. In the pseudo-homogeneous approach, the oxygen concentration gradient varies with the local current density in the active layer, whereas in the agglomerate model, the oxygen diffuses from the gas pores into the agglomerate, which implies a constant oxygen concentration. In the latter model, the effect of oxygen diffusion limitation is characterized by an effectiveness factor in which the characteristics of the agglomerate are taken into account. On the basis of their simulations and a structural study of the catalyst layer, they reach the conclusion that the agglomerate model gives a better representation of the catalyst layer. In particular, they claim that the thickness of the Nafion film surrounding the carbon-platinum agglomerates is a crucial parameter in calculating the limiting current due to mass transport limitations.

- While most models use a macroscopic approach, i.e. consider the catalyst layer as a whole, Bultel, Ozil, Durand and Simonsson (1995) and Bultel, Ozil, Durand (1998) present a more in-depth study of the effects of the geometric arrangement within the catalyst layer at the particle level. This microscopic approach provides information on the effect of competition between neighboring particles and the ionic ohmic drop limitation. However, this study is restricted to the case of a highly porous layer where ohmic drop limitations are stronger than diffusion limitations. One of the authors' conclusions is that the discrete distribution of the catalyst particles results in a local limitation effect that must be added to the ohmic drop effect considered in classical models.

- At General Motors:

- Bernardi and Verbrugge (1992) present a comprehensive steady state, isothermal, one-dimensional model of the physical and electrochemical processes in a PEMFC. One of their important assumptions is that the liquid and gas phases are not in equilibrium in the backing layer. They use a pseudo-homogeneous model to predict the current and the reactants distribution in the catalyst layer. This model is valid only for fully hydrated membranes and does not take into account the drag force on water molecules due to proton flux. In addition, the model is unable to predict the flooding due to liquid water in the cathode catalyst layer and backing layers, and the polarization curve diverges from experimental data for high current densities. 


\subsection{Cathode Catalyst Layer Model Assumptions}

The cathode catalyst layer model presented here is based on the assumptions of isotropy and homogeneity. This means that the catalyst layer is treated as a homogeneous phase made of a mix of very small particles of polymer (membrane) and porous media (backing layer). In addition, it is assumed that protons are transported independently of the other reactants and products present. Mathematically, this allows one to combine models from both the polymer membrane and the backing layer, necessitating, nonetheless, some corrections for porosity and certain physical properties such as diffusivities and conductivities. Thus, the assumptions for the membrane and for the backing layer remain valid.

To model the water flux in the membrane phase, it is necessary to predict water uptake by the membrane within the catalyst layer. This demands a good understanding of the geometric arrangement of the different phases and accurate knowledge of the geometry of the polymer agglomerates. This type of information is difficult to develop. Thus, for this thesis work, it was decided to make the reasonable assumption that the hydration of the polymer phase at the interface between the membrane and the backing layer is in equilibrium with the water activity within the latter. The model presented here, therefore, does not account for water uptake/release within the catalyst layer.

In addition, it is assumed that the pressure of the water molecules within the polymer phase is in equilibrium with the pressure of the liquid water in the pores of the catalyst layer. Also, the water vapor pressure in the backing layer is assumed to be in equilibrium with the liquid phase pressure and the capillary pressure.

Finally, the model presented in sections 3.4 and 3.5 below does not account for the concentration overpotential. In order to do so, bulk species concentrations must be related to surface reactant concentrations. A relationship that does just that has been developed and is presented in section 3.6. 


\subsection{Governing and Constitutive Equations}

The following set of equations is used to model the cathode catalyst layer:

- At the catalyst surface:

(i) Electrochemical reactions and species sources/sinks,

(ii) Electrokinetic equation (Butler-Volmer).

- In the porous media of the catalyst layer:

(iii) Mass (species) conservation equations,

(iv) Momentum equation (Darcy),

(v) State equation,

(vi) Capillary pressure equation (Leverett),

(vii) Water vapor pressure (Kelvin and Clapeyron),

(viii) Mixture model (Dalton),

(ix) Conservation of electronic current,

(x) Potential in the matrix (Ohm's law).

- In the polymer phase of the catalyst layer:

(xi) Mass (species) conservation equations,

(xii) Momentum equation (Darcy),

(xiii) Conservation of ionic current,

(xiv) Potential equation in the polymer,

(xv) Pressure of the mixture,

(xvi) Water activity at the interface with the membrane and the backing layer,

(xvii) Water activity.

- Common equation:

(xviii) Energy equation. 


\subsubsection{Model at the Catalyst Surface}

(i) Electrochemical reactions and species sources/sinks

The general electrochemical reaction is

$$
\sum_{i} b_{i} B_{i} \leftrightarrow n e^{-}
$$

where $b_{i}$ is the stochiometric coefficient of species $i$, and $B_{i}$ is the chemical formula of the same species $i$. The rate of consumption of species $i$ in phase $\alpha\left(\mathrm{mol} . \mathrm{m}^{-3} \cdot \mathrm{s}^{-1}\right)$ is related to the current per unit volume $\left(\mathrm{A} \cdot \mathrm{m}^{-3}\right)$. In one dimension, this relation is expressed as follows (Newman, 1991):

$$
\dot{n}_{i}^{\alpha}=-\frac{b_{i}}{n F} \frac{\partial i_{x}}{\partial x}
$$

where $i_{x}$ is the current density $\left(\mathrm{A} \cdot \mathrm{m}^{-2}\right)$ in the $\mathrm{x}$-direction.

By convention, the sign of the rate of consumption/production of species will be determined by the electrical current. For instance, at the cathode, if the X-axis is directed from the anode to the cathode, the electrical current increases so that the rate of production of species will be chosen to be positive. Likewise, the rate of consumption of species will be negative. Therefore, the electrochemical reaction that takes place at the cathode, which is normally written as

$$
2 \mathrm{H}^{+}+\frac{1}{2} \mathrm{O}_{2}+2 e^{-} \leftrightarrow \mathrm{H}_{2} \mathrm{O}
$$

is now rewritten as

$$
-2 \mathrm{H}^{+}-\frac{1}{2} \mathrm{O}_{2}+\mathrm{H}_{2} \mathrm{O} \leftrightarrow 2 e^{-}
$$

and the rate of consumption or production of each species on the left of expression (3.4) are given by

$$
\begin{aligned}
& \dot{n}_{H^{+}}=-\frac{2}{-2 F} \frac{\partial i}{\partial x}=\frac{1}{F} \frac{\partial i}{\partial x} \\
& \dot{n}_{O_{2}}^{g}=-\frac{1 / 2}{-2 F} \frac{\partial i}{\partial x}=\frac{1}{4 F} \frac{\partial i}{\partial x} \\
& \dot{n}_{H_{2} O}^{l}=-\frac{-1}{-2 F} \frac{\partial i}{\partial x}=-\frac{1}{2 F} \frac{\partial i}{\partial x}
\end{aligned}
$$


Note that the current per unit volume $\frac{\partial i}{\partial x}$ given by the Butler-Volmer equation (equation (3.8) below) is always positive.

(ii) Electrokinetic equation (Butler-Volmer)

The kinetics of the electrochemical reaction are expressed by the Butler-Volmer equation which relates current generation per unit volume with the electrochemical conditions (concentrations and potentials) and material properties of the catalyst present. This relation is expressed as

$$
\frac{\partial i}{\partial x}=a i_{0}\left[\exp \left(\frac{\alpha_{a} F\left(\Phi_{c}-\Phi_{m}\right)}{R T}\right)-\exp \left(\frac{-\alpha_{c} F\left(\Phi_{c}-\Phi_{m}\right)}{R T}\right)\right]
$$

where $a\left(\mathrm{~m}^{2} \cdot \mathrm{m}^{-3}\right.$ or $\left.\mathrm{m}^{-1}\right)$ is the specific interfacial area or the effective catalyst surface area per unit volume of the catalyst layer. $\alpha_{a}$ and $\alpha_{c}$ are the anodic and cathodic transfer coefficients, and $\Phi_{c}$ and $\Phi_{m}$ are the voltage potentials in the carbon and polymer phases, respectively. The difference $\Phi_{c^{-}} \Phi_{m}$ is called the activation overpotential. The exchange current density $\mathrm{i}_{0}{ }^{4}$ is a function of the concentration of the reactants and is given by

$$
i_{0}=i_{o}^{r e f}\left(\frac{c_{O_{2}}}{c_{O_{2}}^{r e f}}\right)^{\gamma_{O_{2}}}\left(\frac{c_{H^{+}}}{c_{H^{+}}^{r e f}}\right)^{\gamma_{H^{+}}}
$$

Values for the cathode and anode catalyst layers parameters and properties appearing in equations (3.8) and (3.9) are those given in Bernardi and Verbrugge (1992), They are summarized in Table 3.2.

\footnotetext{
${ }^{4}$ When the cell experiences the rest potential, the net current is zero. That does not, however, mean that there is no transfer of ions in the electrolyte, but rather that at each electrode (anode and cathode catalyst layers), there is an equal amount of anodic and cathodic current (Bockris, 1969)
} 
Table 3.2 Base-case catalyst layer parameters and properties (Bernardi and Verbrugge, 1992).

\begin{tabular}{|l|c|c|c|c|}
\hline Parameter & $\begin{array}{c}\text { Parameter/ } \\
\text { Property }\end{array}$ & Anode & Cathode & Unit \\
\hline Reference kinetic parameter & $a i_{o}^{r e f}$ & $1.4 \mathrm{e} 11$ & 10 & ${\mathrm{~A} . \mathrm{m}^{-3}}^{-3}$ \\
\hline Anodic transfer coefficient & $\alpha_{a}$ & $1 / 2$ & 2 & - \\
\hline Cathodic transfer coefficient & $\alpha_{c}$ & $1 / 2$ & 2 & - \\
\hline$H^{+}$reference concentration & $c_{H^{+}}^{r e f}$ & $1.2 \mathrm{e} 3$ & $1.2 \mathrm{e} 3$ & $\mathrm{~mol}^{-3}$ \\
\hline$H_{2}$ reference concentration & $c_{H_{2}}^{r e f}$ & 56.4 & - & $\mathrm{mol}^{-3}$ \\
\hline$O_{2}$ reference concentration & $c_{O_{2}}^{r e f}$ & - & 3.39 & $\mathrm{~mol}^{-3} \mathrm{~m}^{-3}$ \\
\hline$H^{+}$concentration parameter & $\gamma_{H^{+}}$ & 2 & $1 / 2$ & - \\
\hline$H_{2}$ concentration parameter & $\gamma_{H_{2}}$ & $1 / 4$ & - & - \\
\hline$O_{2}$ concentration parameter & $\gamma_{O_{2}}$ & - & $1 / 2$ & - \\
\hline
\end{tabular}

\subsubsection{Model in the Porous Media of the Catalyst Layer}

(iii) Mass (species) conservation equations

The mass conservation equation for species $i$ in phase $\alpha$ with phase change and electrochemical reaction is ${ }^{5}$

$$
\varepsilon s^{\alpha} \frac{\partial c_{i}^{\alpha}}{\partial t}+\varepsilon c_{i}^{\alpha} \frac{\partial s^{\alpha}}{\partial t}=-\frac{\partial N_{i}^{\alpha}}{\partial x}-\frac{1}{M_{i}} \dot{m}_{i}^{\alpha \rightarrow \beta}-\dot{n}_{i}^{\alpha}
$$

where $\alpha$ and $\beta$ are the phases (liquid or vapor), $c_{i}^{\alpha}$ is the concentration of species $i$ in phase $\alpha, M_{i}\left(\mathrm{~kg} \cdot \mathrm{mol}^{-1}\right)$ is the molecular mass of species $i, \dot{m}_{i}^{\alpha \rightarrow \beta}\left(\mathrm{kg} \cdot \mathrm{m}^{-3} \cdot \mathrm{s}^{-1}\right)$ represents the inter-phase transfer of species $i$ from phase $\alpha$ into $\beta$, and $\dot{n}_{i}^{\alpha}\left(\mathrm{mol}-\mathrm{m}^{-3} \mathrm{~s}^{-1}\right)$ is the source or sink of species $i$ within phase $\alpha$ due to a heterogeneous reaction. The porosity $\varepsilon$, is

\footnotetext{
${ }^{5}$ Note that this equation does not include the water sorption or desorption by the membrane at the catalyst layer / membrane interface. This can be taken into account with appropriate boundary conditions (see section 3.5).
} 
defined as the fraction of the void volume over the total volume, which for a pseudohomogeneous model is given by

$$
\varepsilon=\frac{d V_{\text {pore }}}{d V}=\frac{d V_{\text {pore }}}{d V_{\text {pore }}+d V_{\text {membrane }}+d V_{\text {matrix }}}
$$

Note that this expression is only valid because of the assumption of a homogeneous catalyst layer. In the case of an agglomerate model, one would only consider the volume of the pores and the matrix in the total volume $d V$.

In a like manner, the volume fraction of the polymer within the catalyst layer (pertinent for water conservation in the membrane polymer phase) is defined as

$$
\varepsilon_{m}=\frac{d V_{\text {membrane }}}{d V_{\text {membrane }}+d V_{\text {pores }}+d V_{\text {matrix }}}
$$

The saturation $s^{\alpha}$ in equation (3.19) is defined as the volume $d V^{\alpha}$ occupied by phase $\alpha$ within the pores, i.e.

$$
s^{\alpha}=\frac{d V^{\alpha}}{d V_{\text {pore }}}
$$

where

$$
\sum_{\alpha} s^{\alpha}=1
$$

while $N_{i}^{\alpha}\left(\mathrm{mol} \cdot \mathrm{m}^{-2} \cdot \mathrm{s}^{-1}\right)$ is the molar flux of species $i$ within phase $\alpha$ expressed by

$$
N_{i}^{\alpha}=\frac{1}{\sum_{j \neq i} \frac{c_{j}^{\alpha}}{D_{i, j}^{e f f}}}\left\{c_{i}^{\alpha} \sum_{j \neq i} \frac{N_{j}^{\alpha}}{D_{i, j}^{e f f}}-c^{\alpha} \nabla c_{i}^{\alpha}+c_{i}^{\alpha} \nabla c^{\alpha}\right\}
$$

where the effective diffusion coefficient $D_{i, j}^{e f f}\left(\mathrm{~m}^{2} \cdot \mathrm{s}^{-1}\right)$, which accounts for the porosity of the catalyst layer, is defined using the Bruggemann correction for porous media, namely,

$$
D_{i, j}^{e f f}=[\varepsilon(1-s)]^{3 / 2} D_{i, j}
$$

In this equation, the diffusivity coefficient for a binary mixture $D_{i, j}\left(\mathrm{~m}^{2} \cdot \mathrm{s}^{-1}\right)$ is given by 


$$
\begin{aligned}
D_{i, j}=\left(1 e^{-4}\right) & \left(\frac{p_{c r i t_{i}} p_{c r i t}}{\left(1.01325 \cdot e^{5}\right)^{2}}\right)^{\frac{1}{3}}\left(T_{c r i t_{i}} T_{c r i t}\right)^{\frac{5}{12}}\left(\frac{1000}{M_{i}}+\frac{1000}{M_{j}}\right)^{\frac{1}{2}} \\
& \frac{1}{\left(\frac{c^{g} R T}{1.01325 \cdot e^{5}}\right)^{g}} a\left(\frac{T}{\sqrt{T_{\text {crit }} T_{\text {crit }}}}\right)^{b}
\end{aligned}
$$

with $c^{g}$ in mol.m ${ }^{-3}, p_{c r i t}$ in $\mathrm{Pa}, T$ in $\mathrm{K}$, and $M_{i}$ in $\mathrm{kg} \cdot \mathrm{mol}^{-1}$. The coefficients $a$ and $b$ are determined experimentally for different pairs of species such that

- For a non-polar gas pair:

$$
\begin{aligned}
& a=2.745 e-4 \\
& b=1.823
\end{aligned}
$$

- For $\mathrm{H}_{2} \mathrm{O}$ with a non-polar gas:

$$
\begin{aligned}
& a=3.640 e-4 \\
& b=2.334
\end{aligned}
$$

Since $N^{\alpha}$ and $M^{\alpha}$ are the molar flux and the molar mass of phase $\alpha$, respectively, the species molar fluxes $N_{i}^{\alpha}$ and molar masses $M_{i}$ sum to give

$$
\begin{aligned}
& M^{\alpha} N^{\alpha}=\sum_{i} M_{i} N_{i}^{\alpha} \\
& M^{\alpha}=\sum_{i} \frac{c_{i}^{\alpha}}{c^{\alpha}} M_{i}
\end{aligned}
$$

Now, assuming that the flow in the catalyst layer is composed of $n$ species, only $n-1$ mass conservation balances need to be solved. The last of these is applied to the a phase in its totality (all species of a given phase combined) such that ${ }^{6}$ :

$$
\varepsilon S^{\alpha} \frac{\partial c^{\alpha}}{\partial t}+\varepsilon c^{\alpha} \frac{\partial s^{\alpha}}{\partial t}=-\frac{1}{M^{\alpha}} \frac{\partial}{\partial x}\left(M^{\alpha} N^{\alpha}\right)-\frac{1}{M^{\alpha}} \sum_{i} \dot{m}_{i}^{\alpha \rightarrow \beta}-\frac{1}{M^{\alpha}} \sum_{i} M_{i} \dot{n}_{i}^{\alpha}
$$

\footnotetext{
${ }^{6}$ Equation (3.19) is derived assuming $\frac{\partial}{\partial t} M^{\alpha}=0$.
} 
Furthermore, since in the two-phase flow within the cathode catalyst layer, water vapor pressure and liquid water pressure are related through the capillary pressure, the Kelvin and Clapeyron equations (equations (3.29) and (3.30) below) give an additional relation for the vapor pressure $p_{\mathrm{H}_{2} \mathrm{O}}^{g}$ so that there is only need to solve n-2 mass conservation balances. In addition, since only two phases exist within the catalyst layer, one can write that

$$
\begin{aligned}
& s^{l}=s \\
& s^{g}=1-s
\end{aligned}
$$

and the mass conservation of water for the liquid phase can then be expressed, using the assumption of incompressibility, as

$$
\varepsilon \frac{\rho_{\mathrm{H}_{2} \mathrm{O}}^{l}}{M_{\mathrm{H}_{2} \mathrm{O}}} \frac{\partial s}{\partial t}=-\frac{\partial}{\partial x} N_{\mathrm{H}_{2} \mathrm{O}}^{l}-\frac{1}{M_{\mathrm{H}_{2} \mathrm{O}}} \dot{m}_{\mathrm{H}_{2} \mathrm{O}}^{l \rightarrow g}-\dot{n}_{\mathrm{H}_{2} \mathrm{O}}^{l}
$$

where $\dot{m}_{\mathrm{H} 2 \mathrm{O}}^{l \rightarrow g}$ is the rate of evaporation of liquid water, and $\dot{n}_{\mathrm{H} 2 \mathrm{O}}^{l}$ is the rate of liquid water produced due to the electrochemical reaction.

In addition to equation (3.21), one can also write a separate mass conservation balance for water vapor, but for the sake of convenience, these two are combined to get a global conservation balance for water, in both the liquid and vapor phase. Thus, adding equation (3.10) for water vapor and equation (3.21) results in the saturation equation ${ }^{7,8}$, namely,

$$
\varepsilon\left(\frac{\rho_{\mathrm{H}_{2} \mathrm{O}}^{l}}{M_{\mathrm{H}_{2} \mathrm{O}}}-c_{\mathrm{H}_{2} \mathrm{O}}^{g}\right) \frac{\partial s}{\partial t}+\varepsilon(1-s) \frac{\partial c_{\mathrm{H}_{2} \mathrm{O}}^{g}}{\partial t}=-\frac{\partial}{\partial x}\left(N_{\mathrm{H}_{2} \mathrm{O}}^{l}+N_{\mathrm{H}_{2} \mathrm{O}}^{g}\right)-\dot{n}_{\mathrm{H}_{2} \mathrm{O}}^{l}
$$

(iv) Momentum equation (Darcy)

In the porous media of the catalyst layer, momentum conservation is expressed with the generalized Darcy law (Kaviany, 1995) given by

$$
M^{\alpha} N^{\alpha}=-\left(1-\varepsilon_{m}\right) K \frac{k_{r}^{\alpha}}{v^{\alpha}}\left(\frac{\partial p^{\alpha}}{\partial x}-M^{\alpha} c^{\alpha} g\right)
$$

\footnotetext{
${ }^{7}$ Since the equation for the mass conservation of water in the gas phase will not be used, the Kelvin equation will give the additional condition for the vapor.

${ }^{8}$ Note that the transient contribution of the water vapor is calculated as a function of saturation because of the equilibrium between the vapor, the liquid and the capillary pressures.
} 
where $\left(1-\varepsilon_{m}\right)$ is a correction factor due to the assumption of a homogeneous model. $K$ denotes the absolute permeability of the porous media and $k_{r}^{\alpha}$ is the relative permeability of phase $\alpha$, which can be expressed as a function of the saturation (Bear, 1972) ${ }^{9}$ such that

$$
\begin{aligned}
& k_{r}^{l}=(s)^{3} \\
& k_{r}^{g}=(1-s)^{3}
\end{aligned}
$$

\section{(v) State equation}

The equation of state for the gas phase gives an additional relation between the partial pressure and the concentration of each species, i.e.

$$
p_{i}^{g}=c_{i}^{g} R T
$$

\section{Capillary pressure equation (Leverett)}

The Leverett equation relates the liquid pressure for the two-phase flow to the gas pressure by the following:

$$
p_{c}=p^{g}-p^{l}=f(s) \tau \sqrt{\frac{\varepsilon}{K}}
$$

where $p_{c}$ is the capillary pressure, $\tau$ the surface tension of the water, and $f(s)$ a correlation based on experimental data (Leverett, 1941) and expressed as a function of the saturation $s$ by

$$
f(s)=1.417(1-s)-2.12(1-s)^{2}+1.263(1-s)^{3}
$$

(vii) Water vapor pressure (Kelvin and Clapeyron)

The Kelvin and Clapeyron equation give an expression for the concentration of water vapor in the two-phase flow written as

$$
c_{\mathrm{H}_{2} \mathrm{O}}^{g}=\frac{p_{s a t}(T)}{R T} \exp \left(-\frac{M_{\mathrm{H}_{2} \mathrm{O}} p_{c}}{\rho_{\mathrm{H}_{2} \mathrm{O}}^{l} R T}\right)
$$

where

\footnotetext{
${ }^{9}$ In this model, the concentration of the gas phase is used as a variable instead of the pressure. Therefore, the pressure gradient appearing in the Darcy equation can be replaced by the appropriate variables: the concentration and the temperature for the gas phase (semi-perfect gas model) and the capillary pressure and gas pressure for the liquid phase (see equation (3.27) above).
} 


$$
p_{\text {sat }}(T)=p_{0}^{\text {sat }} \exp \left(\frac{\left(\frac{1}{T_{0}^{\text {sat }}}-\frac{1}{T}\right) L_{v}}{R} M_{\mathrm{H}_{2} \mathrm{O}}\right)
$$

and $p_{0}{ }^{\text {sat }}$ and $T_{0}{ }^{\text {sat }}$ are the pressure and temperature of a saturation reference point.

(viii) Mixture model (Dalton)

The Dalton model relates the concentrations, partial pressures, and densities of the species in the gas phase such that

$$
\begin{aligned}
& c^{g}=\sum_{i} c_{i}^{g} \\
& p^{g}=\sum_{i} p_{i}^{g} \\
& \rho^{g}=\sum_{i} \rho_{i}^{g}
\end{aligned}
$$

(ix) Conservation of current

The conservation of electrical charge in the cathode catalyst layer relates the current generation per unit volume to the apparent electrical current $i_{c}^{a p p}$ per unit area of the catalyst layer. Thus,

$$
\frac{\partial i}{\partial x}=\frac{\partial i_{c}}{\partial x}=\frac{1}{1-\varepsilon_{m}} \frac{\partial i_{c}^{a p p}}{\partial x}
$$

where $1 /\left(1-\varepsilon_{\mathrm{m}}\right)$ is a correction factor due to the assumption of a homogeneous model.

(x) Potential in the matrix (Ohm's law)

Ohm's law relates the apparent electrical current to the voltage potential in the matrix phase and is expressed as

$$
i_{c}^{a p p}=-\sigma_{c}^{a p p} \frac{\partial \Phi_{c}}{\partial x}
$$

where $\sigma_{c}^{a p p}$ is the apparent electronic conductivity given by

$$
\sigma_{c}^{a p p}=\left(1-\varepsilon_{m}\right) \sigma_{c}^{e f f}
$$

and $\sigma_{c}^{e f f}$ is the effective electronic conductivity defined as 


$$
\sigma_{c}^{e f f}=\left(\frac{1-\varepsilon_{m}-\varepsilon}{1-\varepsilon_{m}}\right)^{3 / 2} \sigma_{c}
$$

where the factor $\left(\frac{1-\varepsilon_{m}-\varepsilon}{1-\varepsilon_{m}}\right)^{3 / 2}$ accounts for the porosity of the matrix phase.

\subsubsection{Model in the Polymer}

(xi) Mass (species) conservation equations

The mass conservation of water in the membrane (polymer) is expressed as follows:

$$
\varepsilon_{m} \frac{\partial c_{H_{2} O}^{m}}{\partial t}=-\frac{\partial}{\partial x} J_{H_{2} O}-\frac{\partial}{\partial x}\left(c_{H_{2} O}^{m} u^{m}\right)
$$

with the diffusive molar flux given by

$$
J_{\mathrm{H}_{2} \mathrm{O}}=-D_{c_{\mathrm{H}_{2} \mathrm{O}}, T} \frac{\partial c_{\mathrm{H}_{2} \mathrm{O}}^{m}}{\partial x}+n_{\text {drag }} \frac{i_{m}}{F}
$$

where the drag coefficient, $n_{d r a g}$, is based on a correlation presented in Springer et al. (1991), i.e.

$$
n_{\text {drag }}=2.5 \frac{\frac{\lambda_{\mathrm{H}_{2} \mathrm{O}}}{\mathrm{SO}_{3}}}{22} \varepsilon_{m}
$$

and

$$
\lambda_{\mathrm{H}_{2} \mathrm{O} / \mathrm{SO}_{3}}=\frac{c_{\mathrm{H}_{2} \mathrm{O}}^{m}}{\frac{\rho_{d r y}^{m}}{M^{m}}-b c_{\mathrm{H}_{2} \mathrm{O}}^{m}}
$$

and

$$
b=0.0126
$$

where $i_{m}$ is the protonic current, $F$ Faraday's constant and $\lambda_{\mathrm{H}_{2} \mathrm{O} / \mathrm{SO}_{3}}$ is the water content $\left(\mathrm{mol}_{\mathrm{H}_{2} \mathrm{O}} \mathrm{mol}_{\mathrm{SO}_{3}^{-}}^{-1}\right), \rho_{d r y}^{m}$ the dry membrane density $\left(\mathrm{kg}_{m_{d r y}} m_{d r y}{ }^{-3}\right), M^{m}$ the membrane molecular mass, and $b$ the membrane extension coefficient in the x-direction. Note that 
the ratio $2.5 / 22$ is the number of $\mathrm{H}_{2} \mathrm{O}$ molecules per sulfonic acid $\left(\mathrm{SO}_{3}\right)$ site (Springer et al., 1991).

The expression for the diffusion coefficient of water, $D_{c_{H_{2} O}, T}\left(\mathrm{~m}^{2} \cdot \mathrm{s}^{-1}\right)$, includes a correction for the temperature and the water content (Springer et al., 1991) such that

$$
D_{c_{H_{2} O}, T}=\varepsilon_{m} D^{\prime}\left\{\exp \left[2416\left(\frac{1}{303}-\frac{1}{T}\right)\right] \lambda_{H_{2} \mathrm{O} / \mathrm{SO}_{3}} \frac{1}{a} \frac{1}{17.81-78.9 a+108 a^{2}}\right\}
$$

where a is the activity of the water molecules, and $D^{\prime}$ is the diffusion coefficient measured at a constant temperature of $30^{\circ} \mathrm{C}$, i.e.

$$
\begin{array}{ll}
D^{\prime}=7.75 e(-11) \lambda_{\mathrm{H}_{2} \mathrm{O} / \mathrm{SO}_{3}}-9.5 e(-11) & \text { for } \lambda_{\mathrm{H}_{2} \mathrm{O} / \mathrm{SO}_{3}} \leq 6 \\
D^{\prime}=2.5625 e(-11) \lambda_{\mathrm{H}_{2} \mathrm{O} / \mathrm{SO}_{3}}+2.1625 e(-10) & \text { for } 6<\lambda_{\mathrm{H}_{2} \mathrm{O} / \mathrm{SO}_{3}} \leq 14
\end{array}
$$

Note that in the expression for the diffusion coefficient of water, $\varepsilon_{m}$, as in the formulation of the drag coefficient, is a correction term for the assumption of a homogeneous model.

The assumption of electro-neutrality in the membrane along with that of a homogeneous distribution of charged sites in the polymer imply that both

$$
\begin{aligned}
& \frac{\partial c_{H^{+}}}{\partial x}=0 \\
& \frac{\partial c_{H^{+}}}{\partial t}=0
\end{aligned}
$$

In other words, the concentration of protons remains constant in the membrane material of the catalyst layer ${ }^{10}$. Thus, the diffusive flux of protons can be expressed as

$$
J_{H^{+}}=-\varepsilon_{m} \frac{F}{R T} D_{H^{+}} c_{H^{+}} \frac{\partial \Phi_{m}}{\partial x}
$$

$\varepsilon_{m}$ is the correction due to the assumption of a homogeneous model.

\footnotetext{
10 The value given in Bernardi and Verbrugge (1991) for Nafion 117 is used here, namely, $c_{H^{+}}=1.2 e^{-3} \mathrm{~mol} \cdot \mathrm{cm}^{-3}$.
} 


\section{(xii) Momentum Equation (Darcy)}

The Darcy equation for the mixture of water and protons in the polymer phase is

$$
u^{m}=-\varepsilon_{m} \frac{K k_{r}^{g}}{\mu}\left[\frac{\partial p}{\partial x}-\rho g\right]
$$

where $u^{m}$ is the mixture velocity, $K$ the absolute permeability, and $k_{r}^{g}$ the relative permeability given by equation (3.25) with $s=0$. The mixture density $\rho$ and the dynamic viscosity $\mu$ are given by

$$
\begin{aligned}
& \rho=M_{H^{+}} c_{H^{+}}+M_{H_{2} O} c_{H_{2} O}^{m} \\
& \mu=\frac{M_{H^{+}} c_{H^{+}}}{\rho} \mu_{H^{+}}+\frac{M_{H_{2} O} c_{H_{2} O}^{m}}{\rho} \mu_{H_{2} O}
\end{aligned}
$$

(xiii) Conservation of current

The conservation of electrical charge at the cathode relates the current generation per unit volume to the apparent protonic current $i_{m}^{a p p}$ per unit area of the catalyst layer such that

$$
\frac{\partial i}{\partial x}=-\frac{\partial i_{m}}{\partial x}=-\frac{1}{\varepsilon_{m}} \frac{\partial i_{m}^{a p p}}{\partial x}
$$

and $1 / \varepsilon_{\mathrm{m}}$ is a correction factor due to the assumption of a homogeneous model.

(xiv) Potential equation in the polymer

The equation for the voltage potential in the polymer phase is written as

$$
\frac{\partial \Phi_{m}}{\partial x}=-\frac{i_{m}^{a p p}}{\sigma_{m}{ }^{a p p}}+\frac{F}{\sigma_{m}{ }^{a p p}} c_{H^{+}} u^{m}
$$

where $\sigma_{m}{ }^{a p p}$ is the apparent conductivity of the membrane (Springer et al., 1991) given by

$$
\sigma_{m}{ }^{a p p}=\varepsilon_{m} \sigma_{m 303} \exp \left[1268\left(\frac{1}{303}-\frac{1}{T}\right)\right]
$$

The conductivity of the membrane at $303 \mathrm{~K}, \sigma_{m 303}$, is expressed by the following correlation as a function of water content: 


$$
\sigma_{m 303}=100\left(0.005139 \lambda_{\mathrm{H}_{2} \mathrm{O} / \mathrm{SO}_{3}}-0.00326\right)
$$

\section{(xv) Pressure of the mixture}

The pressure is assumed to vary linearly through the polymer material. At the interfaces with the membrane and the backing layer, the mixture pressure in the polymer is assumed to be equal to the pressure of the mixture (liquid and gas), i.e.

$$
\begin{aligned}
p & =\left\lfloor s p_{\mathrm{H}_{2} \mathrm{O}_{c c x-}}^{l}+(1-s) p^{g}{ }_{c c x-}\right\rfloor \\
& +\frac{\left[s p_{\mathrm{H}_{2} \mathrm{O}_{c c x+}}^{l}+(1-s) p^{g}{ }_{c c x+}\right]-\left[s p_{\mathrm{H}_{2} \mathrm{O}_{c c x-}}^{l}+(1-s) p_{c c x-}^{g}\right]}{x_{c c x+}-x_{c c x-}}\left(x-x_{c c x-}\right)
\end{aligned}
$$

(xvi) Water activity at the interface with the membrane

At the membrane interface, the water activity is given by:

$$
a=\frac{R T}{p_{\text {sat }}(T)}\left[c_{\mathrm{H}_{2} \mathrm{O}}^{g}+\frac{s}{1-s} \frac{\rho_{\mathrm{H}_{2} \mathrm{O}}^{l}}{M_{\mathrm{H}_{2} \mathrm{O}}}\right] \quad \text { for } a \in[0,3]
$$

in which the last term accounts for a "wet" mixture ${ }^{11}$.

(xvii) Water activity

The water vapor activity within the membrane material is expressed by the following correlations found in Springer et al, (1991):

$$
\begin{aligned}
a & =1 / 2160\left(c_{1}+c_{2} \lambda_{\mathrm{H}_{2} \mathrm{O} / \mathrm{SO}_{3}}+216\left(c_{3}-c_{4} \lambda_{\mathrm{H}_{2} \mathrm{O} / \mathrm{SO}_{3}}\right.\right. \\
& \left.\left.+c_{5} \lambda_{\mathrm{H}_{2} \mathrm{O} / \mathrm{SO}_{3}}{ }^{2}\right)^{(1 / 2)}\right)^{(1 / 3)}-134183 / 2160 / \\
& \left(c_{1}+c_{2} \lambda_{\mathrm{H}_{2} \mathrm{O} / \mathrm{SO}_{3}}+216\left(c_{3}-c_{4} \lambda_{\mathrm{H}_{2} \mathrm{O} / \mathrm{SO}_{3}}\right.\right. \\
& \left.\left.+c_{5} \lambda_{\mathrm{H}_{2} \mathrm{O} / \mathrm{SO}_{3}}{ }^{2}\right)^{(1 / 2)}\right)^{(1 / 3)}+797 / 2160 \\
c_{1}= & -41956 \mathrm{e} 4 \\
c_{2}= & 139968 \mathrm{e} 3 \\
c_{3}= & 382482 \mathrm{e} 6 \\
c_{4} & =251739 \mathrm{e} 3
\end{aligned}
$$

\footnotetext{
${ }^{11}$ The sorption of water at the cathode catalyst layer / membrane interface is given by Springer et al. (1991) as a function of the water vapor activity. To account for the wet mixture, they allow the activity to increase above 1, up to 3 . Although it is incorrect to define a vapor pressure greater than the saturation pressure, this procedure is convenient because it provides a simple relation for the water content at this interface.
} 


$$
c_{5}=419904 \mathrm{e} 6
$$

$$
\begin{aligned}
& a=0.7143\left(\lambda_{\mathrm{H}_{2} \mathrm{O} / \mathrm{SO}_{3}}\right)-9.0021 \\
& a=3
\end{aligned}
$$

$$
\begin{aligned}
& \text { for } 14 \leq\left(\lambda_{\mathrm{H}_{2} \mathrm{O} / \mathrm{SO}_{3}}\right) \leq 16 \\
& \text { for } 16.8 \leq\left(\lambda_{\mathrm{H}_{2} \mathrm{O} / \mathrm{SO}_{3}}\right)
\end{aligned}
$$

\subsubsection{Common Equation}

(xviii) Energy equation

In the catalyst layer, energy is transported by conduction and convection within the polymer membrane (mixture of water, protons, and polymer material) and the porous media (matrix material and liquid and gaseous water). The energy balance is, thus, expressed as follows:

$$
\overline{\rho c_{p}} \frac{\partial T}{\partial t}=\frac{\partial}{\partial x} \lambda^{e f f} \frac{\partial T}{\partial x}-\overline{M c_{p} N} \frac{\partial T}{\partial x}+R_{m}+R_{c}+R_{a c t}+\dot{m}_{H_{2} O}^{l \rightarrow g} L_{v}+Q_{s}
$$

with,

$$
\begin{aligned}
\overline{\rho c_{p}}= & \left(1-\varepsilon-\varepsilon_{m}\right) \rho^{c} c_{p}^{c}+\varepsilon S \rho_{H_{2} O}^{l} c_{p_{H_{2} O}}^{l}+\sum_{i} \varepsilon(1-s) M_{i} c_{i}^{g} c_{p_{i}}^{g} \\
& +\varepsilon_{m} \rho_{m}^{d r y} c_{p_{m}}+\varepsilon_{m} \rho_{H_{2} O}^{m} c_{p_{H_{2} O}}^{m}+\varepsilon_{m} \rho_{H^{+}}^{m} c_{p_{H^{+}}}^{m} \\
\rho_{H^{+}}^{m}= & M_{H^{+}} c_{H^{+}} \\
\rho_{H_{2} O}^{m}= & M_{H_{2} O} c_{H_{2} O}^{m} \\
\overline{M c_{p} N}= & M_{H_{2} O} c_{p_{H_{2} O} O}^{l} N^{l}+\sum_{i} M_{i}^{g} c_{p_{i}}^{g} N_{i}^{g} \\
& +M_{H^{+}} c_{p_{H^{+}}} N_{H^{+}}+M_{H_{2} O} c_{p_{H_{2} O}{ }^{m}} N_{H_{2} O}
\end{aligned}
$$

In the equation (3.57), the effects of phase change, activation overpotential and ohmic losses (in the polymer and the matrix) are taken into account by the source terms $\dot{m}_{H 2 O}^{l \rightarrow g}$, $R_{a c t}, R_{m}, R_{c}$, respectively. The reversible heat produced during the electrochemical reaction is taken into account by the source term $Q_{s} . L_{v}$ is the liquid-gas enthalpy change for the water while $\lambda^{e f f}$ is the total effective thermal conductivity for the catalyst layer given by 


$$
\left(\lambda^{s+l+g+m}\right)^{e f f}=\left(\lambda^{s}\right)^{1-\varepsilon-\varepsilon_{m}}\left(\lambda^{l}\right)^{s s}\left(\lambda^{g}\right)^{\varepsilon(1-s)}\left(\lambda^{m}\right)^{\varepsilon_{m}}
$$

The ohmic resistances within the polymer and within the matrix are expressed as

$$
R_{m}=\frac{i_{m}{ }^{2}}{\sigma_{m}} \varepsilon_{m}=\frac{\left(i_{m}^{a p p}\right)^{2}}{\sigma_{m}^{a p p}}
$$

and

$$
R_{c}=\frac{i_{c}^{2}}{\sigma_{c}} \varepsilon_{m}=\frac{\left(i_{m}^{a p p}\right)^{2}}{\sigma_{c}^{a p p}}
$$

The activation overpotential, which accounts for the irreversibility due to slow electrochemical reactions, is written as ${ }^{12}$

$$
R_{a c t}=\left(\Phi_{c}-\Phi_{m}\right) \frac{\partial i}{\partial x}
$$

While the reversible heat is expressed with the entropies of formation of the reactants $s_{i}^{\alpha}$ $\left(\mathrm{J} \cdot \mathrm{K}^{-1} \cdot \mathrm{mol}^{-1}\right)$ and depends on temperature and partial pressures such that

$$
Q_{s}=T \sum_{i}\left[\dot{n}_{i} s_{i}^{\alpha}\left(T, p_{i}^{\alpha}\right)\right], \quad i=H_{2}, H^{+}, O_{2}, H_{2} O^{l}, \quad \alpha=l, g
$$

where $\dot{n}_{i}$ is the rate of production or consumption of the reactants given by equations (3.5) to (3.7). The entropy of formation for each species at $p_{0}=1$ bar are given in the thermochemical tables. Interpolation with temperature gives a simple approximation to $\left.s_{i}^{\alpha}(T)\right|_{p_{0}}$.

For the liquid phase, the assumption of incompressibility allows one to use the equation for $s_{\mathrm{H}_{2} \mathrm{O}}^{l}$ at $p_{0}=1 \mathrm{bar}$, since dependence on pressure is negligible. For the gas phase, the pressure dependence is given by

$$
s_{i}^{g}\left(T, p_{i}^{\alpha}\right)=\left.s_{i}^{g}(T)\right|_{p_{0}}+\Delta s_{i}^{g}
$$

where $\Delta s_{i}^{g}$ refers to a pressure change at constant temperature. For a semi-perfect gas model, it is written as (Bejan, 1984)

\footnotetext{
${ }^{12}$ Due to the $2^{\text {nd }}$ law of thermodynamics, the activation overpotential is always positive.
} 


$$
\Delta s_{i}^{g}=-R \ln \left(\frac{p_{i}^{g}}{p_{0}}\right)
$$

\subsection{Boundary Conditions and Initial Conditions}

The simplification of all the differential equations and closure relations (governing and constitutive equations) previously presented allows one to write a system of seven differential equations in the cathode catalyst layer since the concentration of protons $c_{H^{+}}$ is constant. Thus, one has to solve for seven constitutive variables:

- the concentration of oxygen $\left(c_{O_{2}}^{g}\right)$,

- the concentration of the gas mixture $\left(c^{g}\right)$,

- the saturation $(s)$,

- the electrical potential $\left(\Phi_{c}\right)$,

- the concentration of water in the polymer phase $\left(c_{\mathrm{H}_{2} \mathrm{O}}^{m}\right)$,

- the proton potential $\left(\Phi_{m}\right)$,

- the temperature $(T)$.

Since the model is one-dimensional, the equations will only have to be solved in the $\mathrm{x}$ direction.

To denote the location of a particular interface, the following notation will be used for subscripts in the expression of boundary conditions:

1) the first letter symbolizes the domain:

c: catalyst layer,

$\mathrm{m}$ : polymer membrane,

b: backing layer.

2) the second indicates the side of the interface:

$\mathrm{x}+$ : higher values of $\mathrm{x}$-coordinates, perpendicular to the surface,

$\mathrm{X}-$ : lower values of $\mathrm{x}$-coordinates, perpendicular to the surface. 


\subsubsection{Oxygen Concentration in the Porous Media $\left(c_{O_{2}}^{g}(t, x)\right)$}

The mass (species) conservation equation for oxygen requires two boundary conditions and one initial condition. At the backing layer interface, the oxygen flux is continuous so that

$$
\left\{N_{O_{2}}^{g}\right\}_{t, x=x_{c x+}}=\left\{N_{O_{2}}^{g}\right\}_{t, x=x_{b x-}}
$$

At the polymer membrane interface, it is assumed that no oxygen leaves, i.e.

$$
\left\{N_{O_{2}}^{g}\right\}_{t, x=x_{c x-}}=0
$$

As to the initial condition, the concentration profile is assumed to be linear across the catalyst layer. Thus,

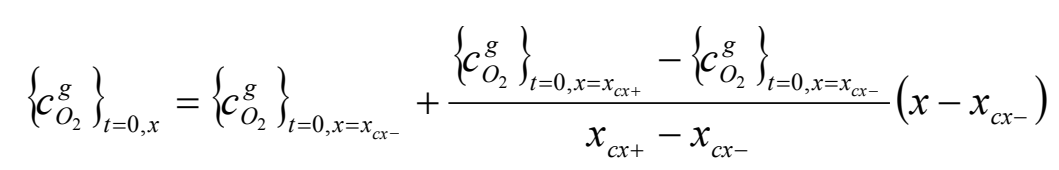

\subsubsection{Concentration of the Gas Mixture in the Porous Media $\left(c^{g}(t, x)\right)$}

The mass conservation equation for the gas mixture in the porous media requires two boundary conditions and one initial condition. At the backing layer interface, part of the water present is transported into the membrane material of the catalyst layer $\left(M_{\mathrm{H}_{2} \mathrm{O}} N_{\mathrm{H}_{2} \mathrm{O}}^{m}\right.$ ). Since the nature of the phase in which water is present within the polymer membrane is unknown, one cannot determine what part of the liquid and gas in the backing layer is transferred to the membrane. Thus, it is assumed that all the water transported within the polymer membrane of the catalyst layer comes from the liquid phase in the backing layer ${ }^{13}$. Thus, the boundary condition is

$$
\left\{M^{g} N^{g}\right\}_{t, x=x_{c x+}}=\left\{M^{g} N^{g}\right\}_{t, x=x_{b x-}}
$$

\footnotetext{
${ }^{13}$ Note that if there is a net water flux from the cathode to the anode, the model results in an error in the energy balance of the stack: as water is absorbed in a liquid phase and released in a vapor phase, the heat of the phase change must be taken into account.
} 
Now, at the polymer membrane interface, it is assumed that no oxygen or nitrogen leaves. It is also assumed that all the water transferred to the membrane comes from the liquid phase in the porous media of the catalyst layer and from the water in the polymer membrane of the catalyst layer. Therefore, no water vapor is transported through this interface. The boundary condition is, thus, written as

$$
\left\{M^{g} N^{g}\right\}_{t, x=x_{c x+}}=0
$$

As to the initial condition, the concentration profile is assumed to be linear across the layer:

$$
\left\{c^{g}\right\}_{t=0, x}=\left\{c^{g}\right\}_{t=0, x=x_{c x-}}+\frac{\left\{c^{g}\right\}_{t=0, x=x_{c x+}}-\left\{c^{g}\right\}_{t=0, x=x_{c x-}}}{x_{c x+}-x_{c x-}}\left(x-x_{c x-}\right)
$$

\subsubsection{Saturation in the Porous Media $(s(t, x))$}

The mass (species) balance equations for the water in liquid and gas phases in the porous media give the equation for the saturation. This equation requires two boundary conditions and one initial condition. At the polymer membrane interface, continuity of the water flux must be expressed. Since it has been assumed that all the water transported from the porous media of the catalyst layer to the membrane is in liquid form, no water vapor leaves through this interface and, thus,

$$
\left\{N_{\mathrm{H}_{2} \mathrm{O}}^{g}\right\}_{t, x=x_{c x+}}=0
$$

and the boundary condition is:

$$
\left\{N_{\mathrm{H}_{2} \mathrm{O}}^{l}\right\}_{t, x=x_{c x-}}+\left\{N_{\mathrm{H}_{2} \mathrm{O}}^{m}\right\}_{t, x=x_{c x-}}=\left\{N_{\mathrm{H}_{2} \mathrm{O}}^{m}\right\}_{t, x=x_{m x+}}
$$

At the backing layer interface, part of the water is transported into the membrane material of the catalyst layer $\left(\mathrm{N}_{\mathrm{H}_{2} \mathrm{O}}^{m}\right)$ :

$$
\left\{N_{\mathrm{H}_{2} \mathrm{O}}^{l}+N_{\mathrm{H}_{2} \mathrm{O}}^{g}\right\}_{t, x=x_{c x+}}+\left\{N_{\mathrm{H}_{2} \mathrm{O}}^{m}\right\}_{t, x=x_{c x+}}=\left\{N_{\mathrm{H}_{2} \mathrm{O}}^{l}+N_{\mathrm{H}_{2} \mathrm{O}}^{g}\right\}_{t, x=x_{b c x-}}
$$

As to the initial condition, the saturation profile is assumed to be linear across the layer: 


$$
\{s\}_{t=0, x}=\{s\}_{t=0, x=x_{c x-}}+\frac{\{s\}_{t=0, x=x_{c x+}}-\{s\}_{t=0, x=x_{c x-}}}{x_{c x+}-x_{c x-}}\left(x-x_{c x-}\right)
$$

\subsubsection{Electrical Potential in the Porous Media $\left(\Phi_{c}(x)\right)$}

The potential equation requires two boundary conditions. At the backing layer interface, the conservation of the electrical current is expressed by

$$
\left\{\frac{\partial \Phi_{c}}{\partial x}\right\}_{t, x=x_{c x+}}=\frac{\left\{\sigma_{c}^{e f f}\right\}_{t, x=x_{b c x-}}}{\left\{\sigma_{c}^{e f f}\right\}_{t, x=x_{c x+}}}\left\{\frac{\partial \Phi_{c}}{\partial x}\right\}_{t, x=x_{b x-}}
$$

At the polymer membrane interface, the electrical current is zero, and, thus,

$$
\left\{\frac{\partial \Phi_{c}}{\partial x}\right\}_{t, x=x_{c x-}}=0
$$

\subsubsection{Water Concentration in the Polymer $\left(c_{H_{2} O}^{m}(t, x)\right)$}

The mass conservation equation for water in the polymer material requires two boundary conditions and one initial condition. At the backing layer interface, part of the water is transported into the membrane material of the catalyst layer. It is assumed that the water activity in the polymer is in equilibrium with the water activity in the porous media. The boundary condition is, therefore,

$$
\left\{c_{\mathrm{H}_{2} \mathrm{O}}^{m}=\lambda_{\mathrm{H}_{2} \mathrm{O} / \mathrm{SO}_{3}} \frac{\rho_{d r y}^{m}}{M^{m}} \frac{1}{1+b \lambda_{\mathrm{H}_{2} \mathrm{O} / \mathrm{SO}_{3}}}\right\}_{t, x=x_{c x+}}
$$

where the water uptake (content) $\lambda_{\mathrm{H}_{2} \mathrm{O} / \mathrm{SO}_{3}}$ is function of the activity of the water molecules given by

$$
\begin{array}{ll}
\left\{\lambda_{\mathrm{H}_{2} \mathrm{O} / \mathrm{SO}_{3}}=0.043+17.81(a)-39.85(a)^{2}+36(a)^{3}\right\}_{t, x=x_{c x+}} & \text { for } a<1 \\
\left\{\lambda_{\mathrm{H}_{2} \mathrm{O} / \mathrm{SO}_{3}}=14+1.4(a-1)\right\}_{t, x=x_{c x+}} & \text { for } 1 \leq a \leq 3
\end{array}
$$




$$
\left\{\lambda_{\mathrm{H}_{2} \mathrm{O} / \mathrm{SO}_{3}}=16.8\right\}_{t, x=x_{c x+}} \quad \text { for } 3<a
$$

and the water activity at the backing layer interface is written as

$$
\{a\}_{t, x=x_{b x-}}=\left\{\frac{R T}{p_{s a t}(T)}\left[c_{H_{2} O}^{g}+\frac{s}{1-s} \frac{\rho_{H_{2} O}^{l}}{M_{H_{2} O} \mathrm{O}}\right]\right\}_{t, x=x_{c x+}}
$$

Now, at the polymer membrane interface, it is assumed that the water activity in the polymer phase is in equilibrium with the water activity in the porous media. The boundary condition is, thus,

$$
\left\{c_{\mathrm{H}_{2} \mathrm{O}}^{m}=\lambda_{\mathrm{H}_{2} \mathrm{O} / \mathrm{SO}_{3}} \frac{\rho_{d r y}^{m}}{M^{m}} \frac{1}{1+b \lambda_{\mathrm{H}_{2} \mathrm{O} / \mathrm{SO}_{3}}}\right\}_{t, x=x_{c x-}}
$$

where the water uptake $\lambda_{\mathrm{H}_{2} \mathrm{O} / \mathrm{SO}_{3}}$ is a function of the activity of the water molecules such that

$$
\begin{array}{ll}
\left\{\lambda_{\mathrm{H}_{2} \mathrm{O} / \mathrm{SO}_{3}}=0.043+17.81(a)-39.85(a)^{2}+36(a)^{3}\right\}_{t, x=x_{c x-}} & \text { for } a \leq 1 \\
\left\{\lambda_{\mathrm{H}_{2} \mathrm{O} / \mathrm{SO}_{3}}=14+1.4(a-1)\right\}_{t, x=x_{c x-}} & \text { for } 1 \leq a \leq 3 \\
\left\{\lambda_{\mathrm{H}_{2} \mathrm{O} / \mathrm{SO}_{3}}=16.8\right\}_{t, x=x_{c x-}} & \text { for } 3 \leq a
\end{array}
$$

and the water activity at the polymer membrane interface is given by

$$
\{a\}_{t, x=x_{m x+}}=\left\{\frac{R T}{p_{\text {sat }}(T)}\left[c_{\mathrm{H}_{2} \mathrm{O}}^{g}+\frac{s}{1-s} \frac{\rho_{\mathrm{H}_{2} \mathrm{O}}^{l}}{M_{\mathrm{H}_{2} \mathrm{O}}}\right]\right\}_{t, x=x_{c x-}}
$$

As to the initial condition, the concentration profile is assumed to be linear across the layer so that

$$
\begin{aligned}
\left\{c_{\mathrm{H}_{2} \mathrm{O}}^{m}\right\}_{t=0, x}= & \left\{c_{\mathrm{H}_{2} \mathrm{O}}^{m}\right\}_{t=0, x=x_{c x-}} \\
& +\frac{\left\{c_{\mathrm{H}_{2} \mathrm{O}}^{m}\right\}_{t=0, x=x_{c x+}}-\left\{c_{\mathrm{H}_{2} \mathrm{O}}^{m}\right\}_{t=0, x=x_{c x-}}}{x_{c x+}-x_{c x-}}\left(x-x_{c x-}\right)
\end{aligned}
$$




\subsubsection{Proton Potential in the Porous Media $\left(\Phi_{m}(x)\right)$}

The potential equation requires two boundary conditions. At the polymer membrane interface, the conservation of the proton current is expressed as

$$
\begin{aligned}
\left\{\frac{\partial \Phi_{m}}{\partial x}\right\}_{t, x=x_{c x-}}= & \frac{1}{\left\{\sigma_{m}^{a p p}\right\}_{t, x=x_{c x-}}} \\
& \left(\left\{\sigma_{m} \frac{\partial \Phi_{m}}{\partial x}-F c_{H+} u^{m}\right\}_{t, x=x_{m x+}}+\left\{F c_{H+} u^{m}\right\}_{t, x=x_{c x-}}\right)
\end{aligned}
$$

At the polymer membrane interface, the electrical current is zero:

$$
\left\{\frac{\partial \Phi_{m}}{\partial x}\right\}_{t, x=x_{c x+}}=0
$$

\subsubsection{Temperature $(T(t, x))$}

The energy conservation equation requires two boundary conditions and one initial condition. At the backing layer and polymer membrane interfaces, the interfacial heat flux is continuous so that

$$
\begin{aligned}
& \left\{\lambda^{e f f} \frac{\partial T}{\partial x}\right\}_{t, x=x_{c x+}}=\left\{\lambda^{e f f} \frac{\partial T}{\partial x}\right\}_{t, x=x_{b x-}} \\
& \left\{\lambda^{e f f} \frac{\partial T}{\partial x}\right\}_{t, x=x_{c x-}}=\left\{\lambda_{m} \frac{\partial T}{\partial x}\right\}_{t, x=x_{m x+}}
\end{aligned}
$$

The initial condition is given by a linear temperature profile across the catalyst layer, namely,

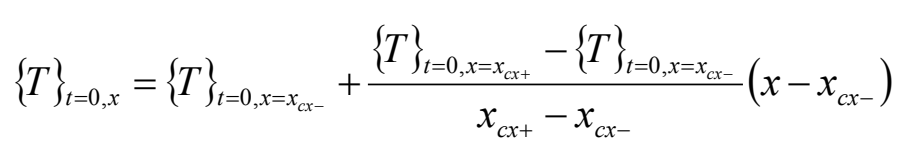




\subsection{Additional Assumptions}

In addition to the model assumptions presented at the beginning of this chapter, some additional assumptions are made to facilitate the resolution of the equations. Also, a relationship for the concentration overpotential is developed through a diffusion layer model.

\subsubsection{Additional Assumptions}

1) Fully developed flow:

It is assumed that the velocity of the mixture in the membrane phase has reached fully developed conditions. Therefore, the term $u^{m}$ given in equation (3.48) is assumed constant with $x$. This assumption is reasonable since the pressure gradient is considered constant across the layer (see equation (3.55)). Also, the results presented in chapter 5 show that the saturation ratio is almost constant across the catalyst layer. Therefore, the relative permeability (equation (3.25)) can be assumed constant across the catalyst layer.

2) Gravity is neglected.

3) Constant voltage potential in the porous media:

Since the conductivity of the carbon (matrix) phase of the catalyst layer is much higher than the conductivity of the membrane material in the catalyst layer, it is reasonable to assume that the voltage potential in the carbon phase (porous media), $\Phi_{c}$, is constant across the catalyst layer. Therefore, the system of differential equations reduces to six equations.

\subsubsection{Diffusion Layer Model}

\section{Pseudo-homogeneous model}

For the pseudo-homogeneous model, a relationship for the concentration overpotential is developed using a diffusion layer model. Since the catalyst layer is solved as a standalone model, the boundary conditions used at the backing layer interface cannot reflect 
the mass transport phenomena in the backing layer, which would include the diffusion of oxygen and the evacuation of liquid water ${ }^{14}$. Therefore, it is necessary to use simplified boundary conditions at the backing layer interface that do not account for the contribution of the backing layer in mass transport limitations. In particular, a fixed value of the concentration of oxygen is assigned at the backing layer interface ${ }^{15}$. As a result, the oxygen flux at the backing layer interface is not limited, and the current generation per unit volume given by equation (3.8) can increase indefinitely. Hence, to model a limiting current it is necessary to make an additional assumption. It will be assumed that the whole catalyst layer is active, and that the limiting current is reached when the oxygen is totally depleted within the entire catalyst layer. Thus, a limiting current is defined for an active catalyst layer of thickness $\delta$, and in the case where the oxygen concentration at the backing layer interface is fixed to a given value $\left\{c_{O_{2}}^{g}\right\}_{t, x=x_{c x+}}$. It is written as

$$
i_{l}=A \frac{D_{O_{2}, j}^{e f f}\left\{c_{O_{2}}^{g}\right\}_{t, x=x_{c x+}} 4 F}{\delta}
$$

where $\delta$ is the thickness of the catalyst layer and $A$ is the catalyst surface area ${ }^{16}$ as shown in Figure 3.4.

\footnotetext{
${ }^{14}$ These effects will be taken into account in future developments, when the entire fuel cell model is solved.

${ }^{15}$ A discussion of the boundary conditions used is included in Chapter 5.

${ }^{16} A$, which is the catalyst surface area, is related to $a$ in the Butler-Volmer equation (equation (3.8)), i.e. the effective catalyst area per unit volume, via the total catalyst layer volume.
} 


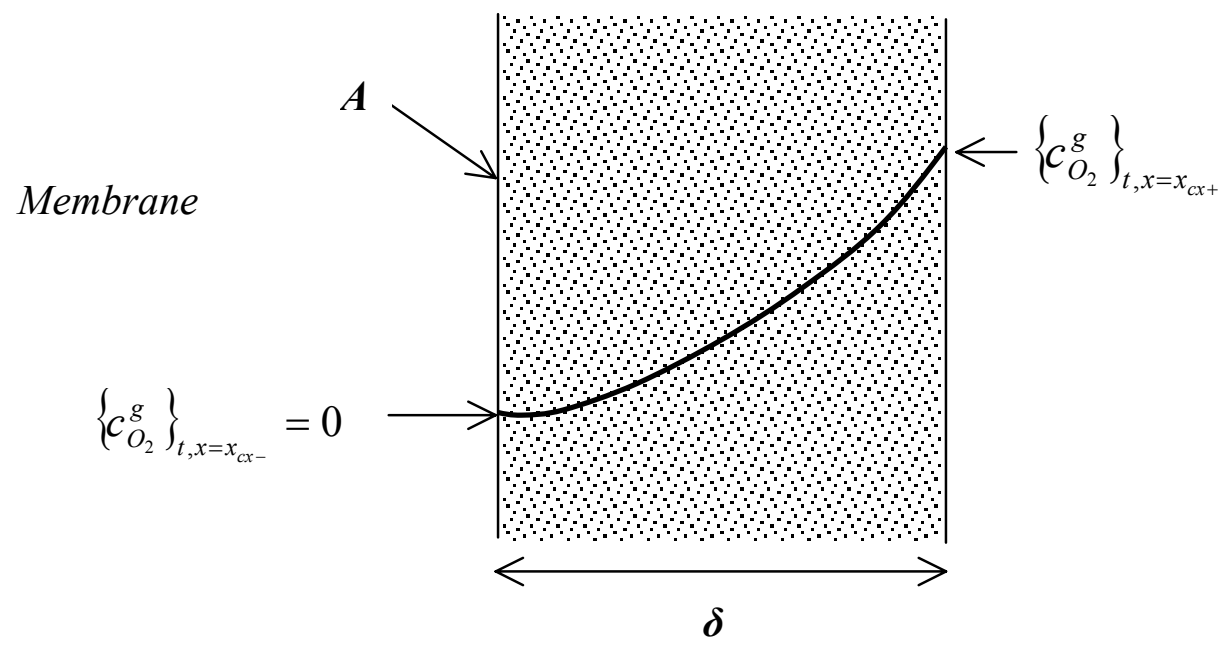

Backing Layer

Figure 3.4 Schematic of the diffusion layer model for the case of a pseudo-homogeneous model of the catalyst layer.

The limiting current is then taken into account in the expression for the exchange current (equation (3.9)) as follows:

$$
i_{0}=i_{o}^{r e f}\left(\frac{c_{O_{2}}}{c_{O_{2}}^{r e f}}\right)^{\gamma_{O_{2}}}\left(\frac{c_{H^{+}}}{c_{H^{+}}^{r e f}}\right)^{\gamma_{H^{+}}}=i_{o}^{r e f}\left(1-\frac{i}{i_{l}}\right)^{\gamma_{O_{2}}}\left(\frac{c_{H^{+}}}{c_{H^{+}}^{r e f}}\right)^{\gamma_{H^{+}}}
$$

Now approximating the Butler-Volmer equation (equation (3.8)) by the Tafel equation ${ }^{17}$ yields

$$
\frac{\partial i}{\partial x}=a i_{0}\left[\exp \left(\frac{-\alpha_{c} F\left(\Phi_{c}-\Phi_{m}\right)}{R T}\right)\right]
$$

which is transformed upon substitution of equation (3.98) into the current generation per unit volume given by

$$
\frac{\partial i}{\partial x}=\frac{a i_{0}^{r e f}}{\frac{a i_{0}^{r e f}}{i_{l}}+\left[\exp \left(\frac{-\alpha_{c} F\left(\Phi_{c}-\Phi_{m}\right)}{R T}\right)\right]}
$$

Replacing the current generation formulation given by the Butler-Volmer equation (equation (3.8)) with equation (3.100) allows one to take into account oxygen transport limitations on the electrokinetics of the reaction. As a result, the current density of the

\footnotetext{
${ }^{17}$ Note that the Butler-Volmer equation reduces to the Tafel equation for large values of $\Phi_{c^{-}} \Phi_{m}$ and is typical of the electrokinetics in the catalyst layer.
} 
cell in a pseudo-homogeneous model is limited by a value that corresponds to diffusion limitations through the entire catalyst layer.

\section{Agglomerate model}

In an agglomerate model, a relationship for the concentration overpotential is developed by taking into account the additional oxygen transport resistance due to a diffusion layer surrounding the reaction site that is located at the surface of the agglomerates. This diffusion layer is formed by the polymer membrane (e.g., Nafion ${ }^{\circledR}$ ) film surrounding the agglomerates. Figure 3.5 shows such a film surrounding the catalyst sites at the surface of an agglomerate. Thus, for the case of an agglomerate model, $\delta$ is the thickness of the diffusion layer, and $A$ is the external surface of the agglomerate.

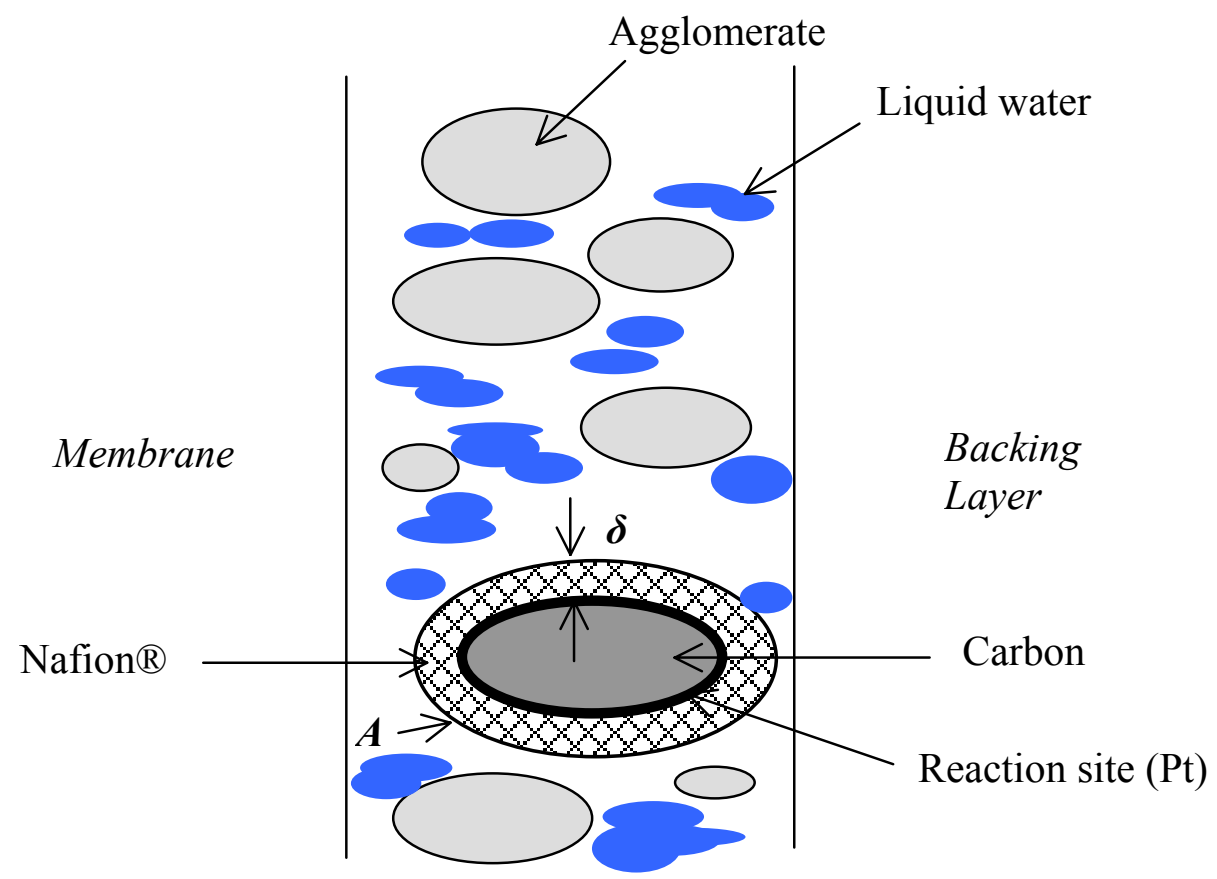

Figure 3.5 Schematic of the diffusion layer model for the case of an agglomerate model of the catalyst layer.

Therefore, in the agglomerate model, the current generation per unit volume given by the Butler-Volmer formulation (equation (3.8)) or the Tafel equation becomes limited 
when the oxygen concentration goes to zero at the reaction sites. For this type of model, the limiting current is defined as

$$
i_{l}=A \frac{D_{O_{2}}^{m} c_{O_{2}}^{g} 4 F}{\delta}
$$

where $D_{\mathrm{O}_{2}}^{m}$ is the diffusivity of dissolved oxygen in the polymer membrane film. The current generation per unit volume then becomes as expressed by equation (3.100) above but with equation (3.101) substituted for the limiting current.

Hence, an agglomerate model when compared to a pseudo-homogeneous model of the catalyst layer provides a different interpretation of the nature of the phenomena of transport limitations even though the mathematical formulations for the limiting current are quite similar. 


\section{Chapter 4. Numerical Solution Approach}

A set of six differential equations ${ }^{18}$ is solved using a finite element approach based on the Galerkin method (Reddy and Gartling, 2000). The equations are implemented in a FORTRAN research code that was initially developed at the Institut Universitaire des Systèmes Thermiques Industriels (IUSTI) of the Université de Provence to solve a nonlinear, transient problem of superheated steam drying in a porous media (Topin, 1995). This code in its initial form was able to deal with most of the phenomena occurring in the catalyst layer, including heat transfer, multi-phase flow, phase change, and multi species transport through plain and porous media. Therefore, it was possible to use this code with some modifications to solve the equations of heat and mass transfer in the catalyst layer. Additional modifications included adding the electrokinetics of the reactions as well as the electric and ionic conduction effects to the code.

The first step in adapting the code to the problem at hand required rewriting the differential equations of the catalyst layer model to identify the coefficients that needed to be entered in the appropriate subroutines of the code. The second step consisted of gradually increasing the number of degrees of freedom from three to six so as to progressively solve the set of six differential equations (i.e. first three then four then five and finally six). Thus, the conservation of energy equation was solved first, then the mass balance equations were added, and finally the current conservation equation was included to complete the system. At each intermediate step, reasonable assumptions for the remaining variables were made to solve each partial set of governing equations. This allowed for checking and validating the preliminary results before solving the complete set of six coupled differential equations.

In the next sections, the formulation of the problem and the finite element code are presented followed by a presentation of the Mathematica ${ }^{\circledR}$ code used to calculate the coefficients of the matrices.

\footnotetext{
${ }^{18}$ Note that the set of seven differential equations outlined in Chapter 3 was reduced to a set of six by assuming a constant voltage potential $\Phi_{c}$ in the matrix
} 


\subsection{Finite Element Formulation}

\subsubsection{Formulation of the Problem}

The system of differential governing equations must be written in the following form before being entered into the code:

$$
\begin{aligned}
& {\left[\begin{array}{llllll}
M_{11} & M_{12} & M_{13} & M_{14} & M_{15} & M_{16} \\
M_{21} & M_{22} & M_{23} & M_{24} & M_{25} & M_{26} \\
M_{31} & M_{32} & M_{33} & M_{34} & M_{35} & M_{36} \\
M_{41} & M_{42} & M_{43} & M_{44} & M_{45} & M_{46} \\
M_{51} & M_{52} & M_{53} & M_{54} & M_{55} & M_{56} \\
M_{61} & M_{62} & M_{63} & M_{64} & M_{65} & M_{66}
\end{array}\right]\left[\begin{array}{c}
\partial T / \partial t \\
\partial s / \partial t \\
\partial c^{g} / \partial t \\
\partial c_{O_{2}}^{g} / \partial t \\
\partial c_{H_{2} O}^{m} / \partial t \\
\partial \phi_{m} / \partial t
\end{array}\right]=} \\
& \nabla\left(\left[\begin{array}{llllll}
K_{11} & K_{12} & K_{13} & K_{14} & K_{15} & K_{16} \\
K_{21} & K_{22} & K_{23} & K_{24} & K_{25} & K_{26} \\
K_{31} & K_{32} & K_{33} & K_{34} & K_{35} & K_{36} \\
K_{41} & K_{42} & K_{43} & K_{44} & K_{45} & K_{46} \\
K_{51} & K_{52} & K_{53} & K_{54} & K_{55} & K_{56} \\
K_{61} & K_{62} & K_{63} & K_{64} & K_{65} & K_{66}
\end{array}\right]\left[\begin{array}{c}
\partial T / \partial x \\
\partial s / \partial x \\
\partial c^{g} / \partial x \\
\partial c_{O_{2}}^{g} / \partial x \\
\partial c_{H_{2} O}^{m} / \partial x \\
\partial \phi_{m} / \partial x
\end{array}\right]\right) \\
& -\left[\begin{array}{c}
V_{1} \\
V_{2} \\
V_{3} \\
V_{4} \\
V_{5} \\
V_{6}
\end{array}\right]\left[\begin{array}{c}
\partial T / \partial x \\
\partial c^{g} / \partial x \\
\partial c_{O_{2}}^{g} / \partial x \\
\partial c_{H_{2} O}^{m} / \partial x \\
\partial \phi_{m} / \partial x
\end{array}\right]+\left[\begin{array}{c}
L_{1} \\
L_{2} \\
L_{3} \\
L_{4} \\
L_{5} \\
L_{6}
\end{array}\right]
\end{aligned}
$$

or in a more compact notation:

$$
[M(\vec{u})] \frac{\partial \vec{u}}{\partial t}=\nabla([K(\vec{u})] \nabla \vec{u})-\vec{V}(\vec{u}) \cdot \nabla \vec{u}+\vec{L}(\vec{u})
$$

where $[M(\vec{u})]$ and $[K(\vec{u})]$ are the mass and rigidity matrices, respectively, $\vec{V}(\vec{u})$ the velocity vector, and $\vec{L}(\vec{u})$ the load vector. Each of the vectors $\vec{V}$ and $\vec{L}$ is dependent on the unknown vector $\vec{u}$. It is noteworthy that despite the strong coupling between them, 
the equations are solved as a global system as opposed to solving separately and iteratively each equation (Daurelle, Topin, Occelli, 1998).

\subsubsection{Space Discretization}

The finite element code uses the Galerkin weighted residual method for discretization of the integral forms of the equations. The values of the unknown variables (functions) $T$, $s, c^{g}, c_{\mathrm{O}_{2}}^{g}, c_{\mathrm{H}_{2} \mathrm{O}}^{m}$, and $\Phi_{m}$ which comprise $\vec{u}$ are approximated inside each finite element by polynomial interpolation according to their nodal values. In this problem, linear interpolation is preferred over quadratic interpolation for two main reasons. Firstly, the computational time for a given number of nodes with quadratic elements is much greater than with linear elements and this without any significant gain in accuracy. Secondly, quadratic interpolation can sometimes generate non-feasible solutions for physical variables due to the nature of the interpolation between the nodes (Daurelle, Topin, Occelli, 1998).

\subsubsection{Time Discretization}

The matrix system discretization in time is made via an Euler-implicit scheme:

$$
\begin{aligned}
{\left[M\left(\vec{u}_{t+\Delta t}\right)\right] \frac{\vec{u}_{t+\Delta t}-\vec{u}_{t}}{\Delta t} } & =\nabla\left(\left[K\left(\vec{u}_{t+\Delta t}\right)\right] \nabla \vec{u}_{t+\Delta t}\right) \\
& -V\left(\vec{u}_{t+\Delta t}\right) \cdot \nabla \vec{u}_{t+\Delta t}+L\left(\vec{u}_{t+\Delta t}\right)
\end{aligned}
$$

Since coefficients can vary strongly during the calculation, it is necessary to use an autoadaptive time step that becomes smaller when the variation of the coefficient is important, and grows larger otherwise. With such an approach, convergence is ensured within an optimum amount of computational time. In the code, a purely numerical adaptive time step is used as opposed to an adaptive time step scaled on the characteristic diffusion time. Besides the fact that the latter method is not adapted to the problem at hand, the former method allows adjusting the time step without any additional computation (Daurelle, Topin, Occelli, 1998). At each time step, the non-linear problem is solved using a fixed-point method. 


\subsubsection{Geometry}

As described in Chapters 1 and 3, the catalyst layer can be approximated by a 10 microns thick, one-dimensional region. Nevertheless, the code requires the use of a $2 \mathrm{D}$ geometry. Thus, the mesh used for the computations is $2 \mathrm{D}$ and is symmetrical with respect to the direction of the problem. It is composed of 50 square elements in the core region and 2 linear elements at the boundaries (see Figure 4.1). Therefore, a total number of 102 nodes are used. The elements are evenly distributed in the x-direction.

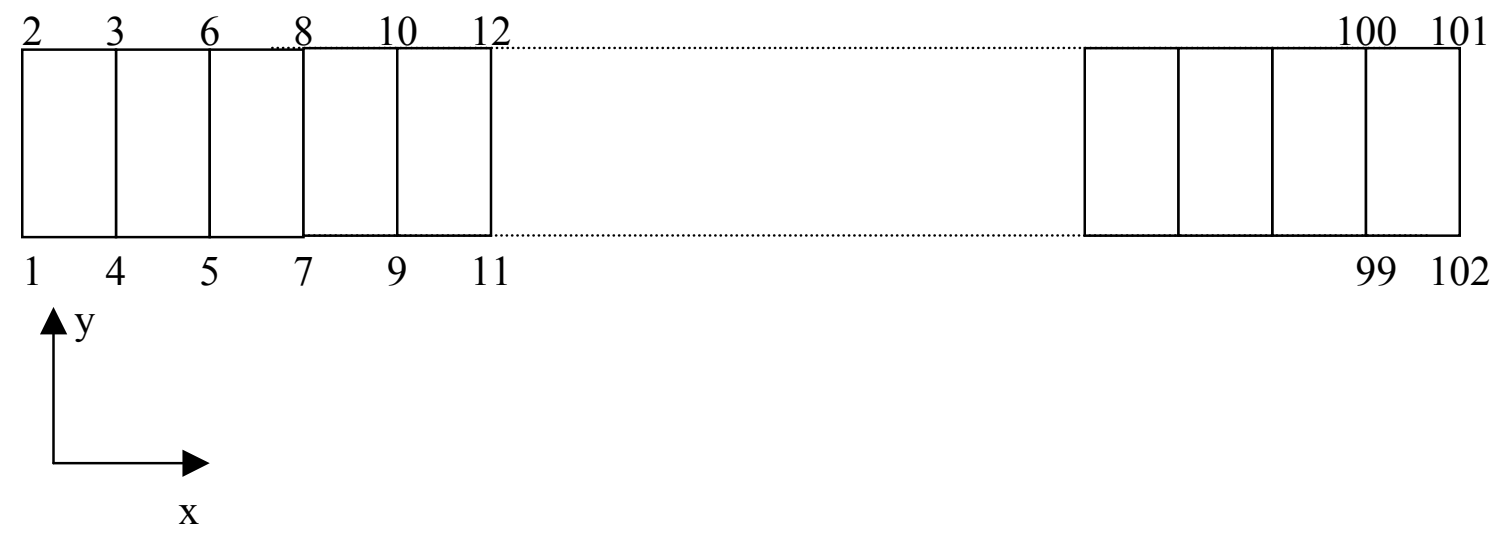

Figure 4.1Geometry of the finite element mesh used.

\subsection{FORTRAN Code}

\subsubsection{Calculation Options}

The basic information necessary for the computations is contained in three files

- The file .COR is used to specify the coordinates of the nodes in the 2D mesh as well as the number of degrees of freedom associated with each of these nodes.

- The file .ELE is used to define the number of elements and the element properties (square or linear).

- The file .INP contains all the information needed to solve the system such as the boundary conditions and the initial values of the properties at each node. It also contains the information necessary to perform the calculation such as the 
time step, the number of steps, and the tolerance criteria for convergence of each iteration inside a time step.

These files are read by the LOGMEF.FIC file at the beginning of the calculations. They provide the code with all the user specified information.

\subsubsection{Main Functions and Program Structure}

The code is composed of one main file YPPAL.F that calls several routines, each of which is being responsible for an important step of the calculations. Before the calculations start, the first step is to read the LOGMEF.FIC file. The main routines of the program are then called to perform a specific task at each iteration as shown in Figure 4.2 . 


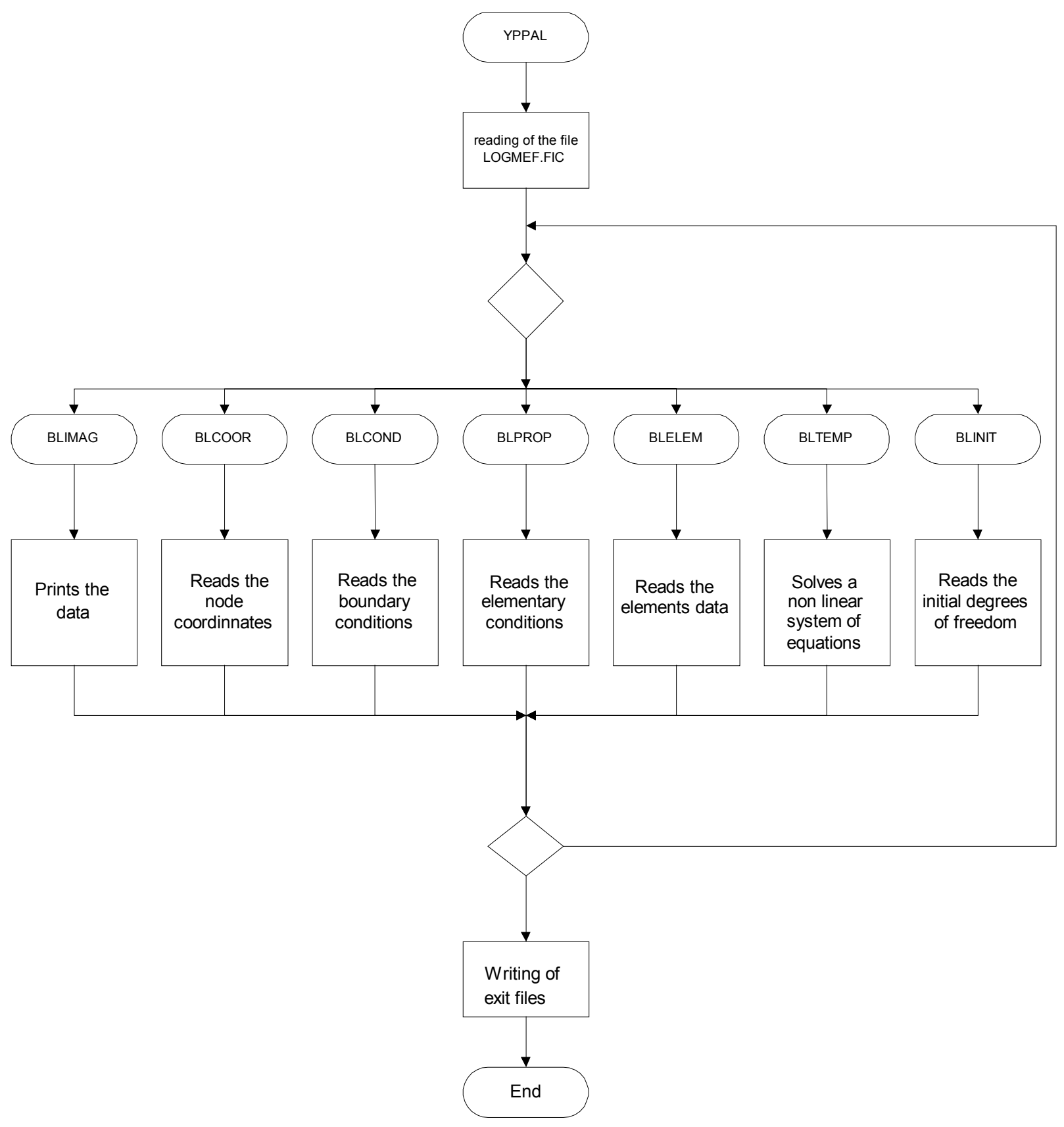

Figure 4.2 Main program flow (Montel, 2000).

The program is composed of seven main subroutines. Subroutine BLIMAG prints a summary of all the input data for the problem along with the solution at each step in the output files (files .OUT and .SOL). Subroutine BLCOOR reads the coordinates of the nodes contained in the file .COR. Subroutine BLCOND reads and takes into account the boundary conditions. All the elementary conditions of the problem are read in subroutine 
BLPROP. These include the type of geometry (axisymetrical or 2D) and the number of degrees of freedom. Subroutine BLELEM reads the data concerning the elements. The non-linear system of differential equations is solved by subroutine BLTEMP, which is described in detail in the next section. Finally, reading in the initial conditions is assigned to subroutine BLINIT.

Each of these main subroutines is linked with several different subroutines and entry files as represented in the program structure (Figure 4.3). All these subroutines can be classified into seven different function groups, depending on the role they play in the computation. In this classification (Table 4.1), each function group is associated with a particular color, which is used in the program structure of Figure 4.3 and in the BLTEMP subroutine description of Figure 4.4 in section 4.1.3.

Table 4.1 Different function groups.

\begin{tabular}{|c|c|}
\hline Group & Description \\
\hline $\begin{array}{c}\text { Vector } \\
\text { Calculations }\end{array}$ & Basic operations on vectors \\
\hline Assembly & Assembly of elementary matrices \\
\hline $\begin{array}{c}\text { Matrix } \\
\text { Calculations }\end{array}$ & Intermediate calculations on matrices \\
\hline Input Files & $\begin{array}{l}\text { Input of the geometry and calculation options } \\
\text { Calculation of the coefficients in the matrices of the system }\end{array}$ \\
\hline Reading & Allocation of the different values specified in the input files \\
\hline Writing & Printing of the results \\
\hline Choice & $\begin{array}{l}\text { Utilization of specific functions of the code depending on the geometry } \\
\text { or the boundary conditions }\end{array}$ \\
\hline
\end{tabular}




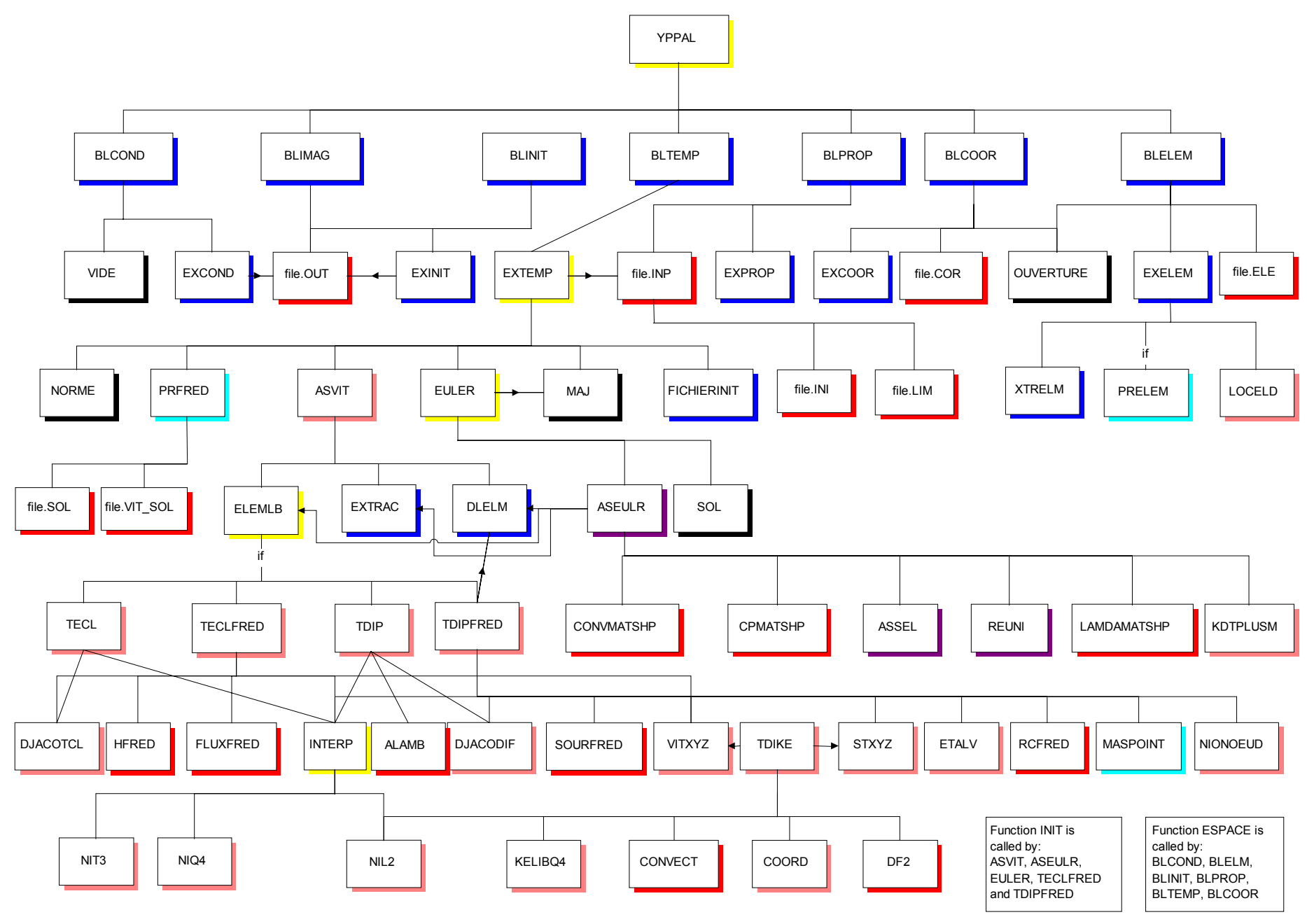

Figure 4.3 Program structure (Montel, 2000).

\subsubsection{Solution of the Non-Linear Transient Problem}

The resolution of the non-linear problem is done at each time step through subroutine BLTEMP. This subroutine includes the calculation of the velocities at each node via the ASVIT subroutine, the resolution of the system of equations using the EULER subroutine, and the phase change rate calculation through ASVIT. A flowchart of BLTEMP is given in Figure 4.4. 
Solving of a non-linear transient problem

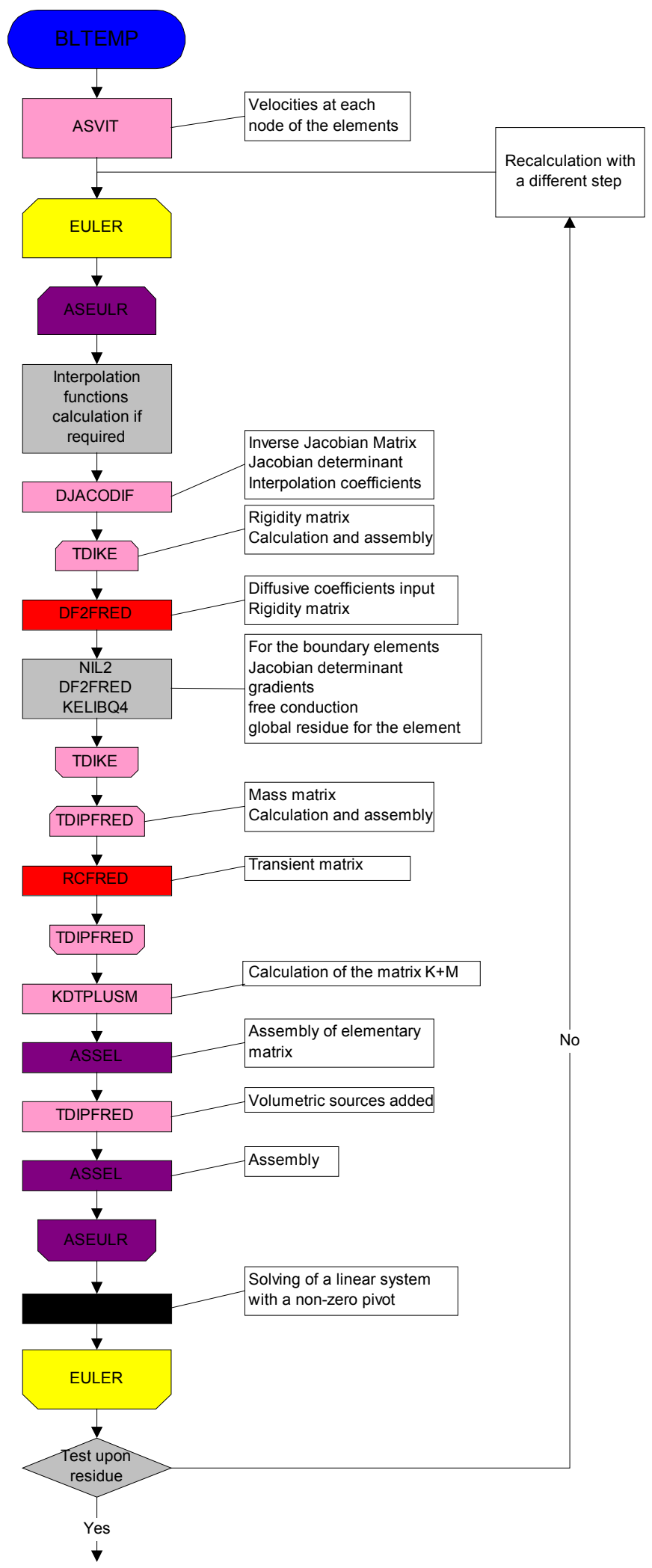



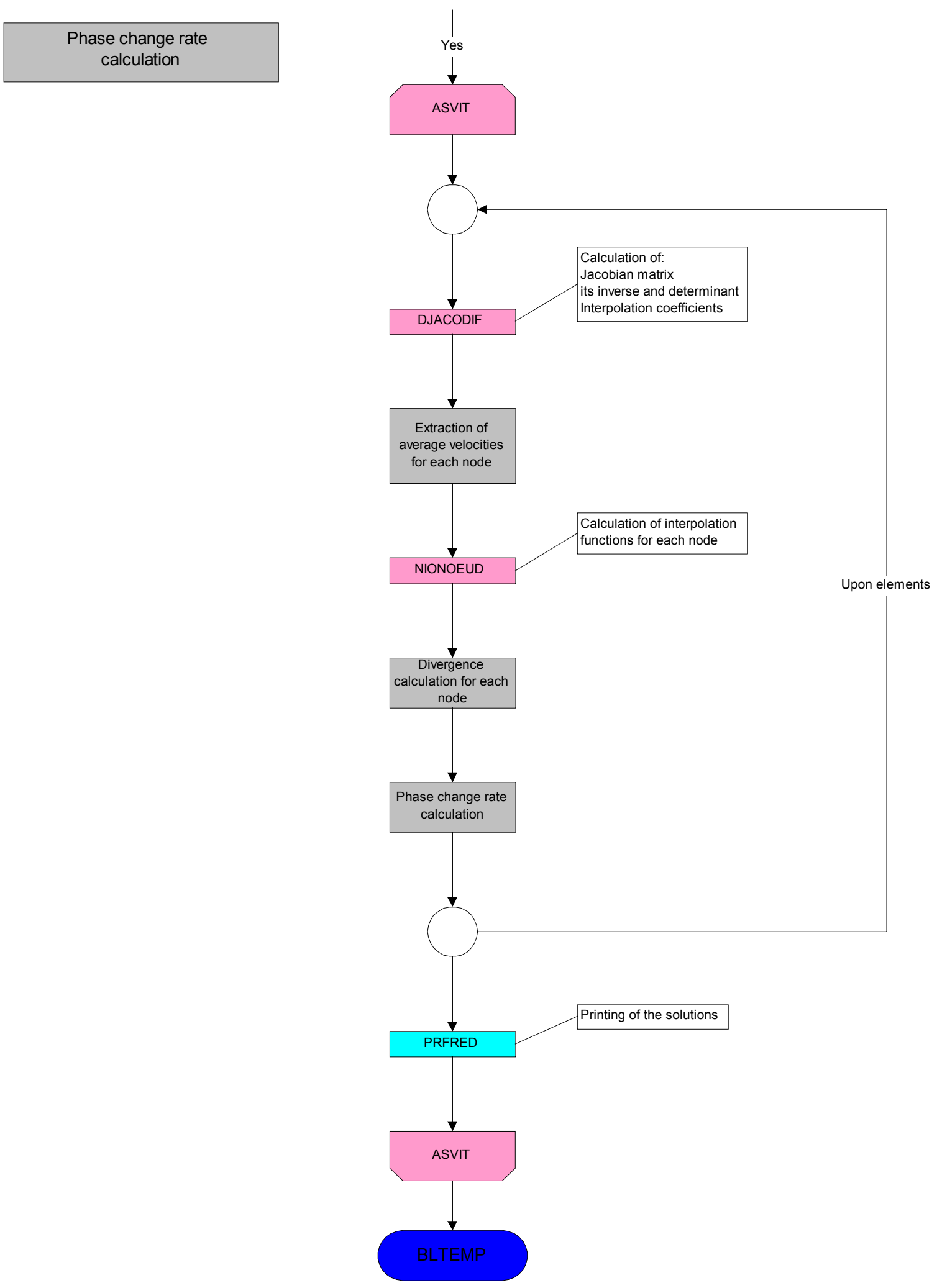

Figure 4.4 The BLTEMP function (Montel, 2000). 


\subsubsection{Summary of Modifications Made}

After having gained a good understanding of the structure of the code, my task was to make the modifications necessary to solve the cathode catalyst layer governing and constitutive equations. These modifications consisted of the following:

- increasing the number of degrees of freedom from three to six,

- calculating the coefficients of the mass matrix and the rigidity matrix, the velocities, and the source terms,

- entering the coefficients in the appropriate subroutines: RCFRED for the mass matrix, DF2FRED for the rigidity matrix, CONVECT for the velocities, and SOURFRED for the sources,

- adapting the size and the number of elements of the mesh to get the best solution within a reasonable amount of computational time.

\subsection{Mathematica Code}

Because of the complexity of the differential equations and the number of closure relations used, the calculation of the coefficients of the system demands particular care. For this reason, the coefficients of the matrices were calculated by hand first, and were then checked using Mathematica ${ }^{\circledR}$.

In particular, it is important to notice that the matrix $[K(\vec{u})]$ in equation (4.2) contains both diffusive and convective terms. In fact, the expression $\nabla([K(\vec{u})] \nabla \vec{u})$ can be expanded into two parts, namely,

$$
\nabla([K(\vec{u})] \nabla \vec{u})=\nabla[K(\vec{u})] \nabla \vec{u}+[K(\vec{u})] \nabla^{2} \vec{u}
$$

where $\nabla[K(\vec{u})]$ is the convective term, and $K(\vec{u})$ the diffusive term.

It is, therefore, necessary to isolate the terms that must be taken into account in the matrix $K(\vec{u})$ from those that are accounted for in the velocity vector $\vec{V}$. In this task, Mathematica ${ }^{\circledR}$ has been a very useful tool. 


\section{Chapter 5. Results}

Solutions to the system of six differential equations are generated using a systematic approach. First, a value for the potential $\Phi_{c}$ in the carbon phase is specified. Since it is assumed constant (cf Chapter 3), its value does not change across the catalyst layer. The value of $\Phi_{c}$ is assumed equal to the cathode overpotential ${ }^{19}$. Boundary conditions for the potential in the polymer phase are then assigned in order to solve the $\Phi_{m}$ equation and determine the current generation per unit volume given by the Butler-Volmer equation. The potential $\Phi_{m}$ is set to zero at the membrane interface ${ }^{20}$, and the proton current is set to zero at the backing layer interface. Therefore, the approach used here consists of specifying the cell voltage first ${ }^{21}$, and calculating the cell current density from the ButlerVolmer current density per unit volume distribution across the catalyst layer.

For this thesis work, the catalyst layer model is solved as a stand-alone model, which requires boundary conditions to be specified at its interfaces as opposed to continuity conditions with the membrane and backing layer solutions. Therefore, it is necessary to provide physically possible conditions at the interfaces, whether they are fixed boundary conditions (Dirichlet) or flux boundary conditions (von Neumann). In addition, these boundary conditions should be time-dependent to match the transient behavior of the problem. As a result, when flux boundary conditions are used, the balance between sources and inlet and outlet conditions cannot be guaranteed to provide a steady-state solution. Nevertheless, using Dirichlet conditions or zero-fluxes, or a combination of both will allow the solution to converge in time. In the future, when the fuel cell model (see Chapter 3) is solved in its entirety, continuity conditions will automatically be expressed at the interfaces between the different domains, and therefore, only the external inlet and

\footnotetext{
19 This assumption is consistent with the Butler-Volmer equation used. The potential $\Phi_{c}$ at the cathode could also be assumed equal to the cell voltage (assuming $\Phi_{c}=0$ at the anode) but in that case, the ButlerVolmer equation would need to be modified accordingly.

${ }^{20}$ This assumption is necessary since the catalyst layer model is solved alone. Otherwise, the value of $\Phi_{m}$ at the membrane interface would have to be determined by continuity with the solution obtained with the membrane model.

${ }^{21}$ The cell voltage is $V_{o c}-\Phi_{c}$, where $V_{o c}$ is the open-circuit voltage and $\Phi_{c}$ takes the value of the overpotential.
} 
outlet conditions of the cell itself will have to be provided. This will facilitate greatly the resolution of the problem since these external conditions are more easily specified.

In the following sections, appropriate boundary conditions are used so that most of the solutions presented converge to steady state. The exception is in section 5.7 where the evolution in time towards the steady state is studied.

\subsection{Validation}

The first step in generating results is validating the solutions obtained for a simple case. This can be done in two ways: first, by checking if the solutions are consistent with expectations and then by comparing the solutions with those obtained by other models in the literature. A third possibility is validation with experimental data. Unfortunately, no experimental data for the catalyst layer is available for comparison. Thus, only expectations and other models are used for the validations presented in this section. The boundary and initial conditions corresponding to the solutions given here are summarized in Table 5.1, using the following color convention:

\begin{tabular}{|c|}
\hline Dirichlet \\
\hline Von Neumann \\
\hline
\end{tabular}

Table 5.1 Boundary and initial conditions

\begin{tabular}{|c|c|c|c|}
\hline Variable & Initial Value & $\begin{array}{c}\text { Membrane Interface } \\
(\mathbf{x}=\mathbf{0})\end{array}$ & $\begin{array}{c}\text { Backing Layer } \\
\text { Interface }(\mathbf{x}=\mathbf{1 0} \boldsymbol{\mu m})\end{array}$ \\
\hline$\Phi_{c}(\mathrm{~V})$ & - & \multicolumn{2}{|c|}{ From 0.20 to 0.29} \\
\hline$\Phi_{m}(\mathrm{~V})$ & - & 0 & Flux $=0$ \\
\hline$c_{H_{2} O}^{m}\left(\mathrm{~mol} . \mathrm{m}^{-3}\right)$ & 19000 & 19000 & 19000 \\
\hline$c_{O_{2}}^{g}\left(\mathrm{~mol}^{-3} \mathrm{~m}^{-3}\right)$ & 2 & Flux $=0$ & 2 \\
\hline$c^{g}\left(\mathrm{~mol} \cdot \mathrm{m}^{-3}\right)$ & 10 & Flux $=0$ & 10 \\
\hline$s$ & 0.05 & Flux $=0$ & 0.05 \\
\hline$T\left({ }^{\circ} \mathrm{C}\right)$ & 80 & Flux $=0$ & 80 \\
\hline
\end{tabular}




\subsubsection{Potential Profile and Current Generation}

In this section, a value of $0.28 \mathrm{~V}$ is assumed for the overpotential. The potential in the polymer membrane phase $\Phi_{m}$ (Figure 5.1) shows that the proton current is zero at the backing layer interface $(\mathrm{x}=10 \mu \mathrm{m})$. At the membrane interface, the proton current is equal to the cell current, and can be calculated from the slope at $\mathrm{x}=0 \mu \mathrm{m}$.

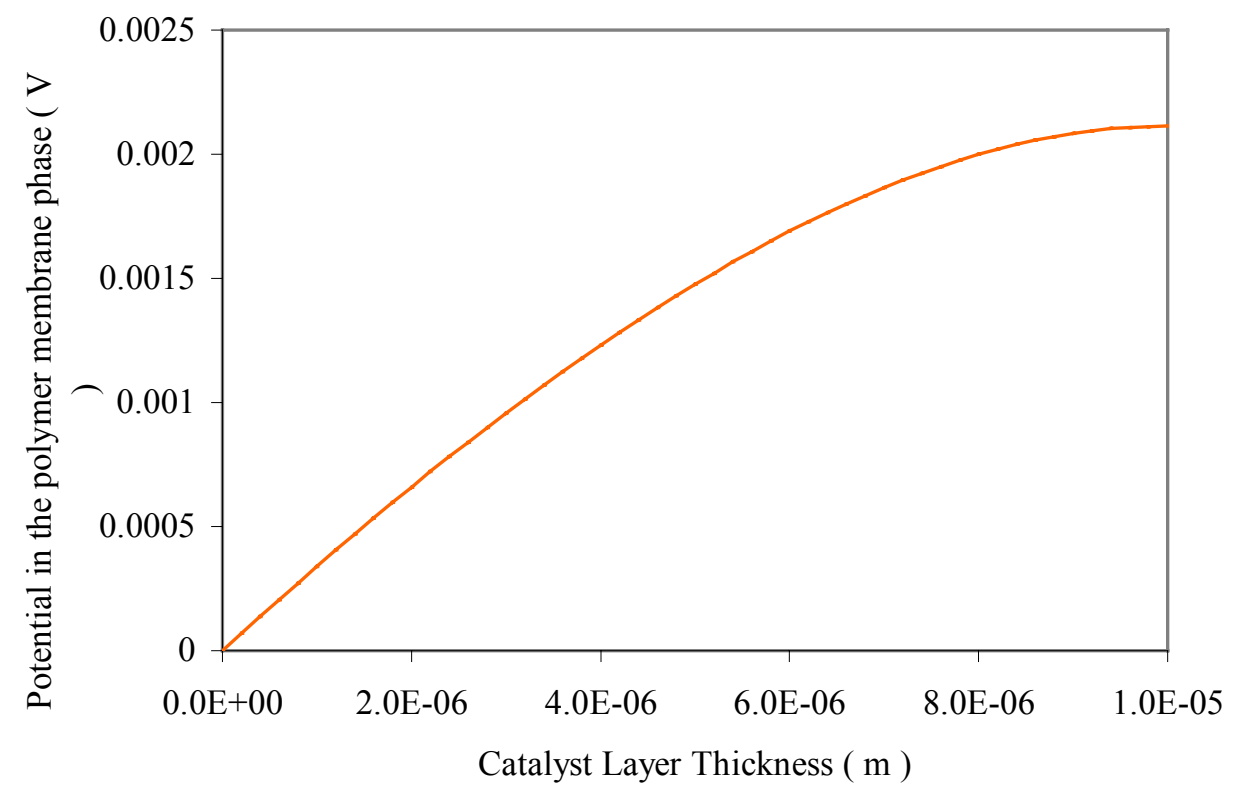

Figure 5.1 Profile across the catalyst layer of the potential $\Phi_{m}$ in the polymer membrane phase. 


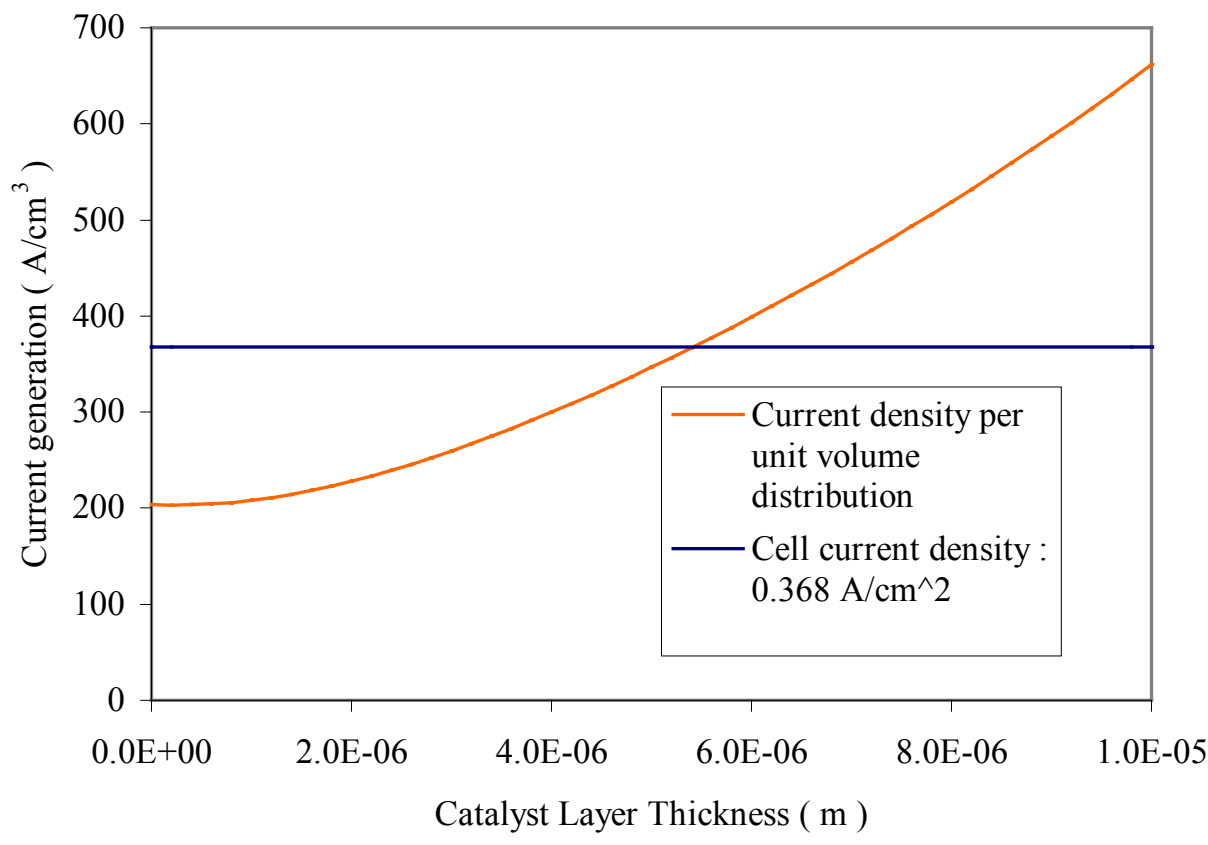

Figure 5.2 Current generation (current density per unit volume) across the catalyst layer.

From the potential $\Phi_{m}$ in the membrane phase, the current generation (current density per unit volume) across the catalyst layer is calculated using the Butler-Volmer equation and plotted in Figure 5.2. The distribution of this Butler-Volmer current generation allows one to calculate the cell current density (per unit area) by integration across the catalyst layer. Therefore, assuming an open-circuit voltage of $1.1 \mathrm{~V}$ and an overpotential of $0.28 \mathrm{~V}$, the cell current density is $0.368 \mathrm{~A} / \mathrm{cm}^{2}$ for a cell voltage of $1.1-0.28=0.82 \mathrm{~V}$. Figure 5.2 shows that from the membrane / catalyst layer interface $(\mathrm{x}=0 \mu \mathrm{m})$ to the catalyst layer / backing layer interface $(\mathrm{x}=10 \mu \mathrm{m})$, current generation increases. This reflects the fact that the electrochemical reaction rate expressed by the Butler-Volmer current generation depends on the local value of the potential $\Phi_{m}$ (see Figure 5.1) and the local concentration of oxygen, which is lower at the membrane interface. 


\subsubsection{Oxygen Concentration Profiles}

Figure 5.3 shows the oxygen concentration distribution for different values of the cell current density obtained for an overpotential ranging from $0.20 \mathrm{~V}$ to $0.29 \mathrm{~V}$. The rate of oxygen reduction depends on the rate of reaction given by the Butler-Volmer current generation. When the cell current density calculated from the Butler-Volmer current generation is low $\left(0.004 \mathrm{~A} / \mathrm{cm}^{2}\right)$, only a small portion of the oxygen available is consumed, and the concentration remains almost constant across the catalyst layer. With an increasing current density, the oxygen consumption rate increases; and the oxygen concentration becomes much lower at the membrane interface. At a current density of $0.525 \mathrm{~A} / \mathrm{cm}^{2}$, a point is finally reached where the oxygen concentration is zero at the membrane interface, which means that all the oxygen available is depleted in the thickness of the catalyst layer.

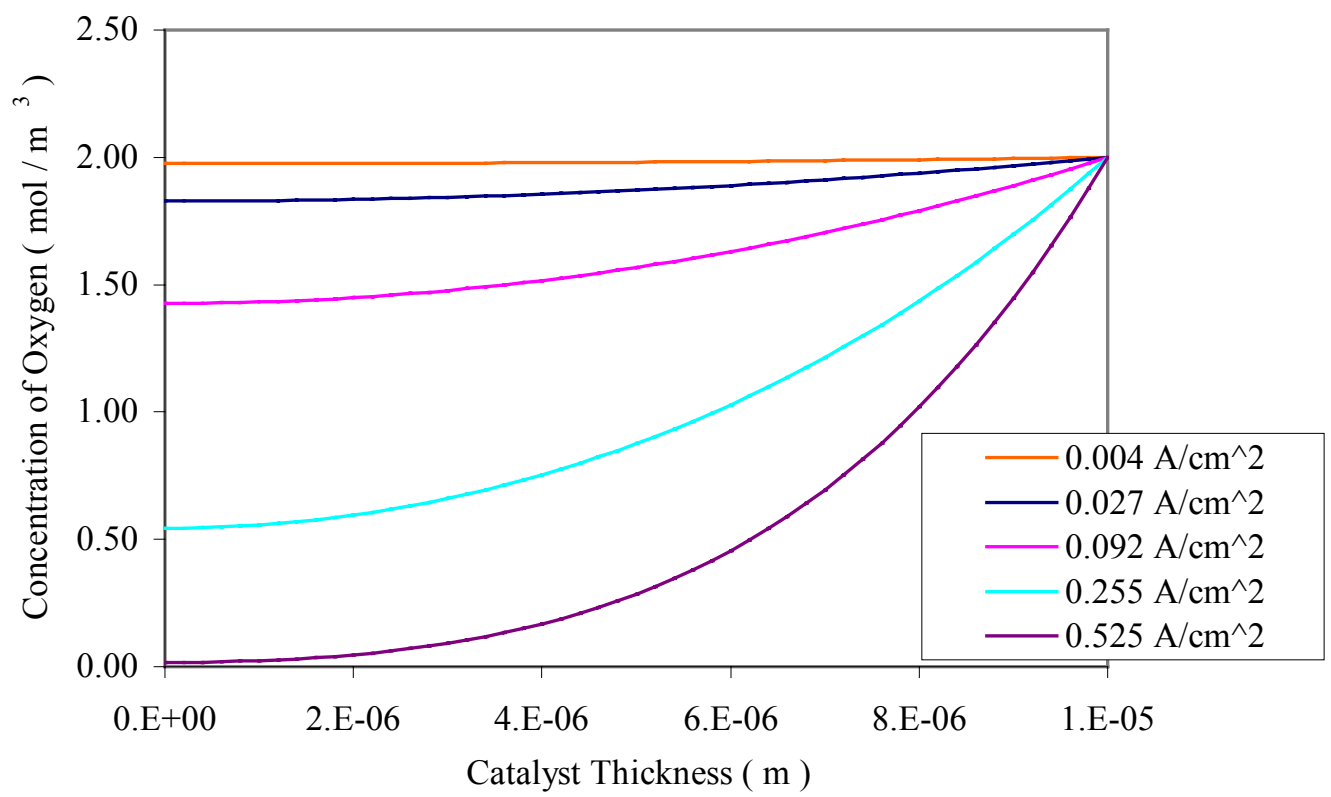

Figure 5.3 Oxygen concentration profiles for different current densities. 


\subsubsection{Polarization curve}

Different values for the overpotential are assumed, ranging from $0.2 \mathrm{~V}$ to $0.29 \mathrm{~V}$. By calculating the corresponding current density for each of these values, a polarization curve can be generated (Figure 5.4). The cell voltage is calculated using an open circuit voltage of $1.1 \mathrm{~V}$. This polarization curve only accounts for the cathode activation overpotential and, therefore, cannot be compared with experimental data, which would include membrane layer ohmic losses and the anode layer overpotential. Nevertheless, it compares well with the values obtained by Bernardi and Verbrugge (1992) and the analytic solution of the pseudo-homogeneous model developed by Sui and Chen (1999) (see Figure 5.5).

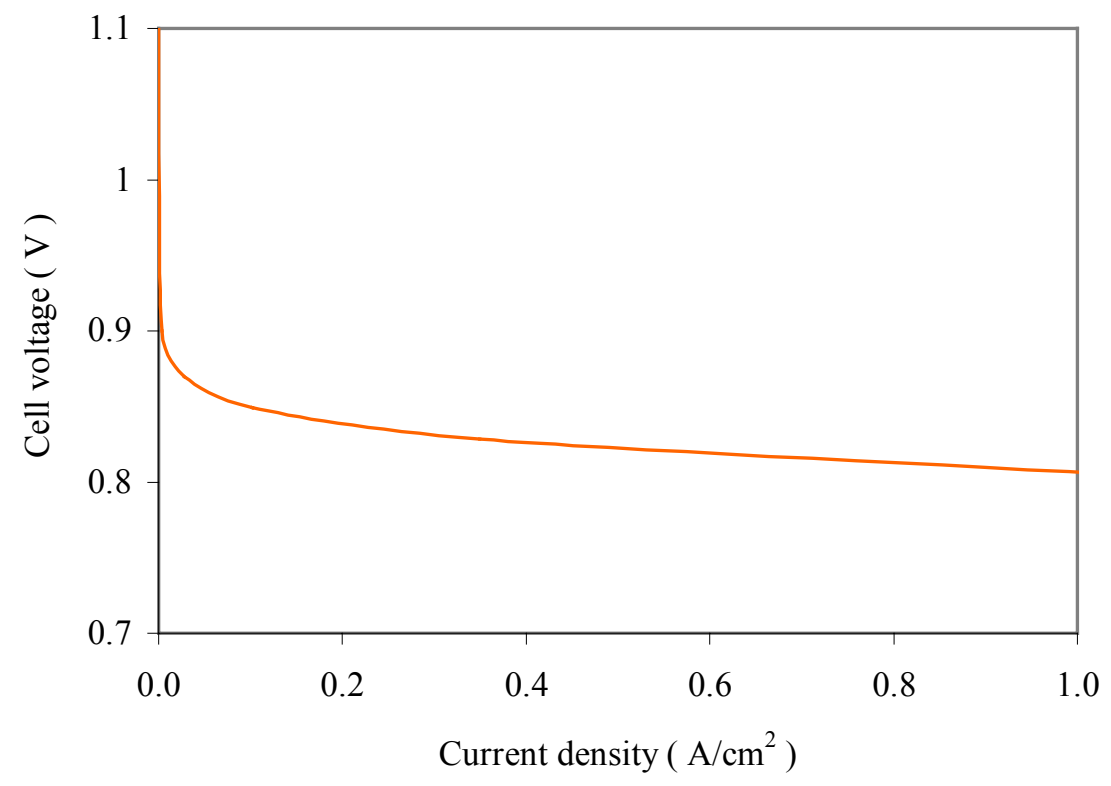

Figure 5.4 Polarization curve for $\mathrm{V}_{\mathrm{oc}}=1.1 \mathrm{~V}$. 


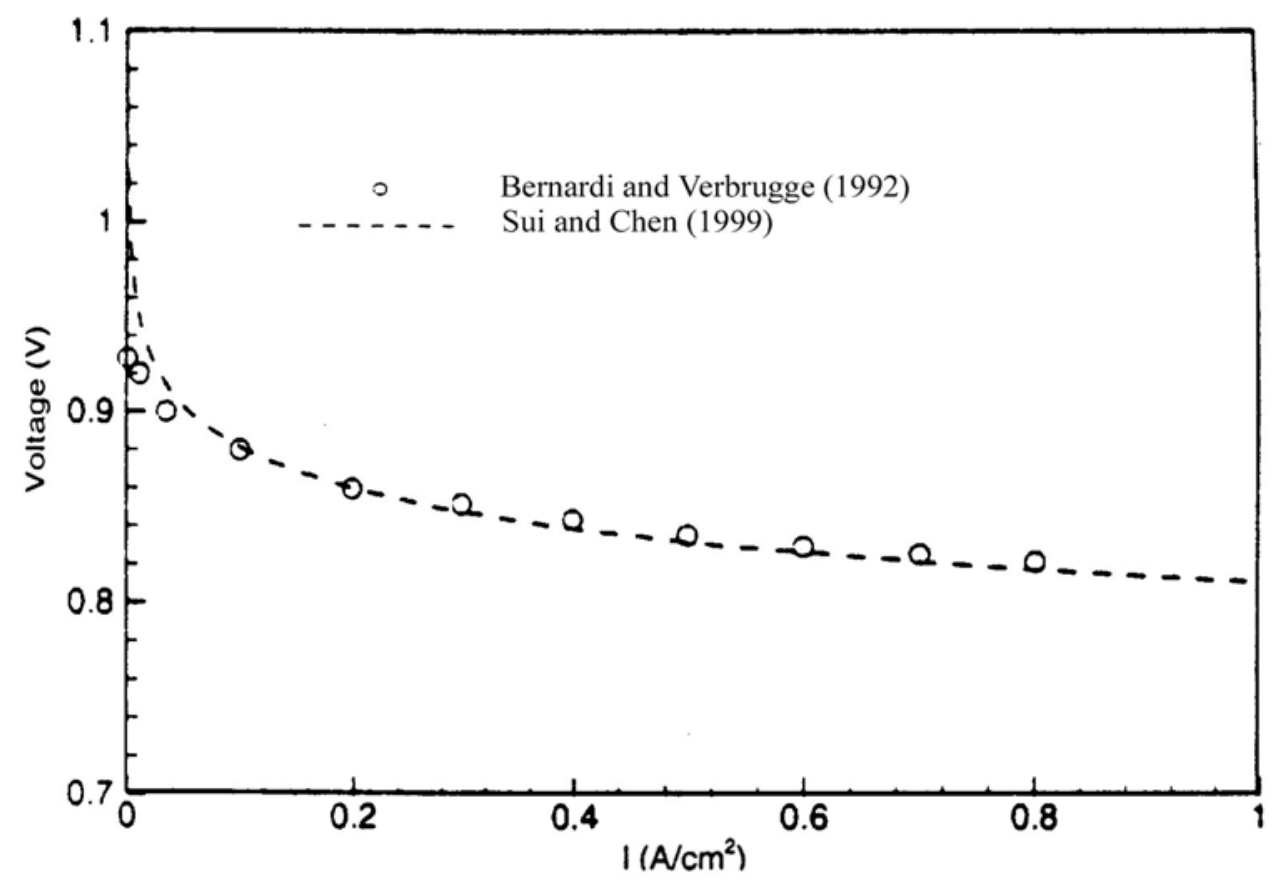

Figure 5.5 Polarization curves from Bernardi and Verbrugge (1992), and Sui and Chen (1999).

\subsection{Parametric Study}

In this section, the influence of various parameters such as the porosity, the permeability of the porous media, and the catalyst layer surface area is presented. The boundary and initial conditions used are the same as those given in Table 5.1.

\subsubsection{Influence of Porosity}

Figures 5.6 and 5.7 show the influence of catalyst layer porosity $(\varepsilon)$ on the concentration of oxygen and the concentration of gas profiles. These profiles have been generated using a constant overpotential of the catalyst layer of $0.28 \mathrm{~V}$. The porosity is defined as the fraction of void volume over the total volume of the catalyst layer. Therefore, the larger the porosity is, the easier the diffusion of gas species within the catalyst layer. This trend is illustrated in Figures 5.6a and b, where the oxygen concentration and the gas concentration experience a greater drop across the layer as the porosity is decreased from 0.2 to 0.02 . With further a decrease in porosity to a value of 
0.002, gas flow resistance becomes so high that almost all the oxygen is depleted in only a small portion of the catalyst layer with the result that even less oxygen is available for the electrochemical reaction. The same trend can be observed in the gas concentration profiles. Therefore, for very small porosities, only a portion of the catalyst layer can be considered as active.

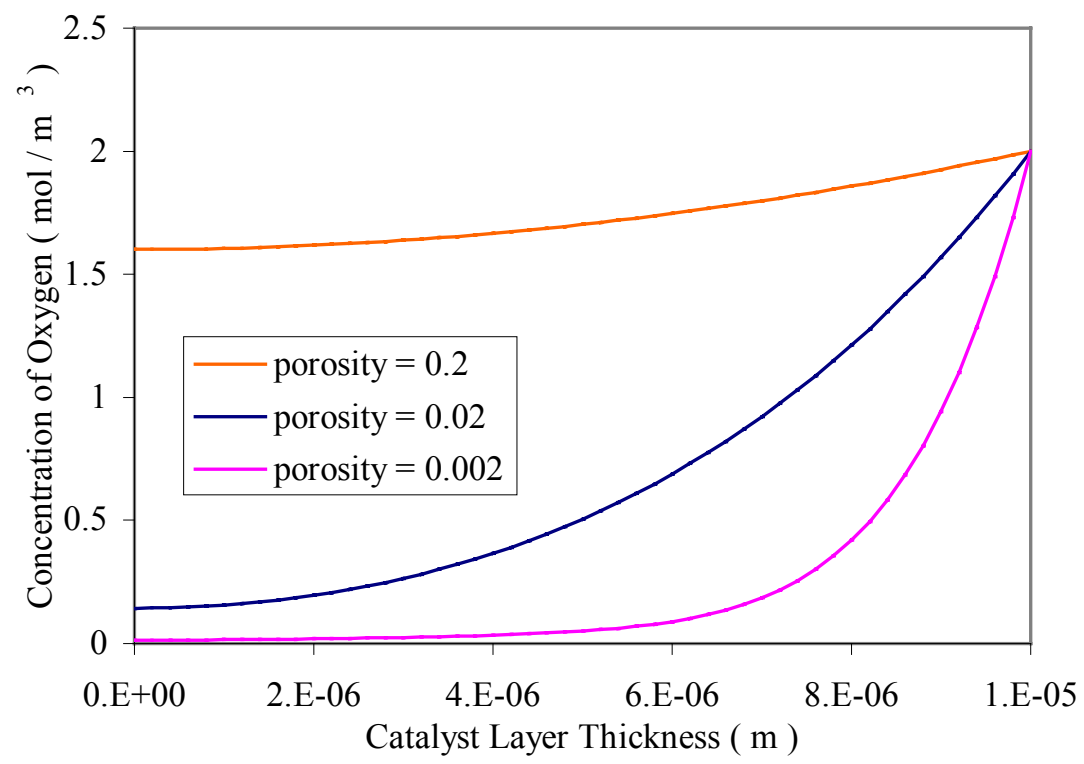

Figure 5.6 Effect of porosity on the oxygen concentration.

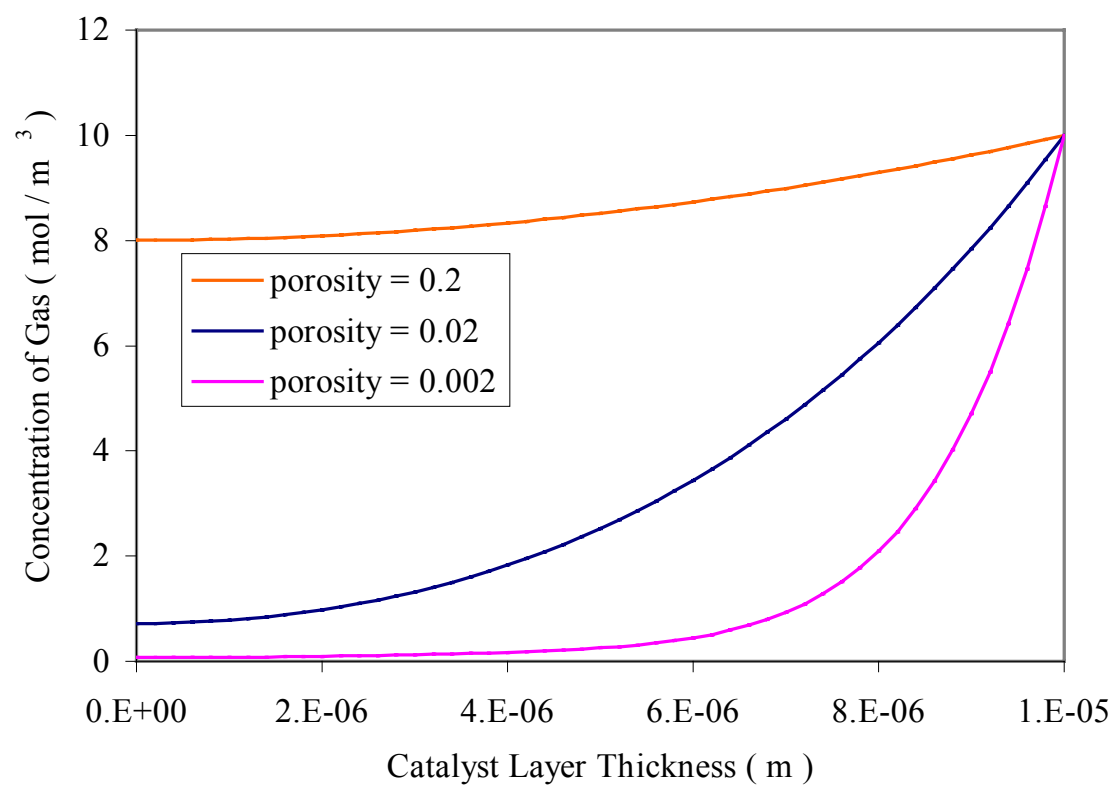

Figure 5.7 Effect of porosity on the concentration of the gas phase. 
Figure 5.8 shows the influence of porosity on the current density and the current generation across the catalyst layer. As can be seen from this figure, porosity can have a major impact on current density. For a porosity of 0.2 , the current generation is evenly distributed across the catalyst layer and results in a current density of $0.617 \mathrm{~A} / \mathrm{cm}^{2}$. With a decreased porosity, the current generation becomes unevenly distributed because of the uneven reactant concentration distribution across the layer (see Figure 5.6). Furthermore, the lower oxygen concentration at the membrane interface results in a lower current generation and, thus, a lower current density. Therefore, a porosity of 0.02 results in a current density of $0.368 \mathrm{~A} / \mathrm{cm}^{2}$, which is almost two times less than the current density obtained with a porosity of 0.2 for the same overpotential of $0.28 \mathrm{~V}$. With a further decrease in porosity to a value of 0.002 , the current density drops to $0.201 \mathrm{~A} / \mathrm{cm}^{2}$, and the current generation occurs for the most part in a small portion of the catalyst layer.

In summary, decreasing the porosity in the catalyst layer can result in poorer performance because of reactant transfer resistance. The impact of porosity on the polarization curve is illustrated in Figure 5.9. It should be noted that for these particular results, the Butler-Volmer formulation used does not account for concentration overpotential $^{22}$. Consequently, the effect of porosity on the limiting current is not predicted.

\footnotetext{
${ }^{22}$ In section 5.5, results using a Butler-Volmer formulation corrected to account for mass transport limitations (see section 3.6 of Chapter 3 ) do indeed predict this concentration overpotential.
} 


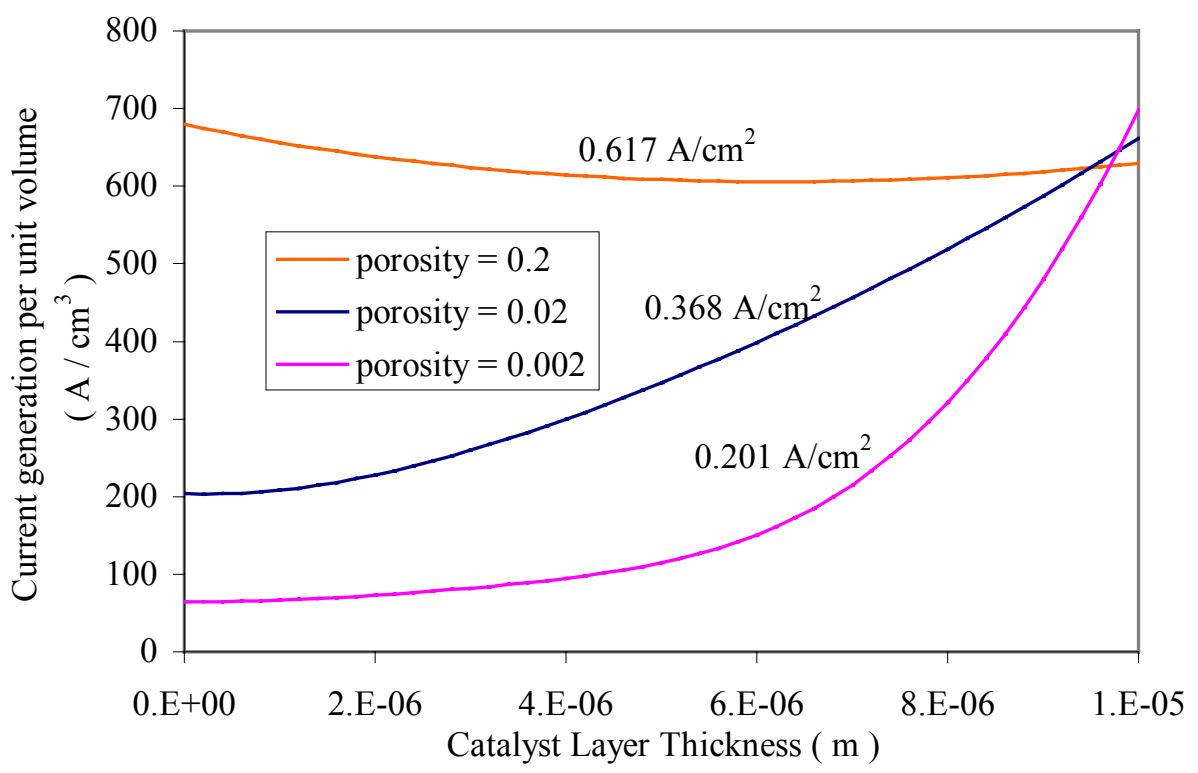

Figure 5.8 Effect of porosity on the current generation for an overpotential of $0.28 \mathrm{~V}$.

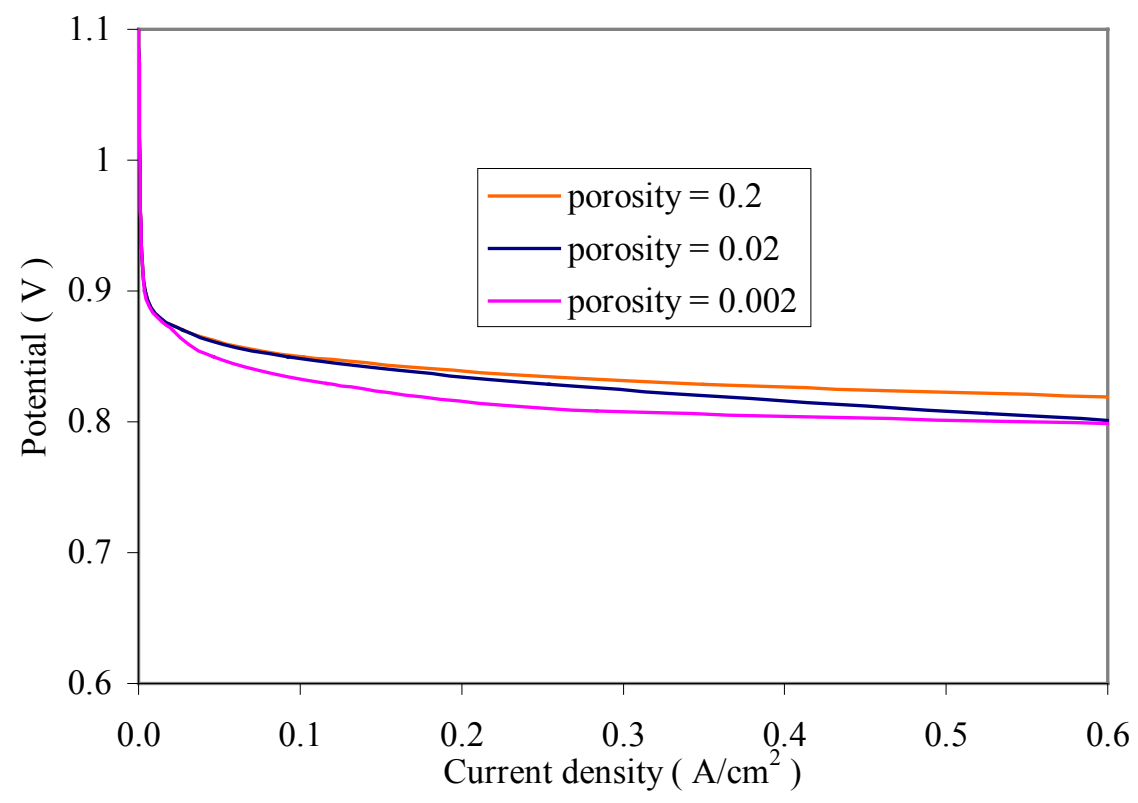

Figure 5.9 Effect of porosity on performance.

\subsubsection{Influence of Permeability}

Figures 5.10 and 5.11 show the influence of the absolute permeability $(K)$ of the porous media on the concentration of oxygen and the concentration of gas profiles. These profiles have been generated using a constant overpotential of $0.28 \mathrm{~V}$. The permeability 
is a property of the porous media and can be different depending on the material. The absolute permeability affects the diffusion of gas and liquid within the porous media. The larger the permeability is, the easier the diffusion of gas species within the catalyst layer. Globally, the same trend can be observed with permeability as with porosity. As shown in Figures 5.10 and 5.11, the oxygen concentration and the gas concentration experience a greater drop across the layer as the permeability is decreased by a factor 10. With a further decrease in permeability, gas flow resistance becomes so high that almost all the oxygen is depleted in only a small portion of the catalyst layer so that less oxygen is available for the electrochemical reaction. The same trend can be observed in the gas concentration profiles. Therefore, for very small permeabilities, only a portion of the catalyst layer can be considered as active.

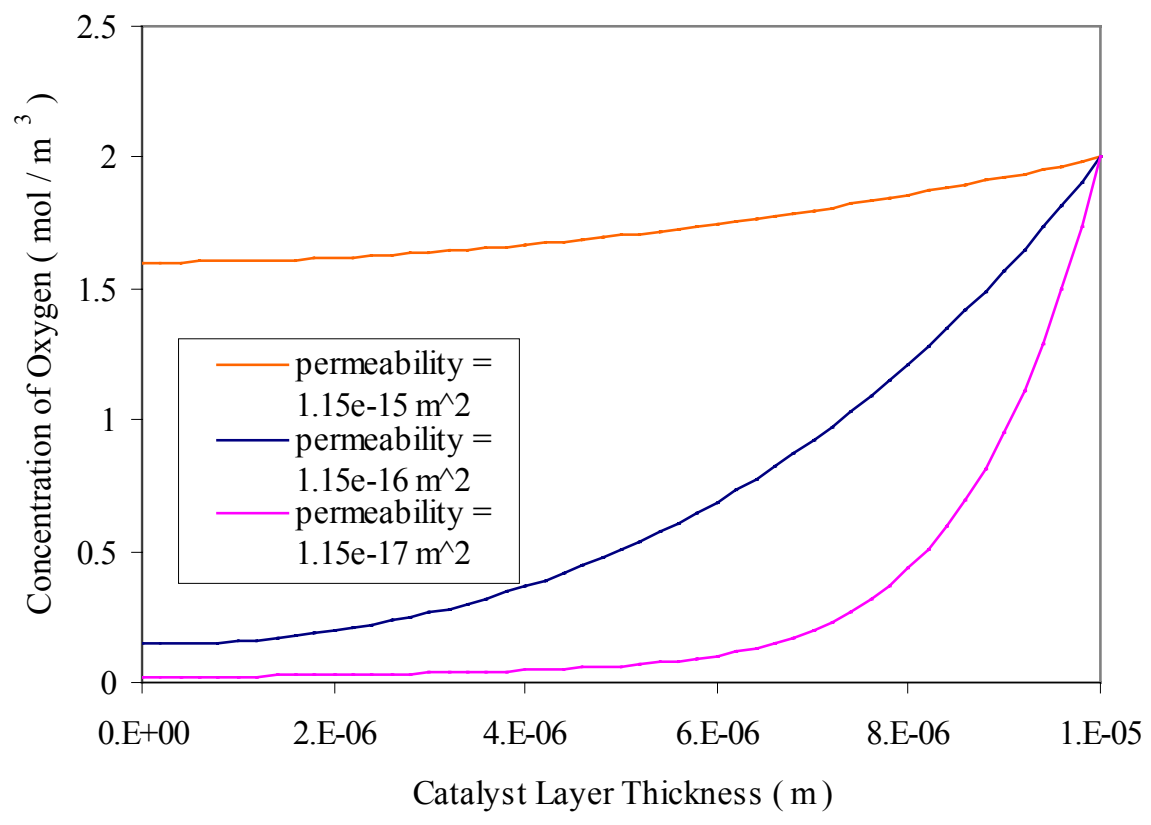

Figure 5.10 Effect of permeability on the oxygen concentration. 


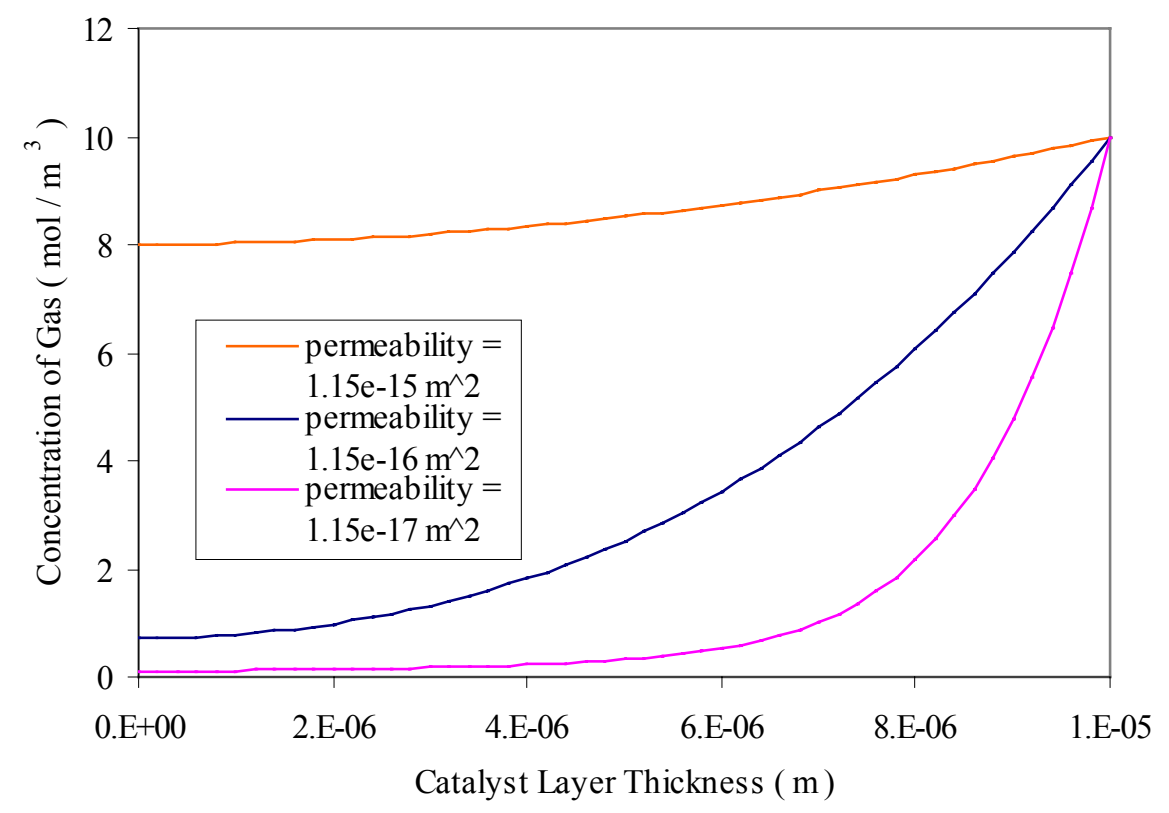

Figure 5.11 Effect of permeability on the concentration of the gas.

Figure 5.12 shows the influence of permeability on the current density and the current generation across the catalyst layer. As with porosity, permeability can have a major impact on current density. While current generation is evenly distributed for relatively high values of the permeability, a decreased permeability results in an uneven current distribution and a lower cell current density.

Thus, decreasing the permeability can result in poorer performance due to reactant transfer resistance. The impact of permeability on the polarization curve is illustrated in Figure 5.13. Again, note that for these results the Butler-Volmer formulation used does not account for concentration overpotential ${ }^{23}$. Consequently, the effect of permeability on the limiting current is not predicted.

\footnotetext{
23 In section 5.5, results using a Butler-Volmer formulation corrected to account for mass transport limitations (see section 3.6 of Chapter 3 ) do indeed predict this concentration overpotential.
} 


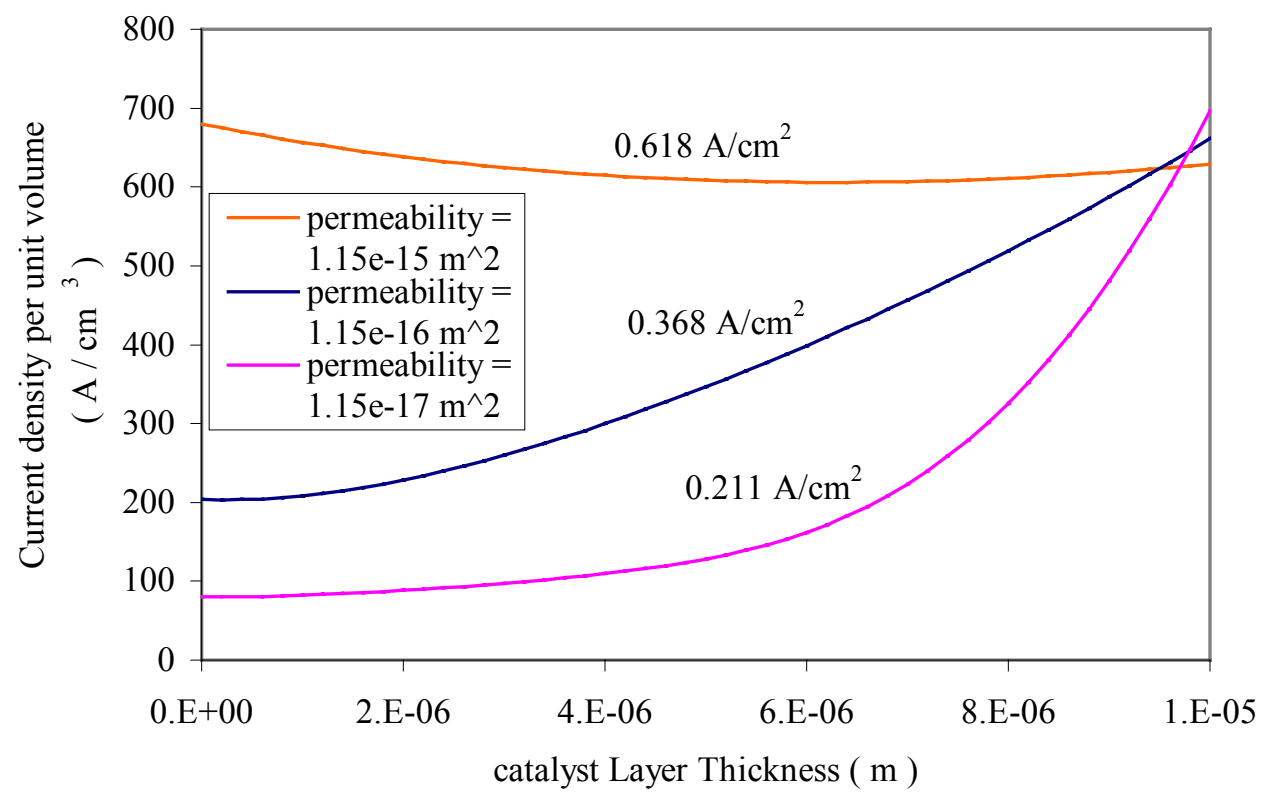

Figure 5.12 Effect of permeability on the current generation for an overpotential of 0.28 $\mathrm{V}$.

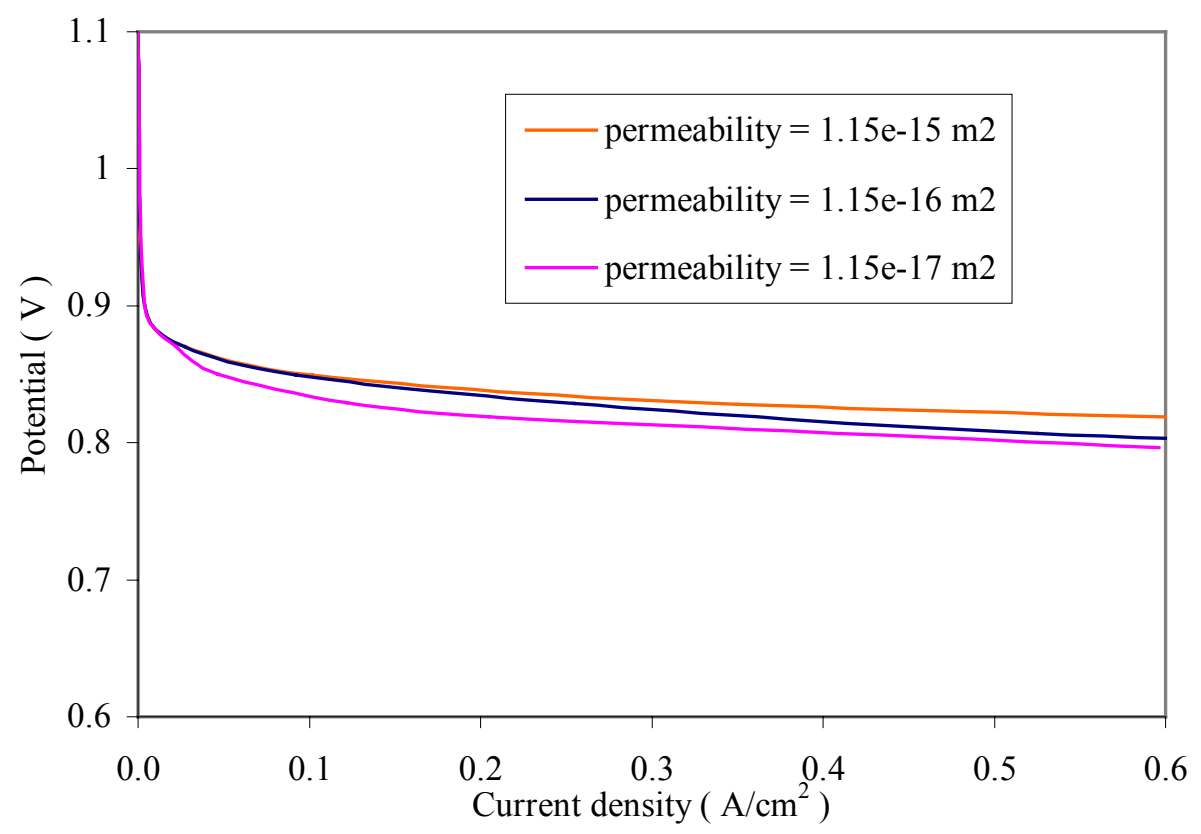

Figure 5.13 Effect of permeability on performance. 


\subsubsection{Influence of the Catalyst Surface Area}

The catalyst specific surface area $(a)$ can be changed by using finer catalyst particles or increasing the platinum loading of the catalyst layer. A study of the effects of the catalyst surface area can help determine whether or not increasing the platinum loading is necessary. In this work, the reference kinetic parameter ( $\left.a i_{o}^{r e f}\right)$ found in the ButlerVolmer relation (equation (3.8)) is set to different values to reflect changes in the catalyst surface area. This means that the results obtained reflect the influence of the exchange current density $\left(i_{O}^{r e f}\right)$ as well.

Figures 5.14 and 5.15 show the influence of catalyst surface area on the concentration of oxygen and the concentration of gas profiles. The higher the catalyst surface area is, the higher the consumption rate of oxygen, provided, of course, that enough oxygen is available for the electrochemical reaction. In contrast, if the catalyst surface area is too small, maximum current generation is reached even though the oxygen has not been totally depleted. As shown in Figure 5.14, oxygen consumption increases with an increased catalyst surface area up to the point where all the oxygen has been consumed within the catalyst layer thickness.

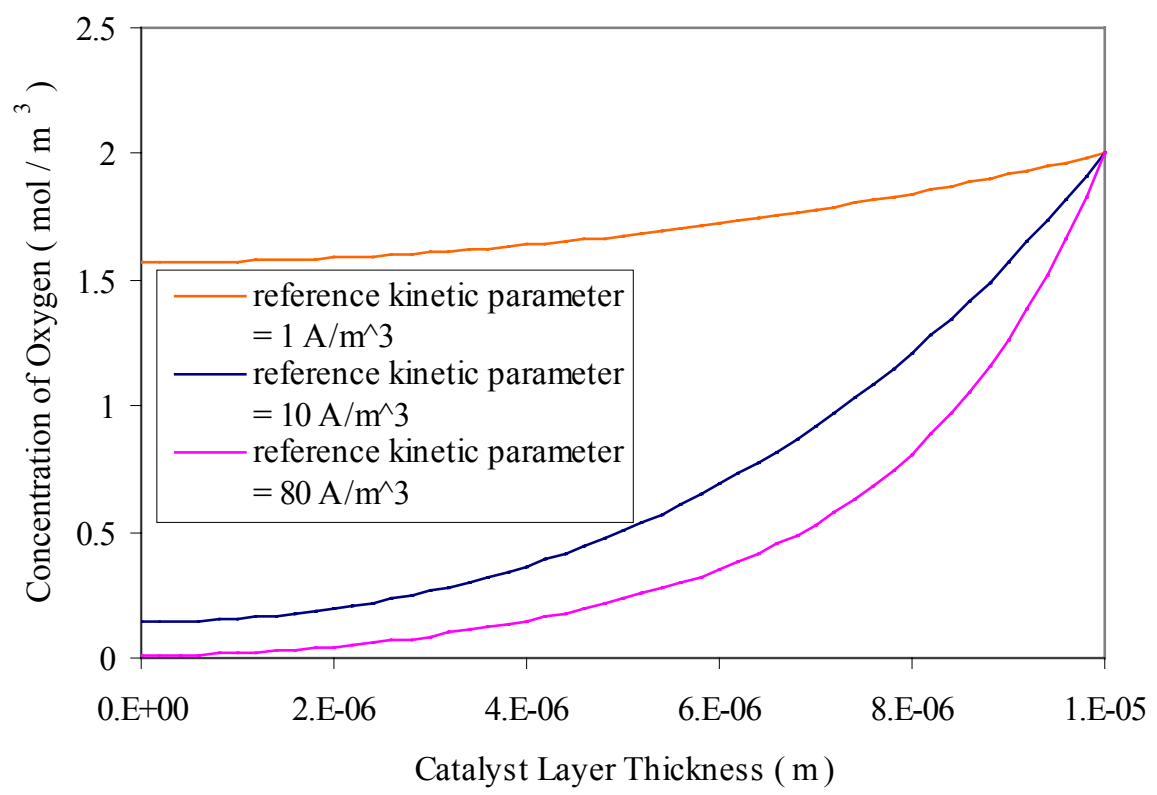

Figure 5.14 Effect of catalyst surface area on the oxygen concentration. 


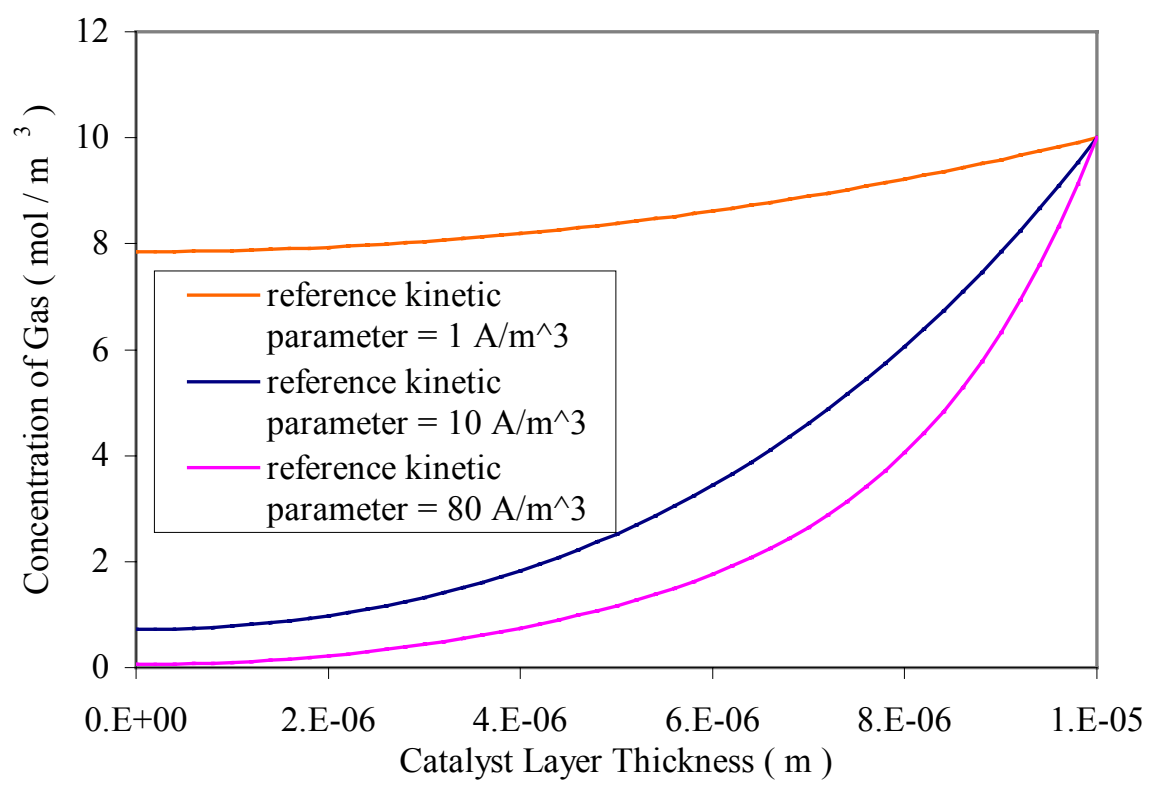

Figure 5.15 Effect of catalyst surface area on the concentration of the gas.

Figure 5.16 shows the effect of catalyst surface area on current density and current generation across the catalyst layer. As expected, the current density increases quickly with catalyst surface area. However, for a value of the reference kinetic parameter of 80 $\mathrm{A} / \mathrm{m}^{3}$, the oxygen is completely depleted at the membrane interface $(\mathrm{x}=0 \mu \mathrm{m})$. As a result, the rate of consumption of oxygen cannot increase anymore at the membrane interface, and current generation occurs for the most part in only a portion of the catalyst layer. Therefore, a further increase in catalyst surface area would only result in a partial utilization of the catalyst layer thickness and, thus, not substantially increase the current density. 


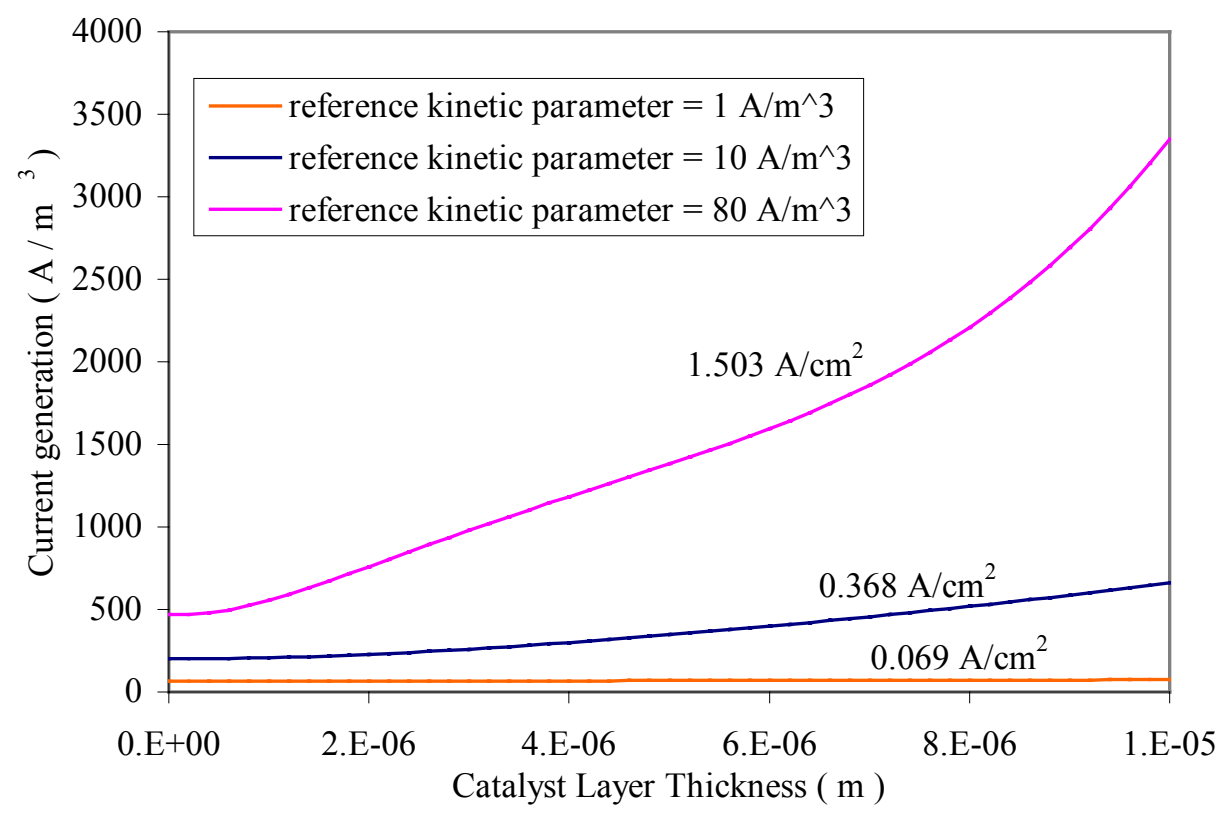

Figure 5.16 Effect of catalyst surface area on current generation for an overpotential of $0.28 \mathrm{~V}$.

\subsection{Influence of Membrane Water Content}

In this section, the influence of membrane water content $\left(\lambda_{\mathrm{H}_{2} \mathrm{O} / \mathrm{SO}_{3}}\right)$ in the catalyst layer on cell performance is presented. Different values of water content are generated using different boundary conditions for the concentration of water in the polymer membrane phase of the catalyst layer. The boundary and initial conditions used are given in Table 5.2. When different values for water concentration are used, the same values are assigned as initial concentrations. 
Table 5.2 Boundary and initial conditions for the results presented in section 5.3.

\begin{tabular}{|c|c|c|c|}
\hline Variable & Initial Value & $\begin{array}{c}\text { Membrane Interface } \\
(\mathbf{x}=\mathbf{0})\end{array}$ & $\begin{array}{c}\text { Backing Layer } \\
\text { Interface (x=10 } \boldsymbol{\mu m})\end{array}$ \\
\hline$\Phi_{c}(\mathrm{~V})$ & - & \multicolumn{2}{|c|}{ From 0.20 to 0.29} \\
\hline$\Phi_{m}(\mathrm{~V})$ & - & 0 & Flux $=0$ \\
\hline$c_{H_{2} O}^{m}\left(\mathrm{~mol}^{-3}\right)$ & 13000,19000, & $13000,19000,25200$ \\
\hline$c_{O_{2}}^{g}\left(\mathrm{~mol}^{-3} \mathrm{~m}^{-3}\right)$ & 25200 & Flux $=0$ & 2 \\
\hline$c^{g}\left(\mathrm{~mol} . \mathrm{m}^{-3}\right)$ & 2 & Flux $=0$ & 10 \\
\hline$s$ & 10 & Flux $=0$ & 0.05 \\
\hline$T\left({ }^{\circ} \mathrm{C}\right)$ & 0.05 & Flux $=0$ & 80 \\
\hline
\end{tabular}

Figure 5.17 shows the influence of membrane water content in the catalyst on the polarization curve. Since membrane proton conductivity increases with water content, the ohmic losses in the polymer membrane phase of the catalyst layer decreases with increased water content. Thus, better performance is obtained with higher water content.

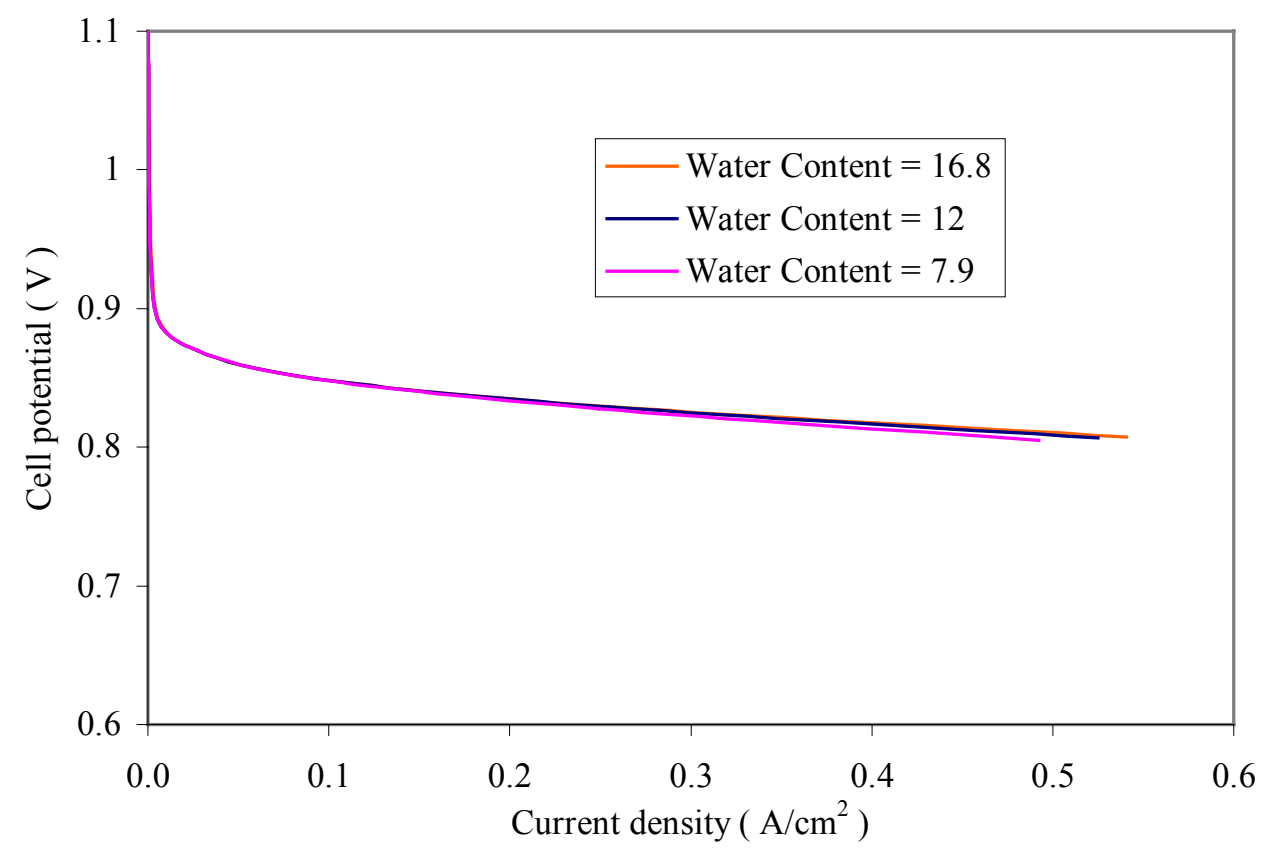

Figure 5.17 Influence of the membrane water content in the catalyst layer on performance. 


\subsection{Influence of Temperature}

In this section, the influence of temperature on cell performance is presented. Different values of the operating temperature are assigned using different values for the boundary condition at the catalyst layer/backing layer interface. For the type of boundary conditions used, the variation of temperature across the catalyst layer is negligible (on the order of $0.001{ }^{\circ} \mathrm{C}$ ) and, therefore, the value assigned at the boundary effectively sets the temperature at a given level. The boundary and initial conditions used are given in Table 5.3. When different values for the temperature are used, the same values are assigned as initial concentrations.

Table 5.3 Boundary and initial conditions.

\begin{tabular}{|c|c|c|c|}
\hline Variable & Initial Value & $\begin{array}{c}\text { Membrane Interface } \\
(\mathbf{x}=\mathbf{0})\end{array}$ & $\begin{array}{c}\text { Backing Layer } \\
\text { Interface }(\mathbf{x}=\mathbf{1 0} \boldsymbol{\mu m})\end{array}$ \\
\hline$\Phi_{c}(\mathrm{~V})$ & - & \multicolumn{2}{|c|}{ From 0.20 to 0.31} \\
\hline$\Phi_{m}(\mathrm{~V})$ & - & 0 & Flux $=0$ \\
\hline$c_{H_{2} O}^{m}\left(\mathrm{~mol} . \mathrm{m}^{-3}\right)$ & 19000 & 19000 & 19000 \\
\hline$c_{O_{2}}^{g}\left(\mathrm{~mol}^{-\mathrm{m}^{-3}}\right)$ & 2 & Flux $=0$ & 2 \\
\hline$c^{g}\left(\mathrm{~mol} \cdot \mathrm{m}^{-3}\right)$ & 10 & Flux $=0$ & 10 \\
\hline$s$ & 0.05 & Flux $=0$ & 0.05 \\
\hline$T\left({ }^{\circ} \mathrm{C}\right)$ & $70,80,90$ & Flux $=0$ & $70,80,90$ \\
\hline
\end{tabular}

Figure 5.18 shows the impact of temperature on the polarization curve. In contrast to what is usually obtained at the cell level, better performance of the catalyst layer is achieved at lower temperature. In other words, the activation overpotential increases as the temperature increases. Mathematically, this results from the Butler-Volmer relation (Equation 3.8), in which the current generation per unit volume is a decreasing function of temperature, for a given overpotential. At the cell level, on the other hand, the membrane layer ohmic losses become large enough to overcome this trend. Therefore, 
temperature has the opposite effect if the membrane layer is added to the catalyst layer model model.

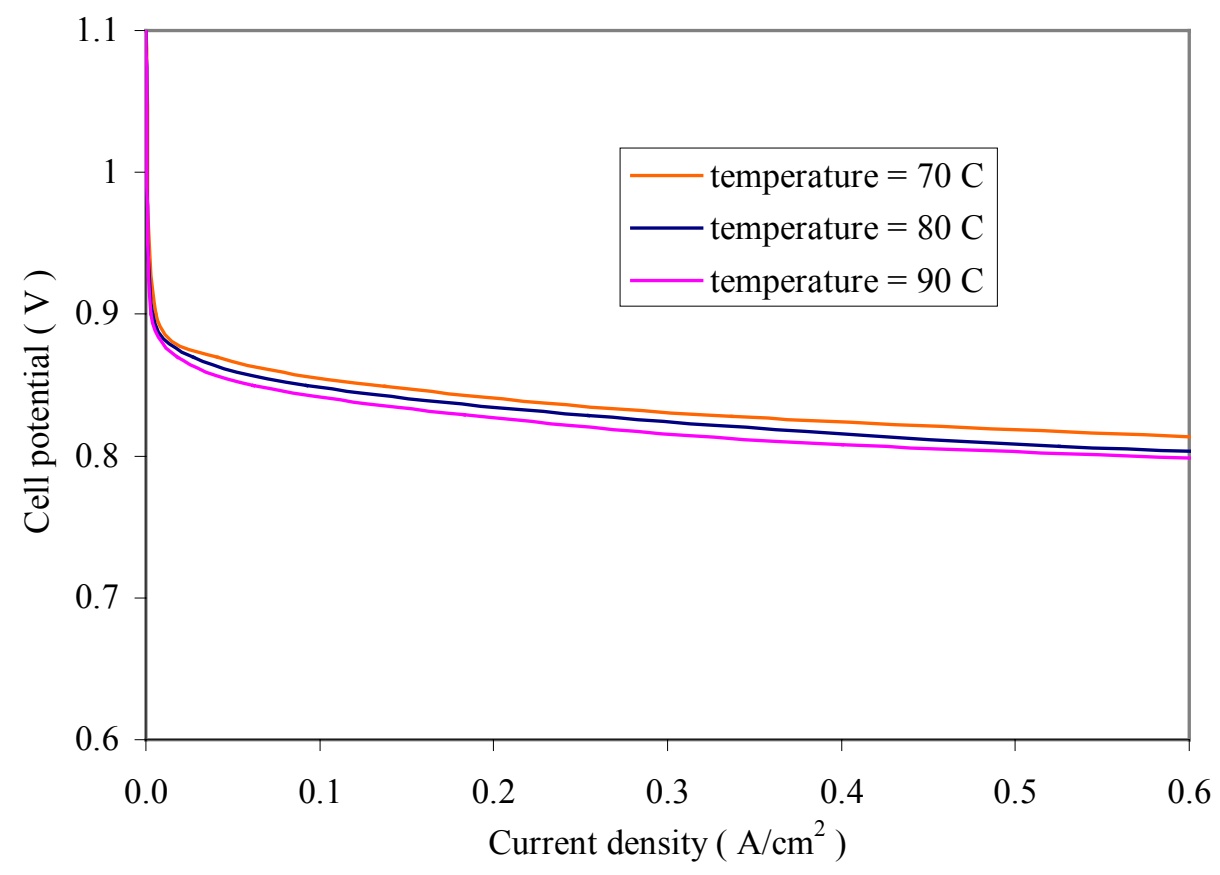

Figure 5.18 Influence of temperature on performance.

\subsection{Mass Transport Limitations}

At high current densities, mass transport limitations become dominant. The diffusion of oxygen to the reaction site, at the platinum surface of the agglomerates, becomes a limiting factor for performance, which results in limiting the current density to some maximum value. As described in Chapter 3, section 3.6, the limiting current can be calculated as a function of the diffusion layer thickness $(\delta$, which, in case of a pseudohomogeneous model is the thickness of the catalyst layer) and the catalyst surface area $(A)$. Therefore, different limiting currents can be obtained by varying the relative importance of these two parameters. 
The relative importance of diffusion layer thickness to catalyst surface area can be affected by varying the ratio $\delta / A^{24}$. The impact of this parameter on the polarization curve is shown in Figure 5.19 where the boundary and initial conditions used to obtain these results are detailed in Table 5.4. A limiting current of $1.27 \mathrm{~A} / \mathrm{cm}^{2}$ is calculated using a ratio $\delta / A=1.5 \mathrm{e}-7 \mathrm{~m}^{-1}$. For greater values of the ratio $\delta / A$, the limiting current becomes lower because of higher diffusion resistance due to an increased diffusion layer thickness or a decreased catalyst surface.

Table 5.4 Boundary and initial conditions for the results presented in section 5.5.

\begin{tabular}{|c|c|c|c|}
\hline Variable & Initial Value & $\begin{array}{c}\text { Membrane Interface } \\
(\mathbf{x}=\mathbf{0})\end{array}$ & $\begin{array}{c}\text { Backing Layer } \\
\text { Interface }(\mathbf{x}=\mathbf{1 0} \boldsymbol{\mu m})\end{array}$ \\
\hline$\Phi_{c}(\mathrm{~V})$ & - & \multicolumn{2}{|c|}{ From 0.20 to 0.80} \\
\hline$\Phi_{m}(\mathrm{~V})$ & - & 0 & Flux $=0$ \\
\hline$c_{\mathrm{H}_{2} \mathrm{O}}^{m}\left(\mathrm{~mol} \cdot \mathrm{m}^{-3}\right)$ & 19000 & 19000 & 19000 \\
\hline$c_{\mathrm{O}_{2}}^{g}\left(\mathrm{~mol}^{-3}\right)$ & 2 & Flux $=0$ & 2 \\
\hline$c^{g}\left(\mathrm{~mol} \cdot \mathrm{m}^{-3}\right)$ & 10 & Flux $=0$ & 10 \\
\hline$s$ & 0.05 & Flux $=0$ & 0.05 \\
\hline$T\left({ }^{\circ} \mathrm{C}\right)$ & 80 & Flux $=0$ & 80 \\
\hline
\end{tabular}

\footnotetext{
${ }^{24}$ In a pseudo-homogeneous model, there is no need to varying the diffusion layer thickness, which is in fact the catalyst layer thickness. However, in these results, $\delta / A$ is chosen as a parameter to show that the same trend can be obtained with an agglomerate model, in which the diffusion layer $\delta$ and the reaction site $A$ would be two variables (see section 3.6 in Chapter 3).
} 


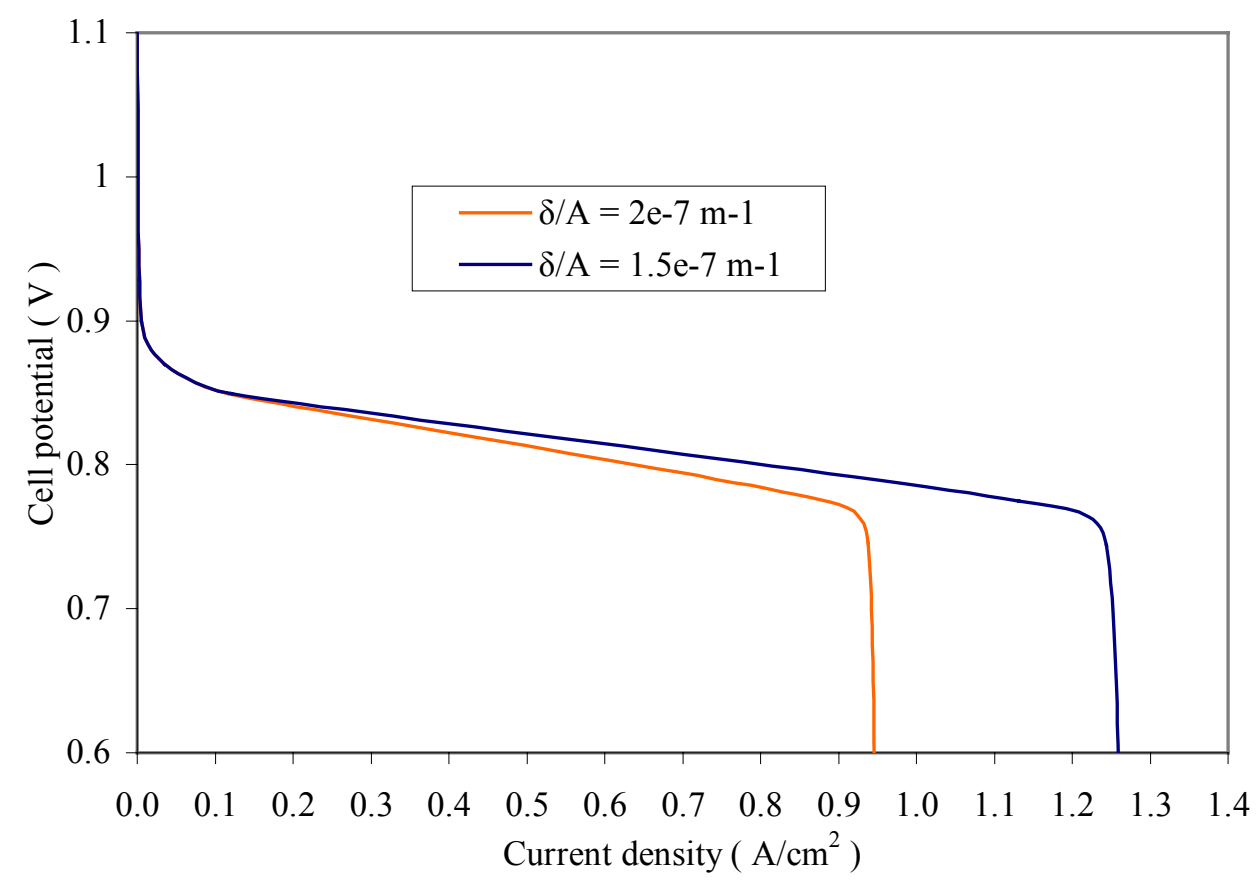

Figure 5.19 Polarization curve for two values of the parameter $\delta / \mathrm{A}$.

\subsection{Flooding}

Excess liquid water in the catalyst layer is believed to dramatically affect cell performance. The purpose of this section is to predict the consequences of flooding on the reactant concentration distributions as well as the current generation. All boundary and initial conditions effectively used in this section are summarized in Table 5.5. To simulate flooding, different values of the saturation ratio, which accounts for the amount of liquid water in the pores of the catalyst layer, are used. A fixed value of the saturation is assumed at the backing layer interface, and a zero flux is assigned at the membrane interface, which means that no liquid water moves from the catalyst layer into the membrane layer. For this combination of boundary conditions, the variation of saturation across the catalyst layer is negligible (on the order of 1e-6); and, therefore, the value assigned at the backing layer interface effectively sets the saturation to a given level (see Figure 5.17). 
Table 5.5 Boundary and initial conditions for the results of section 5.6.

\begin{tabular}{|c|c|c|c|}
\hline Variable & Initial Value & $\begin{array}{c}\text { Membrane } \\
\text { Interface }(\mathbf{x}=\mathbf{0})\end{array}$ & $\begin{array}{c}\text { Backing Layer } \\
\text { Interface }(\mathbf{x}=\mathbf{1 0} \boldsymbol{\mu m})\end{array}$ \\
\hline$\Phi_{c}(\mathrm{~V})$ & - & \multicolumn{2}{|c|}{ From 0.20 to 0.80} \\
\hline$\Phi_{m}(\mathrm{~V})$ & - & 0 & Flux $=0$ \\
\hline$c_{\mathrm{H}_{2} \mathrm{O}}^{m}\left(\mathrm{~mol} \cdot \mathrm{m}^{-3}\right)$ & 19000 & 19000 & 19000 \\
\hline$c_{O_{2}}^{g}\left(\mathrm{~mol}^{-3}\right)$ & 2 & Flux $=0$ & 2 \\
\hline$c^{g}\left(\mathrm{~mol} \cdot \mathrm{m}^{-3}\right)$ & 10 & Flux $=0$ & 10 \\
\hline$s$ & $0.05,0.1,0.2,0.5$ & Flux $=0$ & $0.05,0.1,0.2,0.5$ \\
\hline$T\left({ }^{\circ} \mathrm{C}\right)$ & 80 & Flux $=0$ & 80 \\
\hline
\end{tabular}

Figures 5.20 to 5.23 are generated using an overpotential of $0.28 \mathrm{~V}$, which results in a current density of less than $0.4 \mathrm{~A} / \mathrm{cm}^{2}$. Within this range of current density, the concentration overpotential is not taken into account. Figures $5.17 \mathrm{~b}$ and $\mathrm{c}$ show the influence of saturation on the concentration of oxygen distribution and the concentration of gas distribution across the catalyst layer. For a saturation ratio varying between 0.05 and 0.2 , the presence of liquid water in the pores does not have an important effect on the distribution of the gas species concentration across the catalyst layer. With a further increase of the saturation to a value of 0.5 , the amount of liquid water is sufficiently high to affect the diffusion of gas species through the pores. As a result, the oxygen concentration and the gas concentration drop to very low levels in a large portion of the catalyst layer, so that limited amounts of reactant are available for the electrochemical reaction. 


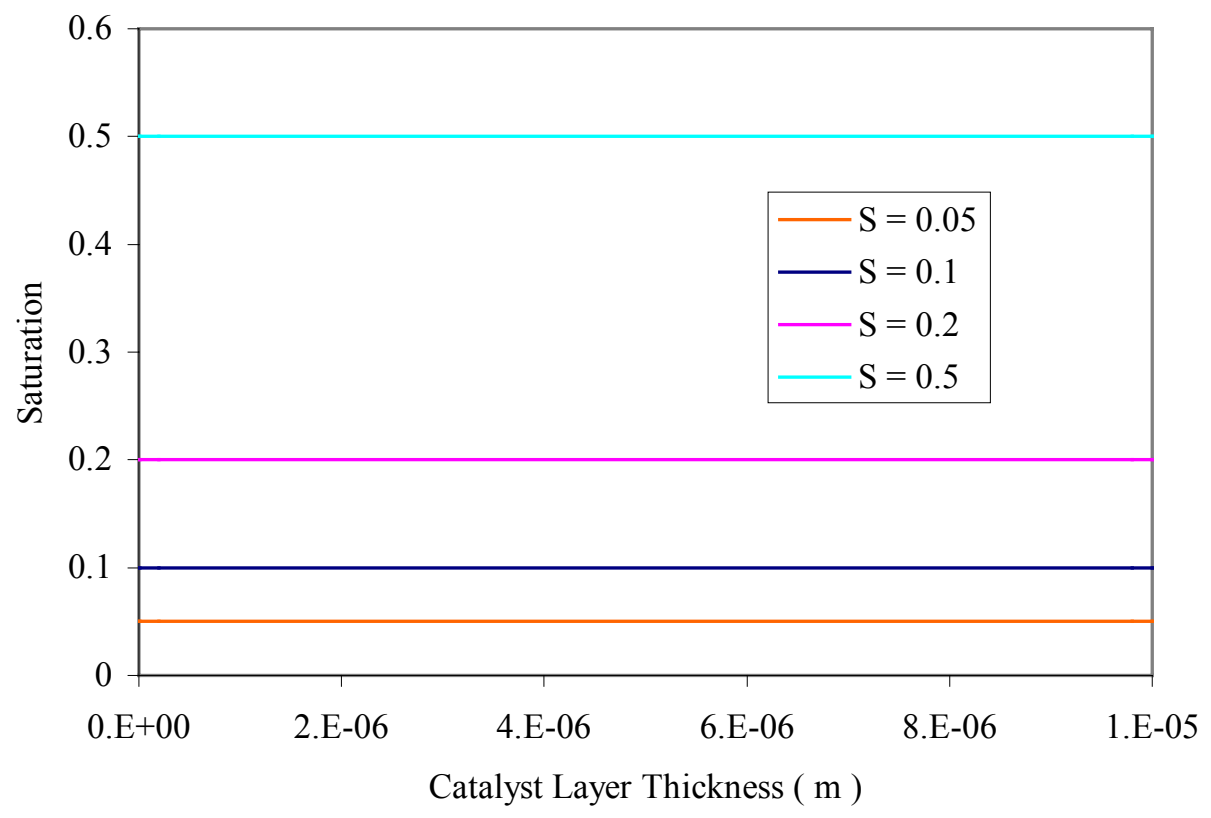

Figure 5.20 Saturation profiles for different values of the boundary conditions at the backing layer interface.

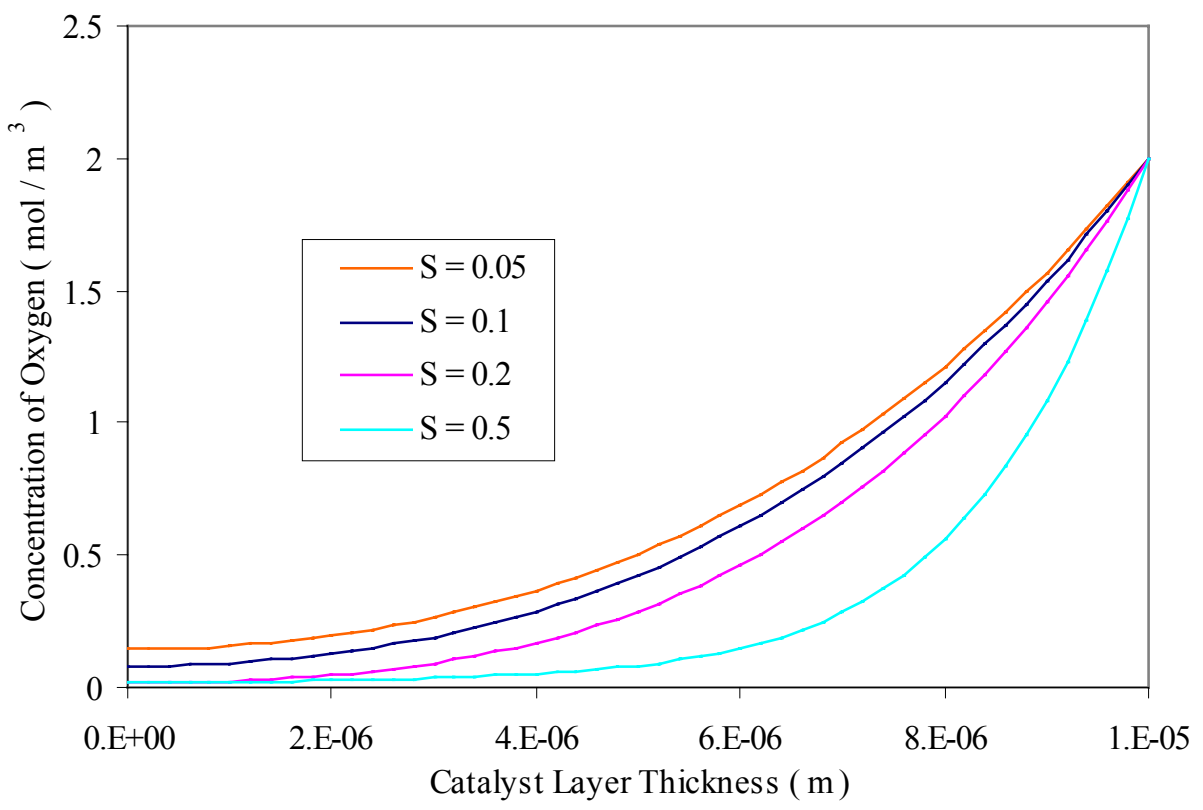

Figure 5.21 Effect of saturation on the oxygen concentration. 


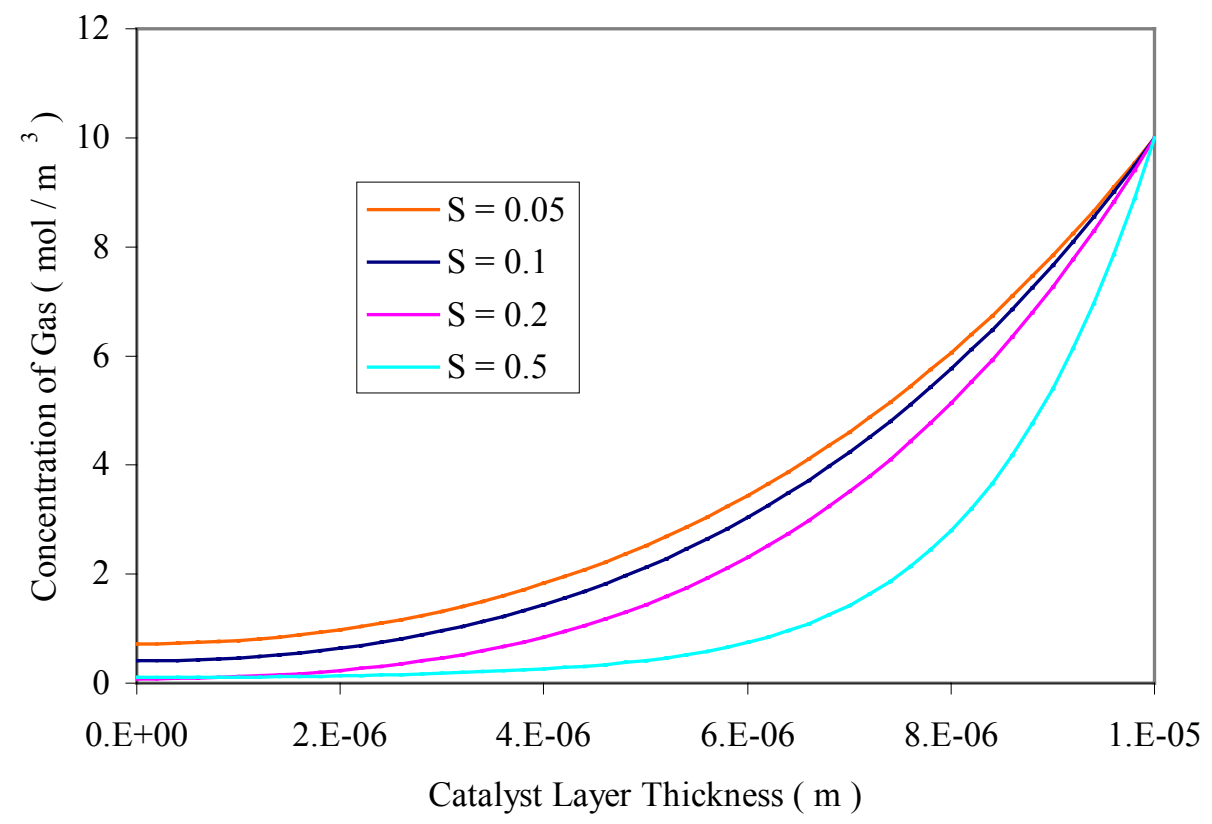

Figure 5.22 Effect of saturation on the concentration of the gas phase.

Figure 5.23 shows the influence of saturation on the current generation and the current density for a given overpotential of $0.28 \mathrm{~V}$. Globally, the saturation has a negative effect on performance, since the current density drops from $0.368 \mathrm{~A} / \mathrm{cm}^{2}$ for a saturation of 0.05 to a value of $0.294 \mathrm{~A} / \mathrm{cm}^{2}$ for a saturation of 0.2 . With a further increase in the saturation, the impact on the current generation distribution across the layer becomes important. As can be seen from Figure 5.23, the values of the current generation towards the membrane interface are affected by the low oxygen concentration in this region. Thus, the current generation becomes unevenly distributed across the catalyst layer when the saturation ratio exceeds 0.5 . 


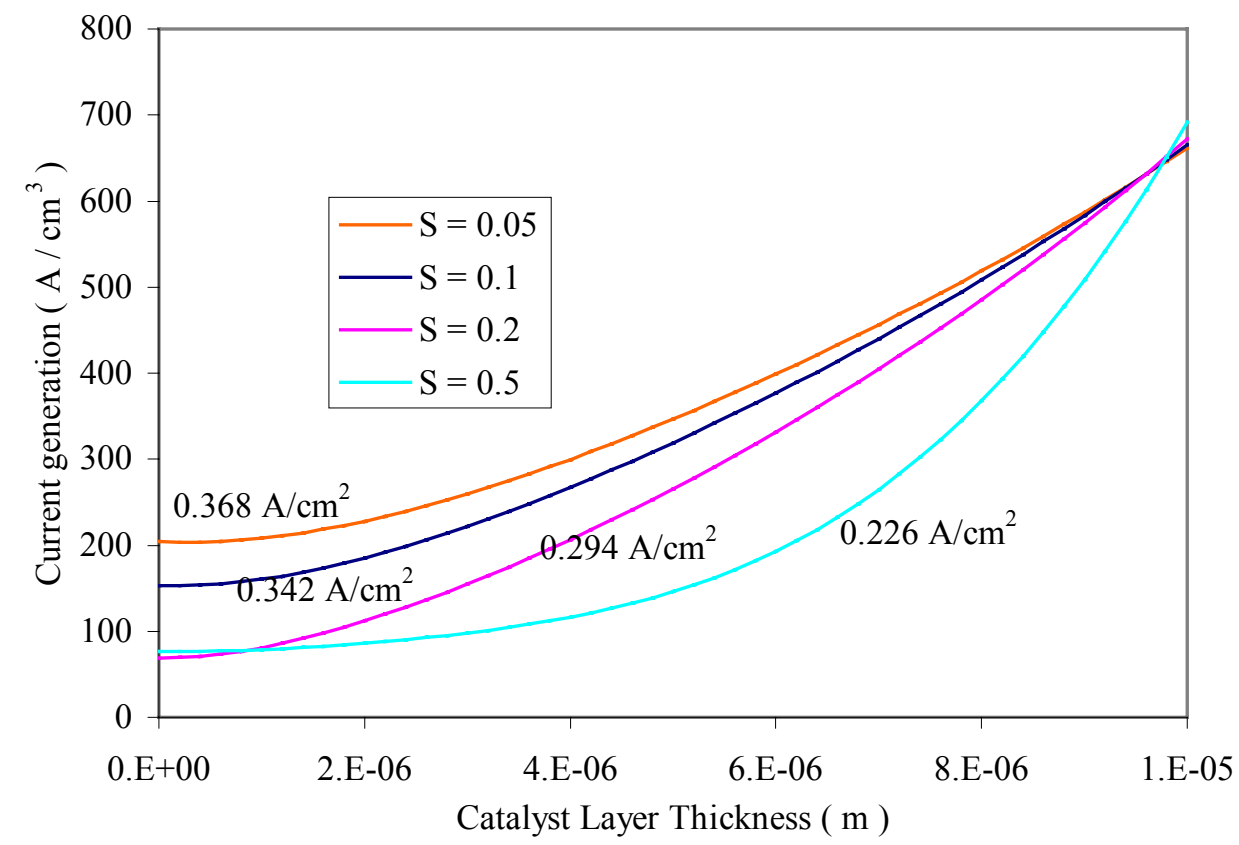

Figure 5.23 Effect of the saturation on the current generation for an overpotential of 0.28 $\mathrm{V}$.

Though effects of diffusion limitations can be observed in the concentration of oxygen profiles, it is important to note that in the previous results (Figures 5.20 to 5.23), the concentration overpotential is not taken into account and, therefore, diffusion limitations do not have an effect on the current density calculated here. Hence, increasing the saturation ratio beyond a value of 0.5 will not result in a limitation on performance, even though transport limitations are known to play an important role with respect to the limiting current. However, for the results presented here, the same boundary conditions used for the gas species concentrations at the backing layer interface are fixed and independent of the saturation ratio. Furthermore, in reality, the value of the concentration of oxygen in the backing layer would decrease with increasing saturation, because mass transport limitations would occur in the porous media of the backing layer before the gas reaches the catalyst layer interface. Therefore, since this model is not coupled to a backing layer model, it is impossible to predict the effect of flooding on the concentration boundary conditions of the gas species at the interface with the backing layer.

Nevertheless, it is possible to study the effect of flooding on the limiting current when the concentration overpotential is taken into account within the catalyst layer using the 
appropriate form for the Butler-Volmer equation (equation (3.100)). This is shown in Figure 5.24, where two polarization curves are presented, each for a different value of the saturation. When the saturation increases from 0.05 to 0.2 , cell performance is globally worsened and the limiting current drops considerably from 1.26 to $0.98 \mathrm{~A} / \mathrm{cm}^{2}$.

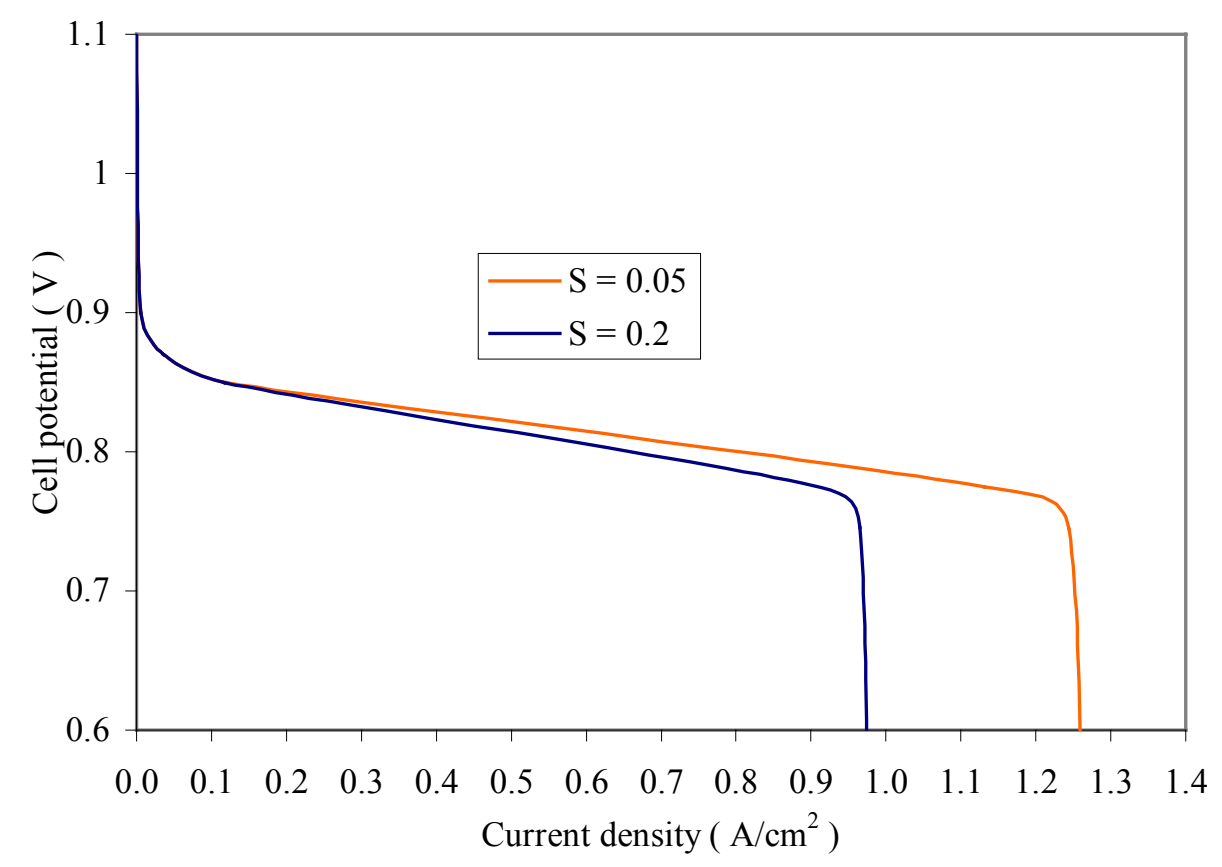

Figure 5.24 Influence of saturation on the limiting current.

Figure 5.25 shows the evolution of the concentration of oxygen profiles for different values of the current density, along the polarization curve obtained for a saturation ratio of 0.2 . As the current density increases, the consumption of oxygen increases up to the point where all the oxygen is depleted at the membrane interface. This point is reached at about $0.90 \mathrm{~A} / \mathrm{cm}^{2}$. The concentration of oxygen at the membrane interface is then equal to zero, and the consumption rate cannot increase further. The limiting current is reached, and further increase in the overpotential will not increase the current density or the oxygen consumption. Therefore, the oxygen concentration profiles converge when the current density approaches the limiting current of $0.98 \mathrm{~A} / \mathrm{cm}^{2}$. As a result of the definition of the limiting current (see equation (3.97)), the oxygen cannot be completely depleted in a smaller region than the catalyst layer thickness itself. In contrast with the pseudo-homogeneous model presented by You and Liu (2000), this model suggests that 
the consumption rate cannot increase up to the point where the oxygen is consumed in only a thin region of the catalyst layer. On the contrary, the profiles in Figure 5.25 show that the oxygen consumption rate becomes limited when the oxygen is completely depleted at the membrane interface.

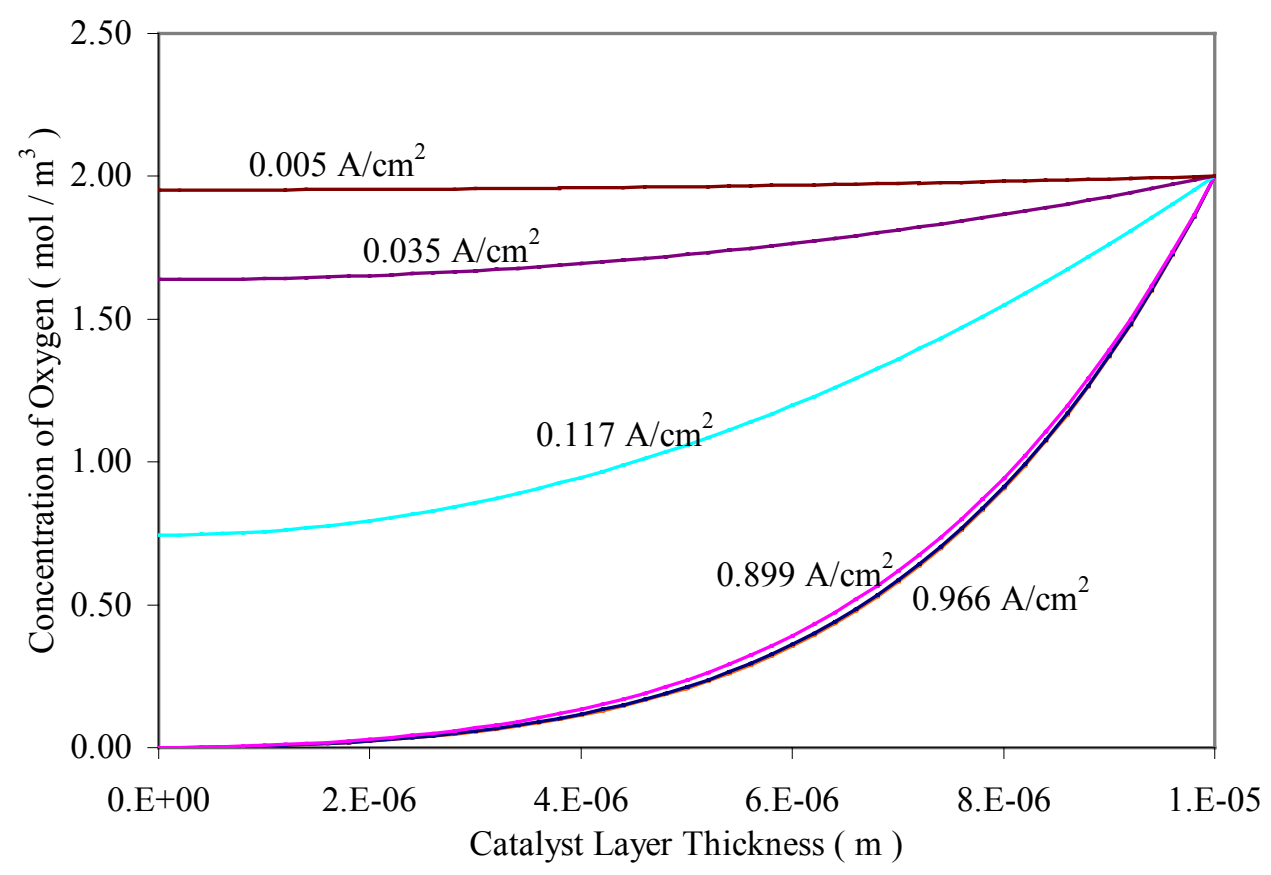

Figure 5.25 Concentration of oxygen profiles along the polarization curve.

\subsection{Transient Behavior of the Catalyst Layer}

In this section, the evolution of the different variables with time is studied, for the case of flooding within the catalyst layer. Boundary conditions are assigned at the membrane and backing layer interfaces to simulate reasonable conditions for each of the dependent variables of the problem. The overpotential is set to a value of $0.28 \mathrm{~V}$, which corresponds to a calculated value of $0.46 \mathrm{~A} / \mathrm{cm}^{2}$ for the current density. The boundary and initial conditions used are summarized in Table 5.6. Two fluxes are assigned at both interfaces for all the dependent variables, except for the concentration of water in the membrane for which two fixed values are assigned at the boundaries. No oxygen or gas is assumed leaving the catalyst layer towards the membrane. Similarly, no liquid water is moving to the membrane, and the catalyst layer/membrane interface is assumed isolated. The 
amount of liquid water leaving the catalyst layer at the backing layer interface is purposely chosen small enough, so that the saturation increases with time inside the catalyst because of water production. The fluxes for the temperature and the gas species at the backing layer interface are chosen to balance as close as possible the oxygen consumption and the heat generation within the catalyst layer.

Table 5.6 Boundary and initial conditions for the results of section 5.7.

\begin{tabular}{|c|c|c|c|}
\hline Variable & Initial Value & $\begin{array}{c}\text { Membrane } \\
\text { Interface }(\mathbf{x}=\mathbf{0})\end{array}$ & $\begin{array}{c}\text { Backing Layer } \\
\text { Interface }(\mathbf{x}=\mathbf{1 0} \boldsymbol{\mu m})\end{array}$ \\
\hline$\Phi_{c}(\mathrm{~V})$ & - & \multicolumn{2}{|c|}{0.28} \\
\hline$\Phi_{m}(\mathrm{~V})$ & - & 0 & Flux $=0$ \\
\hline$c_{H_{2} O}^{m}\left(\mathrm{~mol} . \mathrm{m}^{-3}\right)$ & 19000 & 19000 & 19000 \\
\hline$c_{O_{2}}^{g}\left(\mathrm{~mol}^{-3} \mathrm{~m}^{-3}\right)$ & 2 & Flux $=0$ & Flux $=0.012$ \\
\hline$c^{g}\left(\mathrm{~mol} \cdot \mathrm{m}^{-3}\right)$ & 10 & Flux $=0$ & Flux $=0.022$ \\
\hline$s$ & 0.05 & Flux $=0$ & Flux $=-0.01$ \\
\hline$T\left({ }^{\circ} \mathrm{C}\right)$ & 80 & Flux $=0$ & Flux $=-2500$ \\
\hline
\end{tabular}

Figures 5.26 to 5.30 show the evolution with time of the saturation, concentration of water in the polymer phase, temperature, concentrations of oxygen and gas for this simulated case of flooding. It is important to notice that these profiles do not converge to steady state because of the use of constant flux boundary conditions that may not be realistic. To reach steady state, it would be necessary to adjust the flux boundary conditions with time, which will be done eventually by coupling the catalyst layer model to the other component models of the fuel cell. This work is in progress. 


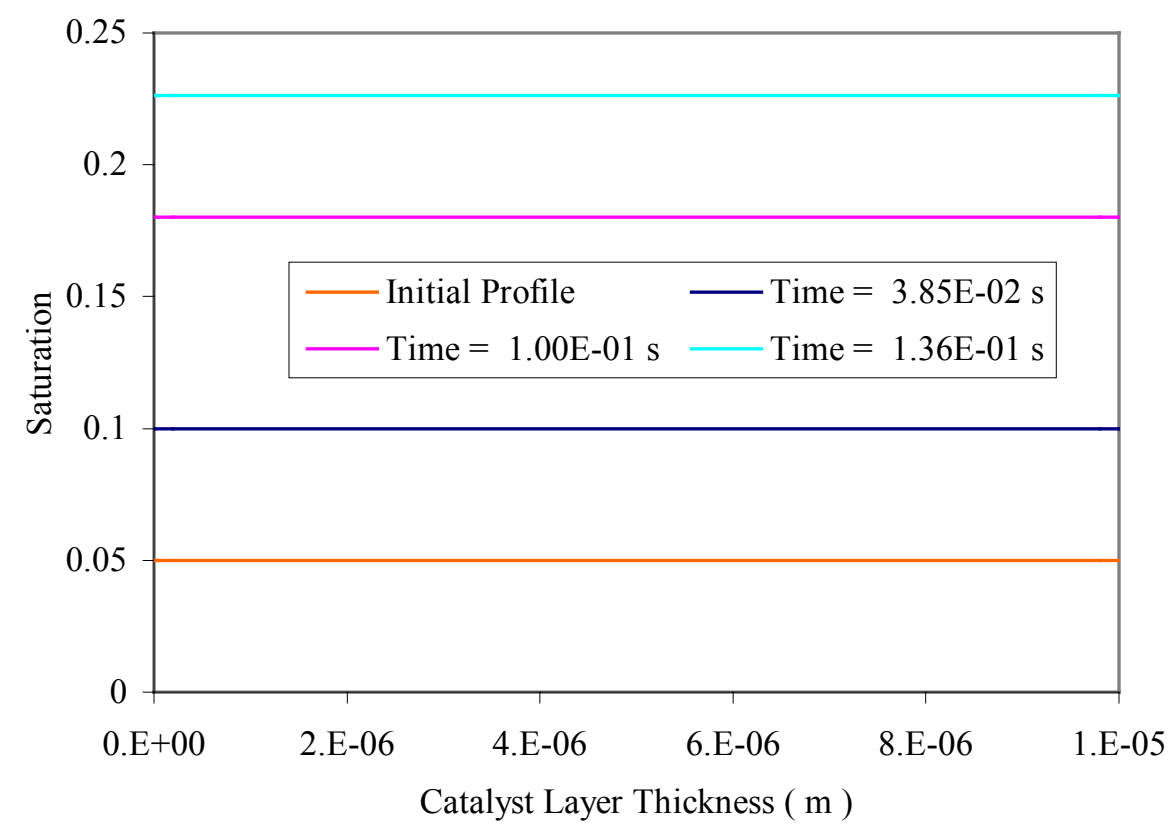

Figure 5.26 Evolution in time of the saturation.

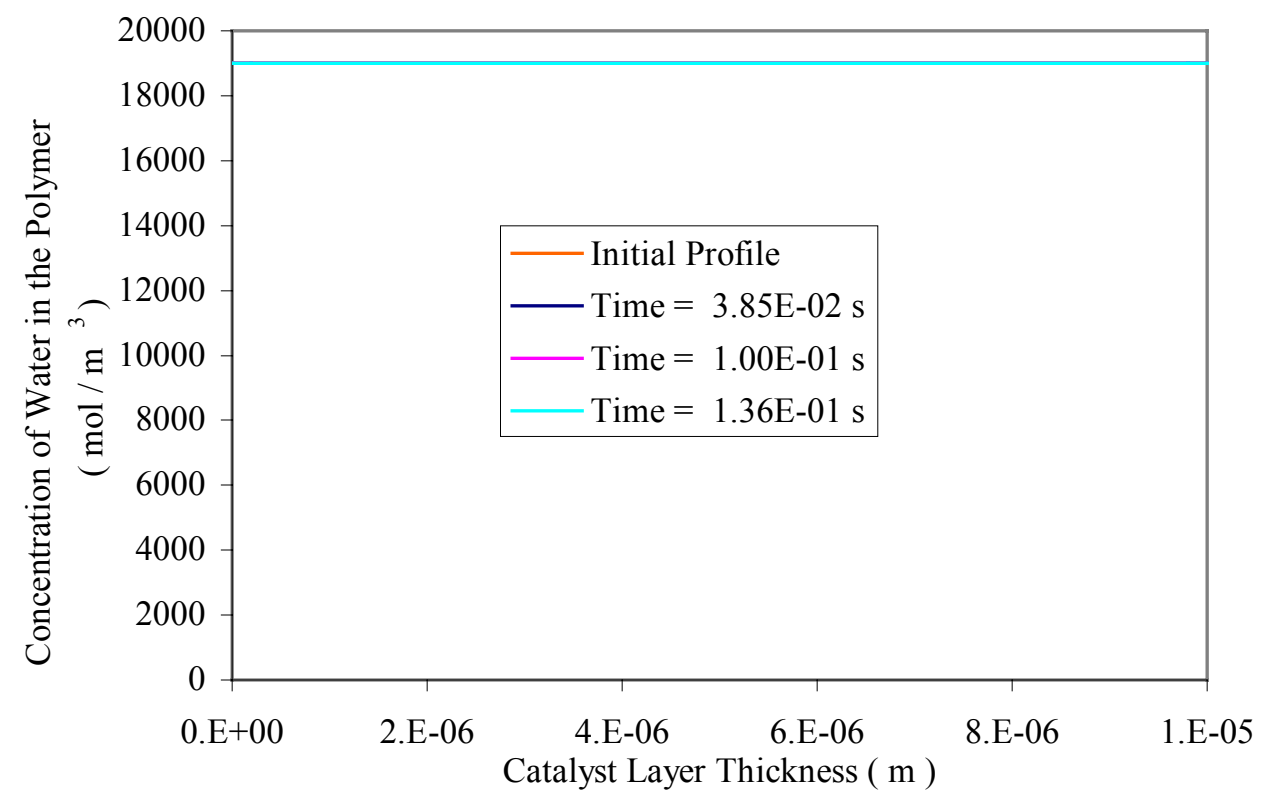

Figure 5.27 Evolution in time of the concentration of water in the polymer phase. 


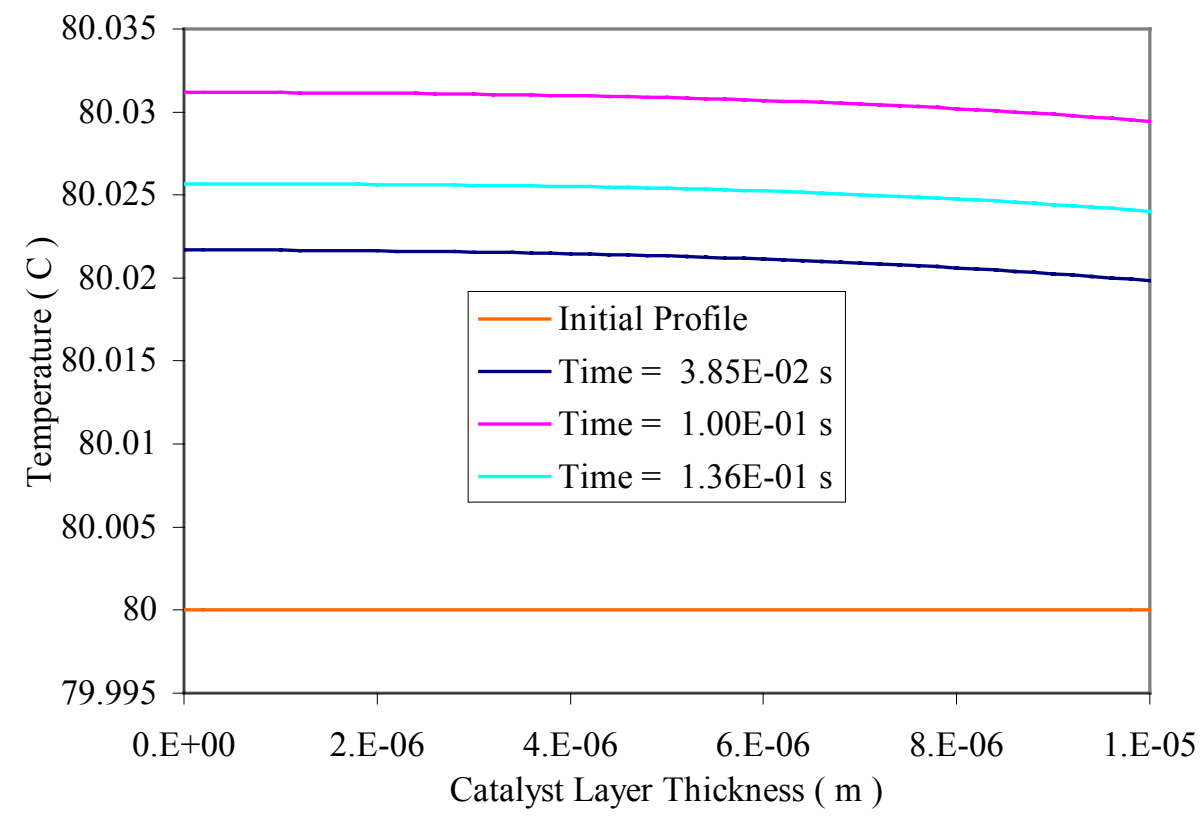

Figure 5.28 Evolution in time of the temperature.

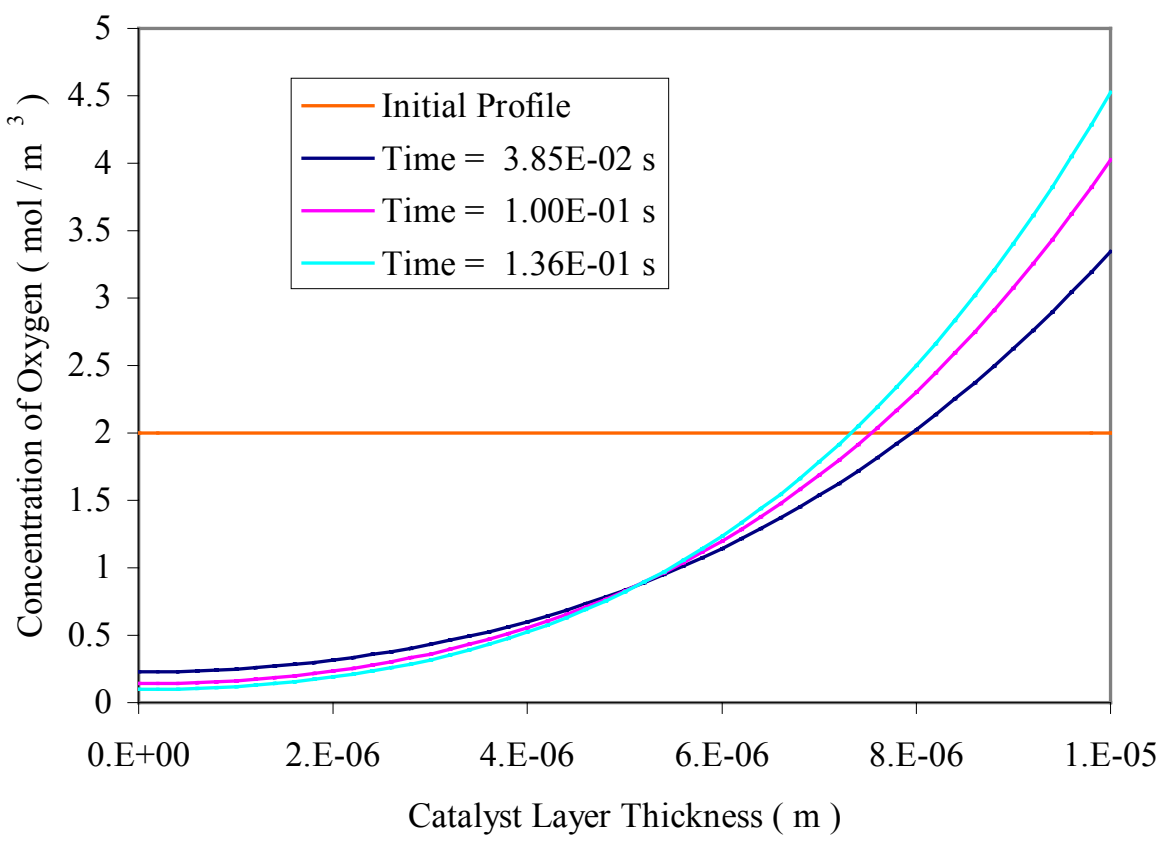

Figure 5.29 Evolution in time of the concentration of oxygen. 


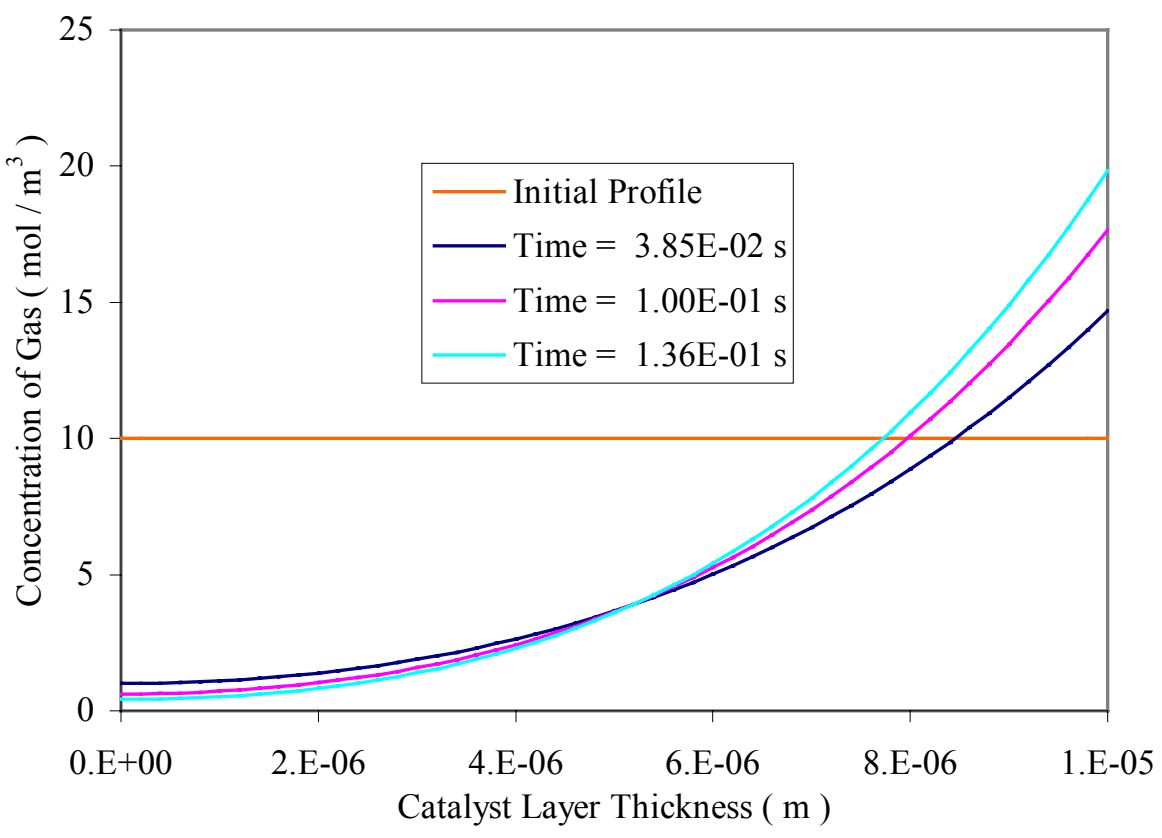

Figure 5.30 Evolution in time of the concentration of gas. 


\section{Chapter 6. Conclusions and Recommendations}

\subsection{Conclusions}

The work presented in this thesis leads to a clearer understanding of the phenomena in the cathode catalyst layer. The governing equations and closure relations developed by Olsommer (2000) for the catalyst layer and improved in this thesis work have been solved using a finite-element approach and show good agreement with the expectations and the solutions obtained by other models. To my knowledge, this is the most complete macroscopic model of the catalyst layer to date in the literature. Additional assumptions and improvements made in this thesis work include being able to account for the effects of oxygen transport limitations on the cell limiting current using assumptions that are specific to the pseudo-homogeneous model. Consequently, when compared to existing catalyst layer models, the model presented in this thesis work features additional prediction capabilities such as those for flooding, concentration overpotential and transient behavior. Based on the results presented in Chapter 5, the following conclusions can be reached as well as specifically quantified:

- A higher porosity is favorable to oxygen diffusion and, therefore, gives better performance. Smaller porosities affect both the oxygen concentration distribution and the current generation per unit volume distribution across the catalyst layer. Decreasing the porosity results in poorer performance.

- The global permeability of the porous media has comparable effects on porosity. Decreasing the permeability affects both the oxygen concentration distribution and the current generation per unit volume distribution across the catalyst layer and, consequently, can result in poorer performance.

- The catalyst loading can considerably increase the cell current density via an increased catalyst surface area. However, the effects of the catalyst surface are limited by the oxygen transport resistance that occurs at high current densities. 
High catalyst surface area results in an uneven distribution of the current generation per unit volume across the catalyst layer.

- The water content of the polymer membrane has a slight effect on performance. An increased water content results in better proton conductivity of the polymer phase of the catalyst layer and improved performance.

- Though higher temperature is known to improve overall cell performance, it has the opposite effect on catalyst layer performance. The activation overpotential increases as temperature increases and results in poorer performance of the catalyst layer.

- A limiting current is calculated when the oxygen concentration becomes zero at the membrane interface (pseudo-homogenous model) or at the reaction sites (agglomerate model).

- As the cell current approaches the limiting current, the oxygen concentration profiles converge to a single concentration distribution profile across the catalyst layer.

- Flooding affects the oxygen concentration distribution and the current generation per unit volume distribution across the catalyst layer. High values of the saturation ratio result in an uneven current generation across the catalyst layer and poorer performance. In addition, the limiting current decreases as the saturation increases.

Finally, in the study of the transient behavior of the catalyst layer for the case of flooding, the model shows the time scale of the evolution in time of the solutions.

\subsection{Recommendations}

In analyzing the results obtained, some recommendations can be made to improve the comprehension of the phenomena in the catalyst layer. These recommendations aim at improving the model presented in this thesis work as well as developing a more in-depth model of the catalyst layer. 
The prediction of the limiting current in the model presented in section 3.6 of Chapter 3 is based on the assumption of a pseudo-homogeneous catalyst layer, which suggests that diffusion limitations occur when all the oxygen available is consumed within the thickness of the catalyst layer. This assumption, however, may not coincide with what is known about the physical makeup of this layer (e.g., see Figure 3.1). Thus, it may be necessary to adopt a different interpretation of the phenomena of mass transfer limitations and use, for example, the agglomerate model of the catalyst layer suggested in section 3.6 of Chapter 3. In that case, the distributions throughout the catalyst layer of the thickness of the gas diffusion layer surrounding each agglomerate $(\delta)$ and the external surface of each agglomerate $(A)$ would become the main parameters that affect the prediction of the limiting current ${ }^{25}$. Experimental measurement of the active catalyst surface area would make possible comparing the results given by this new model to experimental data and, thus, validating the predictions.

Another recommendation would be to study the phenomena of charge and mass transfer at the local level by taking into account the microscopic structure of the catalyst layer. This would provide additional information on the influence of the geometric arrangement of the agglomerate inside the catalyst layer and the distribution of the catalyst particles.

\footnotetext{
${ }^{25}$ This contrasts with the thickness of the catalyst layer $(\delta)$ and the surface area of the catalyst layer $(A)$ as in the pseudo-homogenous model.
} 


\section{Bibliography}

You L., Liu H., 2000, A Peudo-homogeneous Model for Cathode Catalyst Layer of PEM Fuel Cells, HTD-Vol. 366-1, Proceedings of the ASME Heat Transfer Division, pp. 5159, ASME.

Sui P.-C., Chen L.-D., Seaba J.-P, Wariishi Y., 1999, Modeling and Optimization of a PEMFC Catalyst Layer, Fuel Cell Power for Transportation, Society of Automotive Engineers, pp. 61-70.

Bultel Y., Ozil P., Durand R., Simonsson D., 1995, Study of Mass Transfer within the Active Layer of PEMFC Electrodes at the Particle Level, Electrochemical Society Proceedings, Vol.95-23, pp. 34-47.

Bernardi D.M., Verbrugge M.W., 1991, Mathematical Model of a Gas Diffusion Electrode Bonded to a Polymer Electrolyte, AICHE J., Vol. 37, No. 8, pp. 1151-1163.

Bernardi D.M., Verbrugge M.W., 1992, A Mathematical Model of the Solid-PolymerElectrolyte Fuel Cell, Journal of the Electrochemical Society, Vol. 139, No. 9, pp. 24772491.

Broka K., Ekdunge P., 1997, Modelling the PEM fuel cell cathode, J. Applied Electrochemistry, Vol. 27, pp 281-289.

Derouin C., Springer T.E., Uribe F., Valerio J., Wilson M.S., Zawodzinski T.A., and Gottesfeld S., 1992, 1992 Fuel Cell Seminar Program and Abstracts, Tucson AZ, November 29 - December 2, 1992, sponsored by Fuel Cell Organizing Committee, 615, 1992.

Divisek J., Mosig J., Steffen B., Stimming U., 1995, Proton Exchange Membrane Fuel Cell Model, Electrochemical Engineering and Energy, Plenum Press, NY, pp 187-196.

Divisek J., Eikerling M., Mazin V., Schmitz H., Stimming U., Volfkovich YuM., 1998, Study of capillary porous structure and sorption properties of Nafion ${ }^{\circledR}$ proton-exchange membranes swollen in water, Journal of the Electrochemical Society, Vol. 145 No. 8, pp. 2677-2683, 1998.

Eikerling M., Kharkats YuI., Kornyshev A.A., Volfkovich YuM., 1998, Phenomenological theory of electro-osmotic effect and water management in polymer electrolyte proton-conducting membranes, Journal of the Electrochemical Society. Vol. 145 No. 8, pp. 2684-2699.

Energy Partners, 2001, Fuel Cells 101, www.energypartners.net, April 10. 
Fuller T.F., Newman J., 1993, Water and thermal management in solid-polymerelectrolyte fuel cells, Journal of the Electrochemical Society, Vol. 140, No. 5, pp. 12181225.

Gurau V., Kakac S., Liu H., 1998, Mathematical Model for Proton Exchange Membrane Fuel Cells, AES Vol. 38, Proc. of the ASME Advanced Energy Systems Division, pp. 205-214, ASME.

Hinatsu J.T., Mizuhata M., Takenaka H., 1994, Water Uptake of Perfluorosulfonic Acid Membranes from Liquid Water and Water Vapor, Journal of the Electrochemical Society, Vol. 141, No. 6, pp. 1493-1498.

Kjelstrup S., Okada T., and Ottoy M., 1999, Water, Ion and Entropy transport in IonExchange Membranes, Surface Chemistry and Electrochemistry of Membranes, pp. 455481, Marcel Dekker, Inc., NY.

Mosdale R., 1992, Ph. D. Thesis, INPG, Grenoble, France.

Mosdale R., Srinivasan S., 1995, Analysis of Performance and of Water and Thermal Management in Proton Exchange Membrane Fuel Cells, Electrochimica Acta, Vol. 40, No. 4, pp. 413-421.

Nguyen T.V., R.E. White, 1993, A Water and Heat Management Model for ProtonExchange-Membrane Fuel Cells, Journal of the Electrochemical Society, Vol. 140, No. 8, pp. $2178-2186$.

Nguyen T.V., Vanderborgh N., 1998, The Rate of isothermal hydration of polyperfluorosulfonic acid membranes, Journal of Membrane Science, Vol. 143, No. 1-2, pp. 235-248.

Olsommer B., 2000, Mathematical Model for a PEM Fuel Cell, Internal Document, Energy Management Institute, Mechanical Engineering, Virginia Polytechnic and State University, Blacksburg, VA.

Montel N., 2000, Solutions of a Catalyst Layer Model of a Proton Exchange Membrane Fuel Cell, Internal Document, Energy Management Institute, Mechanical Engineering, Virginia Polytechnic and State University, Blacksburg, VA.

Montel N., 2000, User's Manual for the IUSTI Finite Element Code, Internal Document, Energy Management Institute, Mechanical Engineering, Virginia Polytechnic and State University, Blacksburg, VA.

Rho Y.W., Velev O.A., Srinivasan S., Kho Y.T., 1994, Mass Transport Phenomena in Proton Exchange Membrane Fuel Cells Using $\mathrm{O}_{2} / \mathrm{He}, \mathrm{O}_{2} / \mathrm{Ar}$, and $\mathrm{O}_{2} / \mathrm{N}_{2}$ Mixtures: I. Experimental Analysis, Journal of the Electrochemical Society, Vol. 141, No. 8, pp.20842088. 
Rho Y.W., Velev O.A., Srinivasan S., Kho Y.T., 1994, Mass Transport Phenomena in Proton Exchange Membrane Fuel Cells Using $\mathrm{O}_{2} / \mathrm{He}, \mathrm{O}_{2} / \mathrm{Ar}$, and $\mathrm{O}_{2} / \mathrm{N}_{2}$ Mixtures: II. Theoretical Analysis, Journal of the Electrochemical Society, Vol. 141, No. 8, pp.20892096.

Thirumalai D., White R.E., 1997, Mathematical Modeling of Proton Exchange Membrane Fuel Cell Stacks, Journal of the Electrochemical Society, Vol. 144, No. 5, pp. 1717-1723.

Springer T.E., Zawodzinski T.A., and S. Gottesfeld, 1991, Polymer Electrolyte Fuel Cell Model, Journal of the Electrochemical Society, Vol. 138, No. 8, pp. 2334-2342, (a).

Springer T.E., Gottesfeld S., 1991, Pseudohomogeneous Catalyst Layer for Polymer Electrolyte Fuel Cells, Proc. of the Symposium on Modeling of Batteries and Fuel Cells, R.E. White, M.W. Verbrugge, and J.F. Stockel, Editors, PV 91-10, pp. 197-208, The Electrochemical Society Softbound Proceedings Series, Pennington, NJ, (b).

Springer T.E., M.S. Wilson, and Gottesfeld S., 1993, Modeling and Experimental Diagnostics in Polymer Electrolyte Fuel Cells, Journal of the Electrochemical Society, Vol. 140, No. 12, pp. 3513-3526.

Springer T.E , Zawodzinski T.A., Wilson M.S., and Gottesfeld S., 1996, Characterization of Polymer Electrolyte Fuel Cells Using AC Impedance Spectroscopy, Journal of the Electrochemical Society, Vol. 143, No. 2, pp. 587-599. U.S. Fuel Cell Council, 1999, Fuel Cell Glossary. August 19.

Verbrugge M.W., Hill R.F., 1990, Ion and Solvent Transport in Ion-Exchange Membranes, J. Electrochemal Society, Vol. 137, No. 3, pp. 886-893.

van Bussel H.P.L.H, Koene F.G.H, Mallant R.K.A.M, 1998, Dynamic Model of Solid Polymer Fuel Cell Water Management, Journal of Power Sources, Vol. 71, pp. 218-222.

Nguyen T.V., Vanderborgh-Nicholas, 1998, The Rate of isothermal hydration of polyperfluorosulfonic acid membranes, Journal of Membrane Science, Vol. 143, No. 1-2, p 235-248.

von Spakovsky, M.R., Olsommer, B., 1999, Fuel Cell Systems and System Modeling and Analysis Perspectives for Fuel Cell Development, Efficiency, Costs, Optimization, Simulation and Environmental Aspects of Energy Systems (ECOS'99), Tokyo Institute of Technology, ASME, Tokyo, pp. 100-104, June.

von Spakovsky M.R., Nelson D.J, and Ellis M.W., 2000, ME 5984: Fuel Cell Systems, Class Notes, Virginia Polytechnic and State University, Blacksburg, VA, Spring. 
Weisbrod K.R., Grot S.A., and Vanderborgh N.E., 1995, Through the Electrode Model of a Proton Exchange Membrane Fuel Cells, Proceedings of the Electrochemical Society Meeting, Chicago, IL, Vol. 95-23, pp. 152-166.

Weisbrod K.R., Vanderborgh N.E., and Grot S.A., 1996, Modeling of Gaseous Flows within Proton Exchange Membrane Fuel Cells, Proceedings 1996 Fuel Cell Seminar, Orlando, FL, pp. 635-638.

Wilson M.S., Springer T.E., Zawodzinski T.A., Gottesfeld S., 1991, $26^{\text {th }}$ Intersociety Energy Conversion Engineering Conference Proceedings, Vol. 3, Conversion Technologies/Electrochemical Conversion, Boston, Massachusetts, August 4-9.

Yi J.S., Nguyen, T.V., 1999, Multicomponent Transport in Porous Electrodes of Proton Exchange Membrane Fuel Cells Using Interdigitated Gas Distributors, Journal of the Electrochemical Society, Vol. 146, No. 1, pp. 38-45. 


\section{Appendix A. Nomenclature}

\section{Roman symbols:}

\begin{tabular}{|c|c|c|}
\hline$a$ & activity & \\
\hline$A$ & catalyst layer area & $\mathrm{m}^{2}$ \\
\hline$a$ & specific catalyst layer area & $\mathrm{m}^{2} \cdot \mathrm{m}^{-3}$ \\
\hline$c_{i}$ & concentration of species $i$ & mol.m $\mathrm{m}^{-3}$ \\
\hline$c_{i}^{\alpha}$ & concentration of species $i$ in phase $\alpha$ & $\mathrm{kg} \cdot \mathrm{m}^{-3}$ \\
\hline$c_{p}$ & specific heat at constant pressure & $\mathrm{J} \cdot \mathrm{kg}^{-1} \cdot \mathrm{K}^{-1}$ \\
\hline$c_{p}^{\alpha}$ & specific heat at constant pressure of phase $\alpha$ & $\mathrm{J} \cdot \mathrm{kg}^{-1} \cdot \mathrm{K}^{-1}$ \\
\hline$c_{p i}^{\alpha}$ & specific heat at constant pressure of species $i$ in phase $\alpha$ & $\mathrm{J} \cdot \mathrm{kg}^{-1} \cdot \mathrm{K}^{-1}$ \\
\hline$D_{i, j}$ & \multicolumn{2}{|l|}{ diffusion coefficient of the pair $\mathrm{i}, \mathrm{j}$ in a binary mixture } \\
\hline$D_{i, j}^{e f f}$ & \multicolumn{2}{|l|}{ effective diffusion coefficient of the pair $i, j$ in a binary mixture } \\
\hline$D^{\prime}$ & \multicolumn{2}{|c|}{ diffusion coefficient at constant temperature and in coordinates } \\
\hline & moving with the swelling membrane & $\mathrm{m}^{2} \cdot \mathrm{s}^{-1}$ \\
\hline$F$ & Faraday's constant & C.mol ${ }^{-1}$ \\
\hline$g$ & gravitational acceleration & $\mathrm{m} \cdot \mathrm{s}^{-2}$ \\
\hline$i$ & current density & A. $\mathrm{m}^{-2}$ \\
\hline$i_{0}$ & exchange current density & A. $\mathrm{m}^{-2}$ \\
\hline$i_{0}^{r e f}$ & reference exchange current density & A. $m^{-2}$ \\
\hline$i_{c}$ & \multicolumn{2}{|c|}{ current density within the porous media of the backing layers and } \\
\hline \multirow{3}{*}{$i_{\mathrm{m}}$} & catalyst layers & A. $\mathrm{m}^{-2}$ \\
\hline & \multicolumn{2}{|l|}{ protonic current density in the $\mathrm{x}$-direction within the polymer } \\
\hline & membrane & A. $\mathrm{m}^{-2}$ \\
\hline$i_{\mathrm{x}}$ & current density in the $\mathrm{x}$-direction & A. $m^{-2}$ \\
\hline$J_{i}$ & diffusive flux of species $i$ & mol.m $\mathrm{m}^{-2} \cdot \mathrm{s}^{-1}$ \\
\hline$k_{r}^{\alpha}$ & relative permeability of phase $\alpha$ & \\
\hline$K$ & absolute permeability & $\mathrm{m}^{2} \cdot \mathrm{s}^{-1}$ \\
\hline$L_{v}$ & liquid-gas enthalpy of evaporation & $\mathrm{J} \cdot \mathrm{kg}^{-1} \cdot \mathrm{K}^{-1}$ \\
\hline$\dot{\mathrm{m}}^{\alpha}$ & mass flow of phase $\alpha$ & $\mathrm{kg} \cdot \mathrm{s}^{-1}$ \\
\hline
\end{tabular}




\begin{tabular}{|c|c|c|}
\hline$\dot{\mathrm{m}}_{\mathrm{i}}^{\alpha \rightarrow \beta}$ & interphase transfer of species i from phase $\alpha$ to phase $\beta$ & $\mathrm{kg} \cdot \mathrm{s}^{-1}$ \\
\hline$M$ & molecular mass & $\mathrm{kg} \cdot \mathrm{mol}^{-1}$ \\
\hline$M_{i}$ & molecular mass of species $i$ & $\mathrm{~kg} \cdot \mathrm{mol}^{-1}$ \\
\hline$M^{g}$ & molecular mass of the gas mixture & $\mathrm{kg} \cdot \mathrm{mol}^{-1}$ \\
\hline$M^{\alpha}$ & molecular mass of phase $\alpha$ & $\mathrm{kg} \cdot \mathrm{mol}^{-1}$ \\
\hline$M^{m}$ & molecular mass of the membrane & $\mathrm{kg} \cdot \mathrm{mol}^{-1}$ \\
\hline$N^{\alpha}$ & molar flux of phase $\alpha$ & mol.m $\mathrm{m}^{-2} \cdot \mathrm{s}^{-1}$ \\
\hline$N_{i}^{\alpha}$ & molar flux of species $i$ within phase $\alpha$ & mol.m $\mathrm{m}^{-2} \cdot \mathrm{s}^{-1}$ \\
\hline$\dot{\mathrm{n}}_{\mathrm{i}}^{\alpha}$ & source or sink of species i within the phase $\alpha$ & mol.m $\mathrm{m}^{-3} \cdot \mathrm{s}^{-1}$ \\
\hline$p_{0}^{s a t}$ & reference saturation pressure & $\mathrm{Pa}$ \\
\hline$p_{c}$ & capillary pressure & $\mathrm{Pa}$ \\
\hline$p_{i}$ & pressure of species i & $\mathrm{Pa}$ \\
\hline$p_{\text {crit }}$ & critical pressure of species & $\mathrm{Pa}$ \\
\hline$p^{\alpha}$ & pressure of phase $\alpha$ & $\mathrm{Pa}$ \\
\hline$p^{\alpha}{ }_{i}$ & partial pressure of species $i$ in phase $\alpha$ & $\mathrm{Pa}$ \\
\hline$p_{\text {sat }}$ & saturation pressure & $\mathrm{Pa}$ \\
\hline$Q_{s}$ & reversible heat delivered by entropy generation & W. $\mathrm{m}^{3}$ \\
\hline$R_{a c t}$ & heat source due to activation overpotential & W.m $\mathrm{m}^{3}$ \\
\hline$R_{c}$ & porous media (backing layer, catalyst layer) ohmic source & W. $\mathrm{m}^{3}$ \\
\hline$R_{m}$ & membrane ohmic source & $\mathrm{W} \cdot \mathrm{m}^{3}$ \\
\hline$R_{p}$ & collector ohmic source & $\mathrm{W} \cdot \mathrm{m}^{3}$ \\
\hline$R$ & universal gas constant & $\mathrm{J} \cdot \mathrm{mol}^{-1} \cdot \mathrm{K}^{-1}$ \\
\hline$s$ & entropy & $\mathrm{J} \cdot \mathrm{mol}^{-1} \cdot \mathrm{K}^{-1}$ \\
\hline$s$ & saturation & \\
\hline$s^{\alpha}$ & saturation of phase $\alpha$ & \\
\hline$t$ & time & $\mathrm{s}$ \\
\hline$T$ & absolute temperature & $\mathrm{K}$ \\
\hline$T_{0}^{\text {sat }}$ & reference saturation temperature & $\mathrm{K}$ \\
\hline$T_{\text {crit }}$ & critical temperature & $\mathrm{K}$ \\
\hline$u^{m}$ & velocity of phase $\alpha$ in the given direction & $\mathrm{m} \cdot \mathrm{s}^{-1}$ \\
\hline$V_{\alpha}$ & volume of phase $\alpha$ & $\mathrm{m}^{3}$ \\
\hline
\end{tabular}




\section{Greek symbols:}

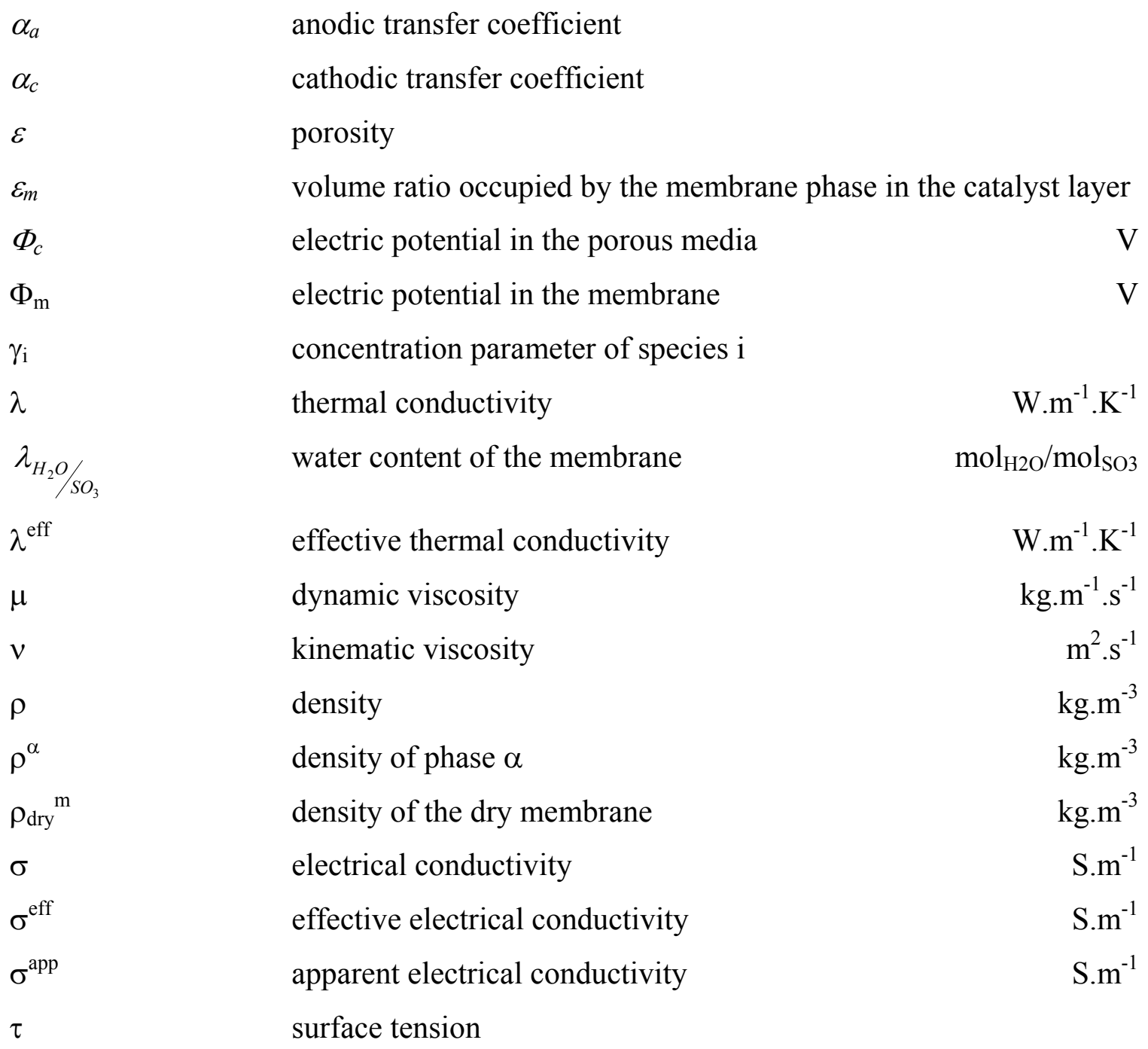

\section{Superscripts, subscripts:}

$\begin{array}{ll}\text { a } & \text { anode side } \\ \text { app } & \text { apparent } \\ \text { b } & \text { backing layer } \\ \text { c } & \text { solid matrix of the catalyst layer (carbon and platinum) } \\ \text { c } & \text { catalyst layer } \\ \text { g } & \text { gas phase }\end{array}$


1

$\mathrm{m}$

S

$\mathrm{X}$

0

$\alpha$ liquid phase

membrane

solid phase

axis directions

reference

phase $(\mathrm{s}, 1, \mathrm{~g}, \mathrm{~m})$ 


\section{Appendix B. Mathematical Model}

\section{DIFFERENTIAL EQUATIONS:}

Mass Conservation for $\mathbf{O 2}$ (constitutive variable: $c_{O_{2}}^{g}$ ):

$$
\varepsilon(1-s) \frac{\partial c_{O_{2}}^{g}}{\partial t}-\varepsilon c_{O_{2}} \frac{\partial s}{\partial t}=-\frac{\partial N_{O_{2}}^{g}}{\partial x}-\frac{1}{4 F} \frac{\partial i_{x}}{\partial x}
$$

Mass Conservation for the Gas (constitutive variable: $c^{g}$ ):

$$
\begin{aligned}
\varepsilon(1-s) \frac{\partial c^{g}}{\partial t}- & \varepsilon\left(\frac{\rho_{\mathrm{H}_{2} \mathrm{O}}^{l}}{M^{g}}-c^{g}\right) \frac{\partial s}{\partial t}= \\
& -\frac{1}{M^{g}} \frac{\partial}{\partial x}\left[M^{g} N^{g}\right]+\frac{M_{\mathrm{H}_{2} \mathrm{O}}}{M^{g}} \frac{\partial}{\partial x}\left[N_{\mathrm{H}_{2} \mathrm{O}}^{l}\right]-\frac{1}{F M^{g}}\left[\frac{1}{4} M_{\mathrm{O}_{2}}-\frac{1}{2} M_{\mathrm{H}_{2} \mathrm{O}}\right] \frac{\partial i_{x}}{\partial x}
\end{aligned}
$$

Mass Conservation for the Water (constitutive variable: $s$ ):

$$
\varepsilon(1-s) \frac{\partial c_{\mathrm{H}_{2} \mathrm{O}}^{g}}{\partial t}+\varepsilon\left(\frac{\rho_{\mathrm{H}_{2} \mathrm{O}}^{l}}{M_{\mathrm{H}_{2} \mathrm{O}}}-c_{\mathrm{H}_{2} \mathrm{O}}^{g}\right) \frac{\partial s}{\partial t}=-\frac{\partial}{\partial x}\left[N_{\mathrm{H}_{2} \mathrm{O}}^{l}+N_{\mathrm{H}_{2} \mathrm{O}}^{g}\right]+\frac{1}{2 F} \frac{\partial i_{x}}{\partial x}
$$

Conservation of Potential in the matrix (constitutive variable: $\Phi_{c}$ ):

$$
\frac{\partial i_{x}}{\partial x}=\sigma_{c}^{e f f} \frac{\partial^{2} \Phi_{c}}{\partial x^{2}}
$$

Mass conservation for $\mathbf{H}_{2} \mathbf{O}$ (constitutive variable: $c_{\mathrm{H}_{2} \mathrm{O}}^{m}$ ):

$$
\varepsilon_{m} \frac{\partial c_{H_{2} \mathrm{O}}^{m}}{\partial t}=\frac{\partial}{\partial x}\left(D_{c_{\mathrm{H}_{2} \mathrm{O}}, T} \frac{\partial c_{\mathrm{H}_{2} \mathrm{O}}^{m}}{\partial x}\right)-\frac{\partial}{\partial x}\left(c_{\mathrm{H}_{2} \mathrm{O}}^{m} u^{m}\right)
$$

Mass Conservation for the Protons (constitutive variable: $c_{H^{+}}$):

$$
c_{H^{+}}=\text {cste }
$$

Conservation of Potential in the membrane (constitutive variable: $\Phi_{m}$ ):

$$
\frac{\partial i_{x}}{\partial x}=\frac{1}{\varepsilon_{m}} \frac{\partial}{\partial x}\left(\sigma_{m}^{a p p} \frac{\partial \Phi_{m}}{\partial x}\right)-\frac{1}{\varepsilon_{m}} \frac{\partial}{\partial x}\left(F c_{H^{+}} u^{m}\right)
$$


Energy Conservation (constitutive variable $T$ ):

$$
\overline{\rho c_{p}} \frac{\partial T}{\partial t}=\frac{\partial}{\partial x} \lambda^{e f f} \frac{\partial T}{\partial x}-\overline{M c_{p} N} \frac{\partial T}{\partial x}+R_{m}+R_{c}+R_{a c t}+\dot{m}_{H_{2} O}^{l \rightarrow g} L_{v}+Q_{s}
$$

\section{CLOSURE RELATIONS:}

Specific heats $\left(\mathrm{J}^{\mathrm{kg}}{ }^{-1} \cdot \mathrm{K}^{-1}\right)$

$$
\begin{aligned}
& c_{p_{H_{2}}}^{g}=12707.9+11.128 T-24.15 \mathrm{e}(-3) T^{2}+22.951 \mathrm{e}(-6) T^{3}-7.5325 \mathrm{e}(-9) T^{4} \\
& c_{p_{H_{2} O}}^{g}=1879.89-0.5118 T+1.9178 \mathrm{e}(-3) T^{2}-1.369 \mathrm{e}(-6) T^{3}+0.3227 \mathrm{e}(-9) T^{4} \\
& c_{p_{O_{2}}}^{g}=942.08-0.4879 T+1.8329 \mathrm{e}(-3) T^{2}-1.7574 \mathrm{e}(-6) T^{3}+0.56 \mathrm{e}(-9) T^{4} \\
& c_{p_{N_{2}}}^{g}=1090.82-0.3587 T+0.6898 \mathrm{e}(-3) T^{2}-0.1876 \mathrm{e}(-6) T^{3}+0.067 \mathrm{e}(-9) T^{4} \\
& c_{p_{H_{2} O}}^{m}=5356.8415-7.4381 T+1.11 \mathrm{e}(-2) T^{2} \\
& c_{p_{H^{+}}}=20633.5
\end{aligned}
$$

Entropy of formation $\left(\mathrm{J} \cdot \mathrm{K}^{-1} \cdot \mathrm{mol}^{-1}\right)$

$$
\begin{aligned}
\left.s_{H_{2}}^{g}(T)\right|_{p_{0}}= & -3.4671 \mathrm{e}(1)+2.9025 \mathrm{e}(1) \ln (T) \\
\left.S_{H^{+}}^{g}(T)\right|_{p_{0}}= & -9.4869+2.0787 \mathrm{e}(1) \ln (T) \\
\left.s_{H_{2} O}^{l}(T)\right|_{p_{0}}= & 70.416+\left\{\frac{1}{3} \times 3.4409 \mathrm{e}(-7) \times T^{3}\right. \\
& \left.\quad-1.3419 \mathrm{e}(-4) \times T^{2}-1.8760 \mathrm{e}(-2) \times T+83.774 \times \ln (T)\right\}-469.259 \\
\left.s_{O_{2}}^{g}(T)\right|_{p_{0}}= & 1.5671 \mathrm{e}(2)+2.4433 \mathrm{e}(-1) T-3.3673 \mathrm{e}(-4) T^{2}+2.0807 \mathrm{e}(-7) T^{3}
\end{aligned}
$$

Liquid-gas enthalpy change for water $\left(\mathrm{J} \mathrm{kg}^{-1}\right)$

$$
\begin{aligned}
L_{v}= & 1.73287 \mathrm{e}(6)+1.03001 \mathrm{e}(4) T \\
& -4.47755 \mathrm{e}(1) T^{2}+7.66293 \mathrm{e}(-2) T^{3}-5.5058 \mathrm{e}(-5) T^{4}
\end{aligned}
$$

\section{At the reaction surface:}

Kinetics of the reaction (dependent variable $i_{x}$ ): 


$$
\frac{\partial i_{x}}{\partial x}=a i_{0}\left[\exp \left(\frac{\alpha_{a} F\left(\Phi_{c}-\Phi_{m}\right)}{R T}\right)-\exp \left(\frac{-\alpha_{c} F\left(\Phi_{c}-\Phi_{m}\right)}{R T}\right)\right]
$$

Exchange current density (dependent variable $i_{0}$ ):

$$
i_{0}=i_{o}^{r e f}\left(\frac{c_{O_{2}}}{c_{O_{2}}^{r e f}}\right)^{\gamma_{O_{2}}}\left(\frac{c_{H^{+}}}{c_{H^{+}}^{r e f}}\right)^{\gamma_{H^{+}}}
$$

\section{In the porous media of the catalyst layer:}

Mass velocity for the gas phase: Darcy: (dependent variable: $M^{g} N^{g}$ ):

(with $N^{g}=c^{g} u^{g}$ )

$$
\begin{aligned}
& M^{g} N^{g}=-\varepsilon K \frac{k_{r}^{g}}{v^{g}}\left(\frac{\partial p^{g}}{\partial x}-\rho^{g} g\right)= \\
& -\varepsilon K \frac{k_{r}^{g}}{v^{g}}\left(R T \frac{\partial c^{g}}{\partial x}+R c^{g} \frac{\partial T}{\partial x}-\left(M_{\mathrm{O}_{2}} c_{\mathrm{O}_{2}}+M_{\mathrm{H}_{2} \mathrm{O}} c_{\mathrm{H}_{2} \mathrm{O}}^{g}+M_{\mathrm{N}_{2}}\left(c^{g}-c_{\mathrm{O}_{2}}-c_{\mathrm{H}_{2} \mathrm{O}}^{g}\right)\right) g\right)
\end{aligned}
$$

Mass velocity for the gas and the liquid phases: Darcy: (dependent variable: $N_{\mathrm{H}_{2} \mathrm{O}}^{l}$ ):

(with $N_{\mathrm{H}_{2} \mathrm{O}}^{l}=\frac{\rho_{\mathrm{H}_{2} \mathrm{O}}^{l}}{M_{\mathrm{H}_{2} \mathrm{O}}} u^{l}$ )

$$
\begin{aligned}
N_{\mathrm{H}_{2} \mathrm{O}}^{l}= & \frac{-\varepsilon K \frac{k_{r}^{l}}{v^{l}}\left(\frac{\partial p^{l}}{\partial x}-\rho_{\mathrm{H}_{2} \mathrm{O}}^{l} g\right)}{M_{\mathrm{H}_{2} \mathrm{O}}}= \\
& \frac{-\varepsilon K \frac{k_{r}^{l}}{v^{l}}}{M_{\mathrm{H}_{2} \mathrm{O}}}\left(R T \frac{\partial c^{g}}{\partial x}+R c^{g} \frac{\partial T}{\partial x}-\tau \sqrt{\frac{\varepsilon}{K}}\left(-0.966+3.338 s-3.789 s^{2}\right) \frac{\partial s}{\partial x}-\rho_{\mathrm{H}_{2} \mathrm{O}}^{l} g\right)
\end{aligned}
$$

Relative permeabilities (dependent variables: $k_{r}^{g}, k_{r}^{l}$ ):

$$
\begin{aligned}
& k_{r}^{g}=(1-s)^{3} \\
& k_{r}^{l}=s^{3}
\end{aligned}
$$


Diffusion equation: Stefan-Maxwell: (dependent variables: $N_{\mathrm{O}_{2}}, N_{\mathrm{H}_{2} \mathrm{O}}^{g}$ )

$$
\begin{aligned}
& N_{O_{2}}=\frac{b_{1} a_{22}-b_{2} a_{12}}{a_{11} a_{22}-a_{12} a_{21}} \\
& N_{H_{2} O}^{g}=\frac{b_{2} a_{11}-b_{1} a_{21}}{a_{11} a_{22}-a_{12} a_{21}}
\end{aligned}
$$

where:

$$
\begin{aligned}
a_{11}= & \frac{c_{H_{2} O}^{g}}{D_{12}}+\frac{c^{g}-c_{H_{2} O}^{g}-c_{O_{2}}\left(1-\frac{M_{O_{2}}}{M_{N_{2}}}\right)}{D_{13}} \\
a_{12}= & c_{O_{2}}\left(\frac{M_{H_{2} O}}{D_{13} M_{N_{2}}}-\frac{1}{D_{12}}\right) \\
a_{21}= & c_{H_{2} O}^{g}\left(\frac{M_{O_{2}}}{D_{23} M_{N_{2}}}-\frac{1}{D_{12}}\right) \\
a_{22}= & \frac{c_{O_{2}}^{g}}{D_{12}}+\frac{c^{g}-c_{O_{2}}-c_{H_{2} O}^{g}\left(1-\frac{M_{H_{2} O}}{M_{N_{2}}}\right)}{D_{23}} \\
b_{1}= & c_{O_{2}}^{g} \frac{\partial c^{g}}{\partial x}-c^{g} \frac{\partial c_{O_{2}}^{g}}{\partial x}-\frac{1}{D_{13} M_{N_{2}}} \varepsilon K \frac{k_{r}^{g}}{v^{g}} c_{O_{2}}^{g} * \\
& {\left[R T \frac{\partial c^{g}}{\partial x}+R c^{g} \frac{\partial T}{\partial x}-g\left(c_{O_{2}}^{g} M_{O_{2}}+c_{H_{2} O}^{g} M_{H_{2} O}+\left(c^{g}-c_{O_{2}}^{g}-c_{H_{2} O}^{g} O M_{N_{2}}\right)\right.\right.} \\
b_{2}= & c_{H_{2} O}^{g} \frac{\partial c^{g}}{\partial x}-c^{g} \frac{\partial c_{H_{2} O}^{g}}{\partial x}-\frac{1}{D_{23} M_{N_{2}}} \varepsilon K \frac{k_{r}^{g}}{v^{g}} c_{H_{2} O}^{g} * \\
& {\left[R T \frac{\partial c^{g}}{\partial x}+R c^{g} \frac{\partial T}{\partial x}-g\left(c_{O_{2}}^{g} M_{O_{2}}+c_{H_{2} O}^{g} M_{H_{2} O}+\left(c^{g}-c_{O_{2}}^{g}-c_{H_{2} O}^{g}\right) M_{N_{2}}\right)\right] }
\end{aligned}
$$


Binary diffusion coefficients (dependent variables: $D_{12}, D_{13}, D_{23}$ ):

$$
\begin{aligned}
& D_{12}=(\varepsilon(1-s))^{\frac{3}{2}}\left(\frac{p_{\mathrm{O}_{2}}^{c r i t} p_{\mathrm{H}_{2} \mathrm{O}}^{c r i t}}{(1.01325 \mathrm{e}(5))^{2}}\right)^{\frac{1}{3}}\left(T_{\mathrm{O}_{2}}^{c r i t} T_{\mathrm{H}_{2} \mathrm{O}}^{c r i t}\right)^{\frac{5}{12}} \\
& \left(\frac{1}{M_{\mathrm{O}_{2}}}+\frac{1}{M_{\mathrm{H}_{2} \mathrm{O}}}\right)^{\frac{1}{2}} \frac{1}{\left(\frac{c^{g} R T}{1.01325 \mathrm{e}(5)}\right)} a\left(\frac{T}{\sqrt{T_{\mathrm{O}_{2}}^{c r i t} T_{\mathrm{H}_{2} \mathrm{O}}^{\text {crit }}}}\right)^{b} \cdot 10^{-4} \\
& a=3.64 \mathrm{e}-4 \\
& \left(M_{\mathrm{H}_{2} \mathrm{O}}, \mathrm{M}_{\mathrm{O}_{2}}\right) \cdot\left(\mathrm{kg}_{\mathrm{kmol}} \mathrm{km}^{-1}\right)
\end{aligned}
$$

$$
\begin{aligned}
& D_{23}=(\varepsilon(1-s))^{\frac{3}{2}}\left(\frac{p_{\mathrm{H}_{2} \mathrm{O}}^{\text {crit }} p_{N_{2}}^{\text {crit }}}{(1.01325 \mathrm{e}(5))^{2}}\right)^{\frac{1}{3}}\left(T_{\mathrm{H}_{2} \mathrm{O}}^{\text {crit }} T_{N_{2}}^{\text {crit }}\right) \frac{5}{12} \\
&\left(\frac{1}{M_{\mathrm{H}_{2} \mathrm{O}}}+\frac{1}{M_{\mathrm{N}_{2}}}\right)^{\frac{1}{2}} \frac{1}{\left(\frac{c^{g} R T}{1.01325 \mathrm{e}(5)}\right)} d\left(\frac{T}{\sqrt{T_{\mathrm{H}_{2} \mathrm{O}}^{\text {crit }} T_{N_{2}}^{\text {crit }}}}\right)^{b} .10^{-4}
\end{aligned}
$$

$a=3.64 \mathrm{e}-4$

$$
\left(M_{\mathrm{H}_{2} \mathrm{O}}, \mathrm{M}_{\mathrm{N}_{2}}\right) \cdot\left(\mathrm{kg} \cdot \mathrm{kmol}^{-1}\right)
$$

$b=2.334$ 
Evaporation rate (dependent variable: $\dot{m}_{\mathrm{H}_{2} \mathrm{O}}^{l \rightarrow g}$ ):

$$
\dot{m}_{\mathrm{H}_{2} \mathrm{O}}^{l \rightarrow g}=-M_{\mathrm{H}_{2} \mathrm{O}} \frac{\partial N_{\mathrm{H}_{2} \mathrm{O}}^{l}}{\partial x}-\varepsilon \rho_{\mathrm{H}_{2} \mathrm{O}}^{l} \frac{\partial s}{\partial t}
$$

Capillary effects on vapor pressure: Kelvin equation (dependent variable: $c_{\mathrm{H}_{2} \mathrm{O}}^{g}$ ):

$$
c_{\mathrm{H}_{2} \mathrm{O}}^{g}=\frac{p_{\text {sat }}(T)}{R T} \exp \left(-\frac{M_{\mathrm{H}_{2} \mathrm{O}} p_{c}}{\rho_{\mathrm{H}_{2} \mathrm{O}}^{l} R T}\right)
$$

Capillary pressure (dependent variable: $\left.p_{c}\right)$ :

$$
p_{c}=p^{g}-p^{l}=f(s) \tau \sqrt{\frac{\varepsilon}{K}}
$$

Leverett function (dependent variable: $f(s)$ ):

$$
f(s)=1.417(1-s)-2.12(1-s)^{2}+1.263(1-s)^{3}
$$

Saturation pressure: Clapeyron (dependent variable: $\mathrm{p}_{\text {sat }}$ ):

$$
p_{\text {sat }}(T)=p_{0}^{\text {sat }} \exp \left(\left[\left(\frac{1}{T_{0}^{\text {sat }}}-\frac{1}{T}\right) L_{v}\right] / R\right)
$$

Molar mass of the gas mixture (dependent variable: $M^{g}$ ):

$$
M^{g}=\frac{M_{\mathrm{O}_{2}} c_{\mathrm{O}_{2}}+M_{\mathrm{H}_{2} \mathrm{O}} c_{\mathrm{H}_{2} \mathrm{O}}^{g}+M_{\mathrm{N}_{2}}\left(c^{g}-c_{\mathrm{O}_{2}}-c_{\mathrm{H}_{2} \mathrm{O}}^{g}\right)}{c^{g}}
$$

Nitrogen concentration (dependent variable: $c_{N_{2}}$ ):

$$
c_{N_{2}}=c^{g}-c_{O_{2}}-c_{H_{2} O}^{g}
$$

Nitrogen molar flux (dependent variable: $N_{N_{2}}$ ):

$$
N_{N_{2}}=\frac{1}{M_{N_{2}}}\left(M^{g} N^{g}-M_{O_{2}} N_{O_{2}}-M_{H_{2} O} N_{H_{2} O}^{g}\right)
$$

Electric current (dependent variable: $i_{\mathrm{cx}}$ ):

$$
i_{c_{x}}^{a p p}=-\sigma_{c}^{a p p} \frac{\partial \Phi_{c}}{\partial x}
$$


Ohmic loss (dependent variable: $R_{c}$ ):

$$
R_{c}=\frac{i_{c_{x}}^{a p p^{2}}}{\sigma_{c}{ }^{a p p}}
$$

Effective electrical conductivity (dependent variable: $\sigma_{c}^{\text {eff }}$ ):

$$
\sigma_{c} \text { eff }=\left(\frac{1-\varepsilon-\varepsilon_{m}}{1-\varepsilon_{m}}\right)^{3 / 2} \sigma_{c}
$$

Apparent electrical conductivity (dependent variable: $\sigma_{c}{ }^{a p p}$ ):

$$
\sigma_{c}^{a p p}=\left(1-\varepsilon_{m}\right) \sigma_{c}^{e f f}
$$

\section{In the polymer phase of the catalyst layer:}

Molar velocity for the mixture: Darcy (dependent variable: $u^{m}$ ):

$$
u^{m}=-K \frac{k_{r}^{g}}{\mu}\left[\frac{\partial P}{\partial x}-\rho \cdot g\right]
$$

Diffusion coefficient (dependent variable: $D_{c_{\mathrm{H}_{2} \mathrm{O}}, T}$ ):

$$
D_{c_{H_{2} O}, T}=\varepsilon_{m} D^{\prime}\left\{\exp \left[2416\left(\frac{1}{303}-\frac{1}{T}\right)\right] \lambda_{H_{2} \mathrm{O} / \mathrm{SO}_{3}} \frac{1}{a} \frac{1}{17.81-78.9 a+108 a^{2}}\right\}
$$

Diffusion coefficient at 303 (K) (dependent variable: $D^{\prime}$ ):

$$
\begin{array}{ll}
D^{\prime}=7.75 \mathrm{e}(-11) \lambda_{\mathrm{H}_{2} \mathrm{O} / \mathrm{SO}_{3}}-9.5 \mathrm{e}(-11) & \text { for }\left(\lambda_{\mathrm{H}_{2} \mathrm{O} / \mathrm{SO}_{3}}\right) \leq 6 \\
D^{\prime}=2.5625 \mathrm{e}(-11) \lambda_{\mathrm{H}_{2} \mathrm{O} / \mathrm{SO}_{3}}+2.1625 \mathrm{e}(-10) & \text { for } 6 \leq\left(\lambda_{\mathrm{H}_{2} \mathrm{O} / \mathrm{SO}_{3}}\right) \leq 14
\end{array}
$$

Water uptake (dependent variable: $\lambda_{\mathrm{H}_{2} \mathrm{O} / \mathrm{SO}_{3}}$ ):

$$
\lambda_{\mathrm{H}_{2} \mathrm{O} / \mathrm{SO}_{3}}=\frac{c_{\mathrm{H}_{2} \mathrm{O}}^{m}}{\frac{\rho_{d r y}^{m}}{M^{m}}-b c_{\mathrm{H}_{2} \mathrm{O}}^{m}} \quad \mathrm{~b}=0.0126
$$

Pressure for the water molecules (dependent variable: $p$ ):

$$
p=\left\{p^{g}\right\}_{c c x-}+\frac{\left\{p^{g}\right\}_{c c x+}-\left\{p^{g}\right\}_{c c x-}}{x_{c c x+}-x_{c c x-}}\left(x-x_{c c x-}\right)
$$


Activity of the water molecules (dependent variable: $a$ ):

$$
\begin{aligned}
& a=1 / 2160\left(c_{1}+c_{2} \lambda_{\mathrm{H}_{2} \mathrm{O} / \mathrm{SO}_{3}}+216\left(c_{3}-c_{4} \lambda_{\mathrm{H}_{2} \mathrm{O} / \mathrm{SO}_{3}}\right.\right. \\
& \left.\left.+c_{5} \lambda_{\mathrm{H}_{2} \mathrm{O} / \mathrm{SO}_{3}}{ }^{2}\right)^{(1 / 2)}\right)^{(1 / 3)}-134183 / 2160 / \\
& \left(c_{1}+c_{2} \lambda_{\mathrm{H}_{2} \mathrm{O} / \mathrm{SO}_{3}}+216\left(c_{3}-c_{4} \lambda_{\mathrm{H}_{2} \mathrm{O} / \mathrm{SO}_{3}}\right.\right. \\
& \left.\left.+c_{5} \lambda_{\mathrm{H}_{2} \mathrm{O} / \mathrm{SO}_{3}}{ }^{2}\right)^{(1 / 2)}\right)^{(1 / 3)}+797 / 2160 \\
& c_{1}=-41956 \mathrm{e} 4 \\
& c_{2}=139968 \mathrm{e} 3 \\
& c_{3}=382482 \mathrm{e} 6 \\
& c_{4}=251739 \mathrm{e} 3 \\
& c_{5}=419904 \mathrm{e} 6 \\
& \text { for }\left(\lambda_{\mathrm{H}_{2} \mathrm{O} / \mathrm{SO}_{3}}\right) \leq 14 \\
& a=0.7143\left(\lambda_{\mathrm{H}_{2} \mathrm{O} / \mathrm{SO}_{3}}\right)-9.0021 \\
& \text { for } 14 \leq\left(\lambda_{\mathrm{H}_{2} \mathrm{O} / \mathrm{SO}_{3}}\right) \leq 16.8 \\
& a=3 \\
& \text { for } 16.8 \leq\left(\lambda_{\mathrm{H}_{2} \mathrm{O} / \mathrm{SO}_{3}}\right)
\end{aligned}
$$

Proton current (dependent variable: $i_{m_{x}}$ ):

$$
i_{m x}^{a p p}=-\sigma_{m} \frac{\partial \Phi_{m}}{\partial x}+F c_{H^{+}} u^{m}
$$

Ohmic loss (dependent variable: $\mathrm{R}_{\mathrm{m}}$ ):

$$
R_{m}=\frac{i_{m x}^{a p p^{2}}}{\sigma_{m}^{a p p}}
$$

Electrical conductivity (dependent variable: $\sigma_{m}^{a p p}$ ):

$$
\begin{aligned}
& \sigma_{m}^{a p p}=\varepsilon_{m} \exp \left[1268\left(\frac{1}{303}-\frac{1}{T}\right)\right]\left[0.5139{\frac{\lambda}{\frac{\mathrm{H}_{2} \mathrm{O}}{\mathrm{SO}_{3}}}}-0.326\right] \quad \text { for } \lambda_{\frac{\mathrm{H}_{2} \mathrm{O}}{\mathrm{SO}_{3}}} \geq 1 \\
& \left.\sigma_{m}^{a p p}=\sigma_{m}^{a p p}\left(\frac{\lambda_{\frac{\mathrm{H}_{2} \mathrm{O}}{S \mathrm{O}_{3}}}}{S}\right)=1\right) \quad \text { for } 0<\lambda_{\frac{\mathrm{H}_{2} \mathrm{O}}{\mathrm{SO}_{3}}}<1
\end{aligned}
$$




\section{Common Equation:}

Heat capacity of the phase mixture (dependent variables: $\overline{\rho c_{p}}, \overline{M c_{p} N}$ ):

$$
\begin{aligned}
& \overline{\rho c_{p}}=\left(1-\varepsilon-\varepsilon_{m}\right) \rho^{c} c_{p}^{c}+\varepsilon(1-s) M_{O_{2}} c_{O_{2}} c_{p_{O_{2}}} \\
& +\varepsilon(1-s) M_{\mathrm{H}_{2} \mathrm{O}} c_{\mathrm{H}_{2} \mathrm{O}}^{g} c_{p_{\mathrm{H}_{2} \mathrm{O}}}^{g}+\varepsilon(1-s) M_{\mathrm{N}_{2}}\left(c^{g}-c_{\mathrm{O}_{2}}-c_{\mathrm{H}_{2} \mathrm{O}}^{g}\right) c_{p_{N_{2}}} \\
& +\varepsilon_{m} \rho_{m}^{d r y} c_{p_{m}}+\varepsilon_{m} M_{\mathrm{H}_{2} \mathrm{O}} c_{\mathrm{H}_{2} \mathrm{O}}^{m} c_{p_{\mathrm{H}_{2} \mathrm{O}}}^{m}+\varepsilon_{m} M_{H^{+}} c_{H^{+}}^{m} c_{p_{H^{+}}} \\
& \overline{M c_{p} N}=M_{\mathrm{H}_{2} \mathrm{O}} c_{p_{\mathrm{H}_{2} \mathrm{O}}}^{l} N_{\mathrm{H}_{2} \mathrm{O}}^{l}+M_{\mathrm{H}_{2} \mathrm{O}} c_{p_{\mathrm{H}_{2} \mathrm{O}}}^{g} N_{\mathrm{H}_{2} \mathrm{O}}^{g}+M_{\mathrm{O}_{2}} c_{p_{\mathrm{O}_{2}}} N_{\mathrm{O}_{2}}^{g}
\end{aligned}
$$

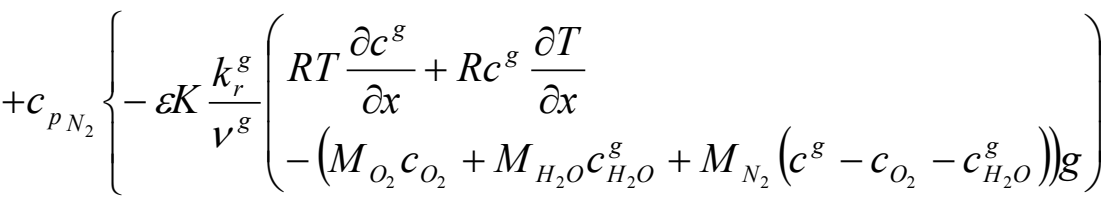

$$
\begin{aligned}
& \left.-M_{\mathrm{H}_{2} \mathrm{O}} N_{\mathrm{H}_{2} \mathrm{O}}^{g}-M_{\mathrm{O}_{2}} N_{\mathrm{O}_{2}}^{g}\right\} \\
& +M_{H^{+}} c_{p_{H^{+}}} N_{H^{+}}+M_{H_{2} O} c_{p_{H_{2} O} O}^{m}\left(c_{H_{2} O}^{m} u^{m}-D_{c_{H_{2} O}, T} \frac{\partial c_{H_{2} O}^{m}}{\partial x}\right)
\end{aligned}
$$

Activation overpotential (dependent variable: $\left.R_{a c t}\right)$ :

$$
R_{a c t}=\left(\Phi_{c}-\Phi_{m}\right) \frac{\partial i_{x}}{\partial x}
$$

Proton molar flux (dependent variable: $N_{H^{+}}$):

$$
N_{H^{+}}=\frac{i_{m x}^{a p p}}{c_{H^{+}} F}
$$

Reversible heat (dependent variable: $Q_{s}$ ):

$$
Q_{s}=T \frac{1}{F} \frac{\partial i_{x}}{\partial x}\left[s_{H^{+}}+\frac{1}{4} s_{O_{2}}-\frac{1}{2} s_{H_{2} O}^{l}\right]
$$

Entropy of formation (dependent variables: ${ }_{\mathrm{H}^{+}}, s_{\mathrm{O}_{2}}, s_{\mathrm{H}_{2} \mathrm{O}}$ )

$$
\begin{aligned}
s_{H^{+}}= & -9.4869+2.0787 \mathrm{e}(1) \ln (T)-R \ln \left(\frac{c_{H^{+}} R T}{p_{0}}\right) \\
s_{O_{2}}= & 1.5671 \mathrm{e}(2)+2.4433 \mathrm{e}(-1) \mathrm{T}-3.3673 \mathrm{e}(-4) \mathrm{T}^{2}+2.0807 \mathrm{e}(-7) \mathrm{T}^{3} \\
& -R \ln \left(\frac{c_{O_{2}} R T}{p_{0}}\right)
\end{aligned}
$$




$$
s_{\mathrm{H}_{2} \mathrm{O}}^{l}=-398.843+\left\{\begin{array}{c}
\frac{1}{3} \times 3.4409 \mathrm{e}(-7) \times T^{3} \\
-1.3419 \mathrm{e}(-4) \times T^{2}-1.8760 \mathrm{e}(-2) \times T+83.774 \times \ln (T)
\end{array}\right\}
$$

Thermal conductivity (dependent variable: $\lambda^{\text {eff)}}$ :

$$
\lambda^{e f f}=\left(\lambda^{s}\right)^{1-\varepsilon-\varepsilon m}\left(\lambda^{l}\right)^{\varepsilon s}\left(\lambda^{g}\right)^{\varepsilon(1-s)}\left(\lambda^{m}\right)^{\varepsilon m}
$$

Specific heats (dependent variables: $c_{p_{O_{2}}}, c_{p_{H_{2}} \mathrm{O}}^{g}, c_{p_{N_{2}}}, c_{p_{H_{2} O}}^{m}, c_{p_{H^{+}}}$)

$$
\begin{aligned}
& c_{p_{\mathrm{O}_{2}}}=942.08-0.4879 T+1.8329 e(-3) T^{2}-1.7574 e(-6) T^{3}+0.56 e(-9) T^{4} \\
& c_{p_{H_{2} \mathrm{O}}}^{g}=1879.89-0.5118 T+1.9178 \mathrm{e}(-3) T^{2}-1.369 \mathrm{e}(-6) T^{3}+0.3227 \mathrm{e}(-9) T^{4} \quad(63 \mathrm{~b}) \\
& c_{p_{N_{2}}}=1090.82-0.3587 T+0.6898 \mathrm{e}(-3) T^{2}-0.1876 \mathrm{e}(-6) T^{3}+0.067 \mathrm{e}(-9) T^{4} \quad(63 \mathrm{c}) \\
& c_{p_{H_{2} \mathrm{O}}}^{m}=5356.8415-7.4381 T+1.11 e(-2) T^{2} \\
& c_{p_{H^{+}}}=20633.5
\end{aligned}
$$

Liquid-gas enthalpy change for water (dependent variable: $L_{v}$ )

$$
\begin{aligned}
L_{v}= & 1.73287 \mathrm{e}(6)+1.03001 \mathrm{e}(4) T \\
& -4.47755 \mathrm{e}(1) T^{2}+7.66293 \mathrm{e}(-2) T^{3}-5.5058 \mathrm{e}(-5) T^{4}
\end{aligned}
$$

State equation for the gas: (dependent variables: $p_{i}^{g}, p^{g}$ ):

$$
\begin{aligned}
& p_{i}^{g}=c_{i}^{g} R T \quad i \in\left\{\mathrm{H}_{2} \mathrm{O}, \mathrm{H}_{2}\right\} \\
& p^{g}=c^{g} R T
\end{aligned}
$$


SUMMARY OF NOTATIONS APPEARING IN EOUATIONS 1-65:

\begin{tabular}{|c|c|c|c|c|}
\hline Notation & $\begin{array}{l}\text { Constitutive } \\
\text { variables }\end{array}$ & $\begin{array}{l}\text { Dependent } \\
\text { variables }\end{array}$ & Constants & Units \\
\hline$c_{O_{2}}^{g}$ & Eq. 1 & & & mol.m ${ }^{-3}$ \\
\hline$c^{g}$ & Eq. 2 & & & mol.m ${ }^{-3}$ \\
\hline$s$ & Eq. 3 & & & - \\
\hline$\Phi_{c}$ & Eq. 4 & & & V \\
\hline$c_{\mathrm{H}_{2} \mathrm{O}}^{m}$ & Eq. 5 & & & mol.m ${ }^{-3}$ \\
\hline${ }^{c H^{+}}$ & Eq. 6 & & $1.2 \mathrm{e} 3$ & mol.m ${ }^{-3}$ \\
\hline$\Phi_{m}$ & Eq. 7 & & & $\mathrm{~V}$ \\
\hline$T$ & Eq. 8 & & & $\mathrm{~K}$ \\
\hline$i_{x}$ & & Eq. 12 & & A.m ${ }^{-2}$ \\
\hline$i_{0}$ & & Eq. 13 & & A. $\mathrm{m}^{-2}$ \\
\hline$M^{g} N^{g}$ & & Eq. 14 & & $\mathrm{~kg} \cdot \mathrm{m}^{-2} \cdot \mathrm{s}^{-1}$ \\
\hline $\mathrm{N}_{\mathrm{H}_{2} \mathrm{O}}^{l}$ & & Eq. 15 & & mol.m $\mathrm{m}^{-2} \cdot \mathrm{s}^{-1}$ \\
\hline$k_{r}^{g}$ & & Eq. 16 & & - \\
\hline$k_{r}^{l}$ & & Eq. 17 & & - \\
\hline$N_{\mathrm{O}_{2}}$ & & Eq. 18 & & mol.m $\mathrm{m}^{-2} \cdot \mathrm{s}^{-1}$ \\
\hline$N_{\mathrm{H}_{2} \mathrm{O}}^{g}$ & & Eq. 19 & & mol.m $\mathrm{m}^{-2} \cdot \mathrm{s}^{-1}$ \\
\hline$D_{12}$ & & Eq. 26 & & - \\
\hline$D_{13}$ & & Eq. 29 & & - \\
\hline$D_{23}$ & & Eq. 32 & & - \\
\hline$\dot{m}_{\mathrm{H}_{2} \mathrm{O}}^{l \rightarrow g}$ & & Eq. 35 & & $\mathrm{~kg} \cdot \mathrm{m}^{-1} \mathrm{~s}^{-1}$ \\
\hline$c_{\mathrm{H}_{2} \mathrm{O}}^{g}$ & & Eq. 36 & & mol.m ${ }^{-3}$ \\
\hline $\mathrm{p}_{\mathrm{c}}$ & & Eq. 37 & & $\mathrm{~Pa}$ \\
\hline $\mathrm{f}(\mathrm{s})$ & & Eq. 38 & & - \\
\hline$p_{\text {sat }}$ & & Eq. 39 & & $\mathrm{~Pa}$ \\
\hline$M^{g}$ & & Eq. 40 & & kg.mol ${ }^{-1}$ \\
\hline$c_{N_{2}}$ & & Eq. 41 & & mol.m ${ }^{-3}$ \\
\hline$N_{N_{2}}$ & & Eq. 42 & & mol.m $\mathrm{m}^{-2} \cdot \mathrm{s}^{-1}$ \\
\hline $\mathrm{i}_{\mathrm{cx}}$ & & Eq. 43 & & A.m ${ }^{-2}$ \\
\hline$R_{c}$ & & Eq. 44 & & W. $\mathrm{m}^{-3}$ \\
\hline$\sigma_{c}^{e f f}$ & & Eq. 45 & & $\Omega^{-1} \cdot \mathrm{m}^{-1}$ \\
\hline$\sigma_{c}^{a p p}$ & & Eq. 46 & & $\Omega^{-1} \cdot \mathrm{m}^{-1}$ \\
\hline$u^{m}$ & & Eq. 47 & & $\mathrm{~m} \cdot \mathrm{s}^{-1}$ \\
\hline
\end{tabular}




\begin{tabular}{|c|c|c|c|}
\hline$D_{c_{H_{2} O}, T}$ & Eq. 48 & & - \\
\hline$D^{\prime}$ & Eq. $49 a$ and $b$ & & - \\
\hline$\lambda_{\mathrm{H}_{2} \mathrm{O} / \mathrm{SO}_{3}}$ & Eq. 50 & & $\mathrm{~mol}_{\mathrm{H}_{2} \mathrm{O}} \cdot\left(\mathrm{mol}_{\mathrm{SO}_{3}}\right)^{-1}$ \\
\hline $\mathrm{p}$ & Eq. 51 & & $\mathrm{~Pa}$ \\
\hline$a$ & Eq. 52 a to $h$ & & - \\
\hline$i_{m_{x}}$ & Eq. 53 & & A. $\mathrm{m}^{-2}$ \\
\hline $\mathrm{R}_{\mathrm{m}}$ & Eq. 54 & & W. $\mathrm{m}^{-3}$ \\
\hline$\sigma_{m}^{a p p}$ & Eq. 55a and $b$ & & $\Omega^{-1} \cdot \mathrm{m}^{-1}$ \\
\hline$\rho c_{p}$ & Eq. 56 & & $\mathrm{~J} \cdot \mathrm{m}^{-3} \cdot \mathrm{K}^{-1}$ \\
\hline$\overline{M c_{p} N}$ & Eq. 57 & & $\mathrm{~W} \cdot \mathrm{m}^{-2} \cdot \mathrm{K}^{-1}$ \\
\hline$R_{a c t}$ & Eq. 58 & & W. $\mathrm{m}^{-3}$ \\
\hline$N_{H^{+}}$ & Eq. 59 & & $\mathrm{~mol} \cdot \mathrm{m}^{-2} \cdot \mathrm{s}^{-1}$ \\
\hline$Q_{s}$ & Eq. 60 & & W. $\mathrm{m}^{-3}$ \\
\hline$\lambda^{e f f}$ & Eq. 62 & & $\mathrm{~W} \cdot \mathrm{m}^{-1} \cdot \mathrm{K}^{-1}$ \\
\hline$p_{i}^{g}$ & Eq. 65 & & $\mathrm{~Pa}$ \\
\hline$p^{g}$ & Eq. 66 & & $\mathrm{~Pa}$ \\
\hline $\mathrm{ai}_{0}{ }^{\text {ref }}$ & & 10 & A. $\mathrm{m}^{-3}$ \\
\hline $\mathrm{b}$ & & 0.0126 & - \\
\hline$\alpha_{a}$ & & 2 & - \\
\hline$\alpha_{c}$ & & 2 & - \\
\hline$\varepsilon$ & & 0.2 & - \\
\hline$\overline{\varepsilon_{\mathrm{m}}}$ & & 0.5 & - \\
\hline $\mathrm{F}$ & & 96485 & $\mathrm{C}$ \\
\hline $\mathrm{g}$ & & 9.81 & $\mathrm{~m} \cdot \mathrm{s}^{-2}$ \\
\hline$\gamma_{\mathrm{H}^{+}}$ & & 0.5 & - \\
\hline$\gamma_{\mathrm{O} 2}$ & & 0.5 & - \\
\hline $\mathrm{K}$ & & $1.15 \mathrm{e}-16$ & $\mathrm{~m}^{2}$ \\
\hline$\lambda^{g}$ & & $30 \mathrm{e}-3$ & $\mathrm{~W} \cdot \mathrm{m}^{-1} \cdot \mathrm{K}^{-1}$ \\
\hline$\lambda^{1}$ & & 0.668 & $\mathrm{~W} \cdot \mathrm{m}^{-1} \cdot \mathrm{K}^{-1}$ \\
\hline$\lambda^{\mathrm{m}}$ & & 0.2 & $\mathrm{~W} \cdot \mathrm{m}^{-1} \cdot \mathrm{K}^{-1}$ \\
\hline$\lambda^{\mathrm{s}}$ & & 140 & $\mathrm{~W} \cdot \mathrm{m}^{-1} \cdot \mathrm{K}^{-1}$ \\
\hline $\mathrm{M}_{\mathrm{H}+}$ & & $1 \mathrm{e}-3$ & kg.mol ${ }^{-1}$ \\
\hline $\mathrm{M}_{\mathrm{H} 2 \mathrm{O}}$ & & $18 \mathrm{e}-3$ & $\mathrm{~kg} \cdot \mathrm{mol}^{-1}$ \\
\hline $\mathrm{M}_{\mathrm{N}}$ & & $28 \mathrm{e}-3$ & kg.mol ${ }^{-1}$ \\
\hline $\mathrm{M}^{\mathrm{m}}$ & & 1.1 & $\mathrm{~kg} \cdot\left(\mathrm{mol}_{\mathrm{SO}_{3}}\right)^{-1}$ \\
\hline$\mu_{\mathrm{H}+}$ & & $98.8 \mathrm{e}-7$ & $\mathrm{~kg} \cdot \mathrm{m}^{-1} \cdot \mathrm{s}^{-1}$ \\
\hline$\mu_{\mathrm{H} 2 \mathrm{O}}$ & & $365 e-6$ & $\mathrm{~kg} \cdot \mathrm{m}^{-1} \cdot \mathrm{s}^{-1}$ \\
\hline$v^{g}$ & & $20.92 \mathrm{e}-6$ & $\mathrm{~m}^{2} \cdot \mathrm{s}^{-1}$ \\
\hline$v^{1}$ & & $0.375 \mathrm{e}-6$ & $\mathrm{~m}^{2} \cdot \mathrm{s}^{-1}$ \\
\hline
\end{tabular}




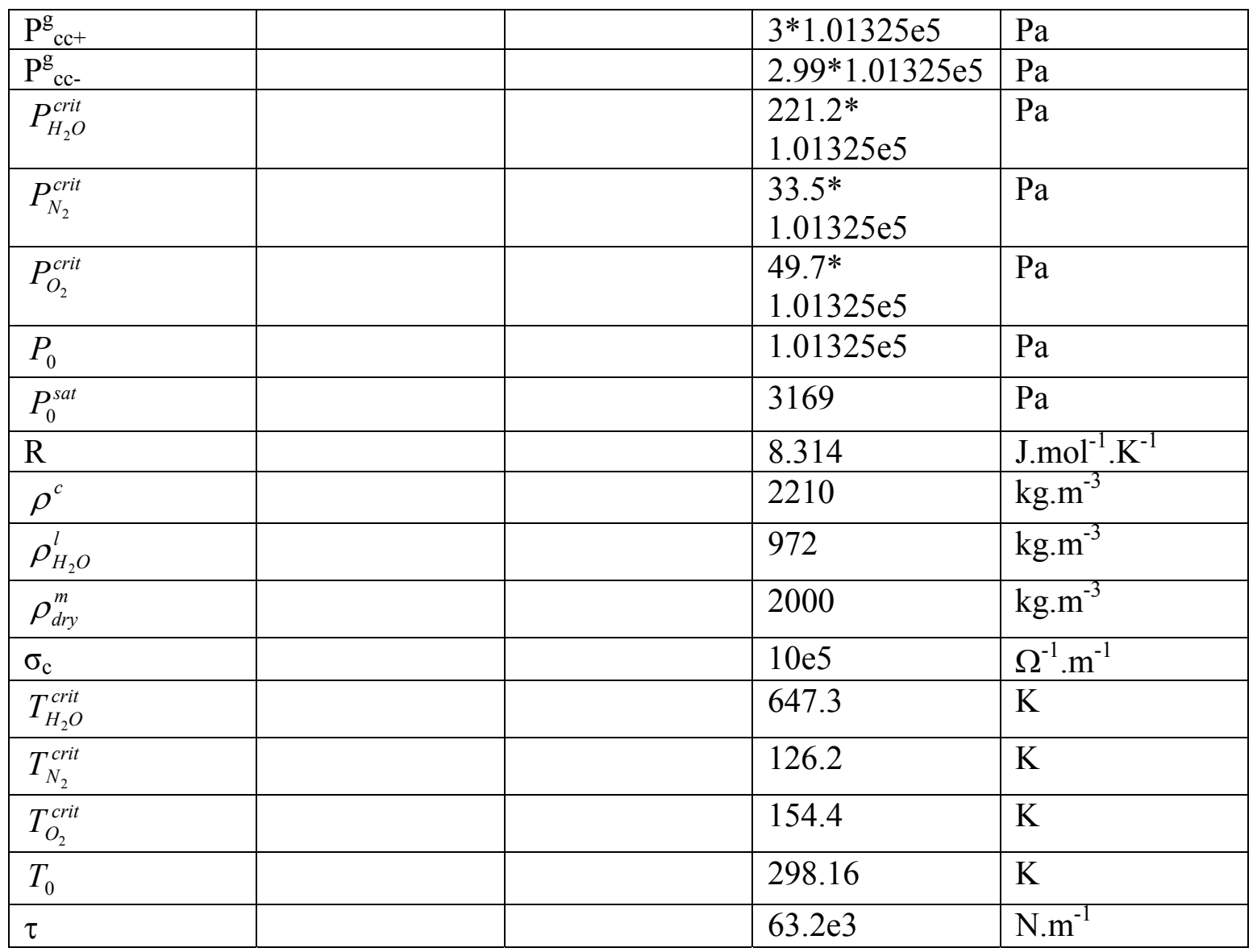


Vita

\section{A N I E L B . G E N E V E Y}

\section{EDUCATION}

VIRGINIA POLYTECHNIC INSTITUTE AND STATE UNIVERSITY Blacksburg, VA M.S., Mechanical Engineering, December 2001

Overall GPA: 3.65/4.0

\section{ECOLE NATIONALE SUPERIEURE DE MECANIQUE ET DES \\ MICROTECHNIQUES (ENSMM) Besançon, France}

Diplôme d'Ingénieur, December 2001

\section{EXPERIENCE}

9/00-Present Virginia Polytechnic Institute and State University

Graduate Research Assistant

- Adapted a research finite element FORTRAN code for the resolution of a fuel cell catalyst layer model.

- Developed a finite element solution for a fuel cell catalyst layer model.

3/00-8/00 SNECMA Vernon, France

Intern

- Conducted torque measurements on the Ariane 5 cryogenic engine Vulcain.

- Participated in the development of a model for prediction of the torque of Vulcain.

6/99-8/99 Portescap La Chaux de Fonds, Switzerland

Intern

- Realization of 2-D and 3-D sketches of electronic motors.

- CAD using SolidWorks®. 